
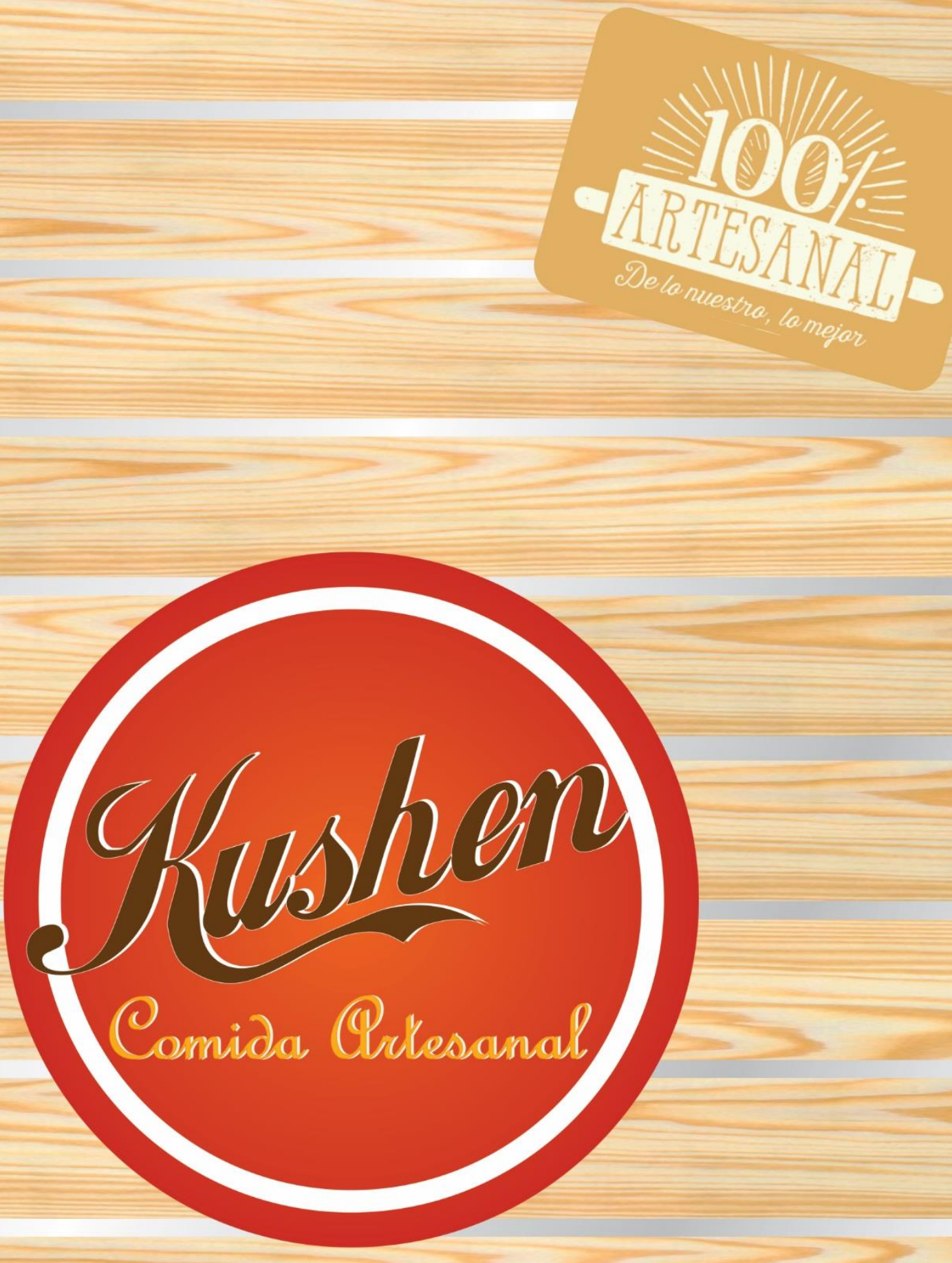

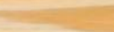




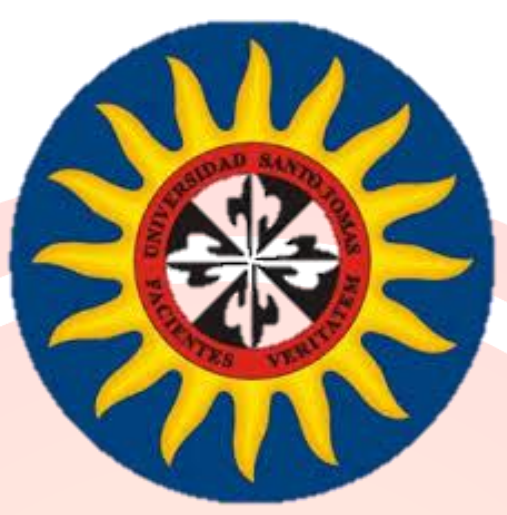

\section{Kushen House}

Facultad De Administración De Empresas

Estudiante: Sharon Yaneth Mesa Cuellar

Coordinador trabajos de grado: Elías Rodríguez Parra

Tutor académico: Alirio Céspedes Gil

07 De Julio De 2017, Bogotá D.C. 


\section{TABLA DE CONTENIDO}

Justificación

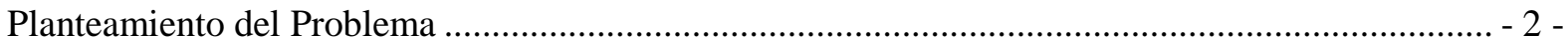

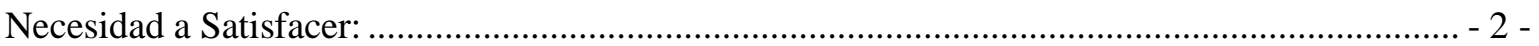

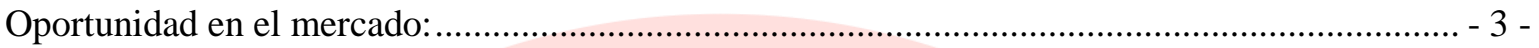

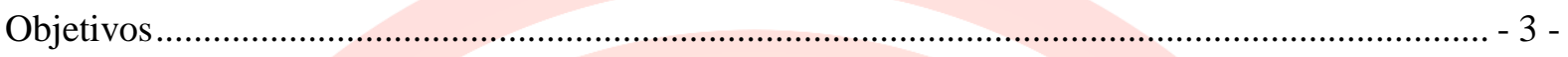

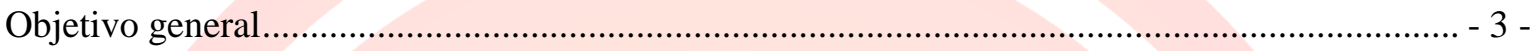

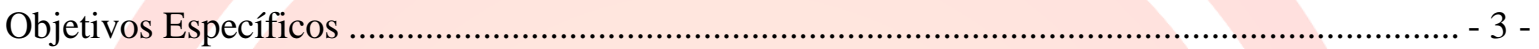

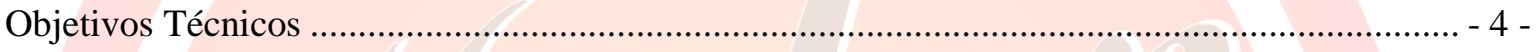

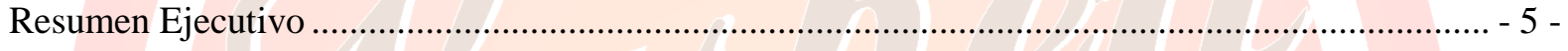

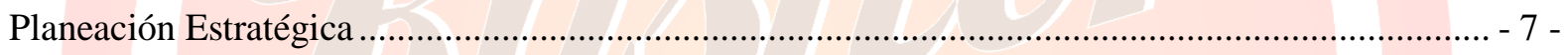

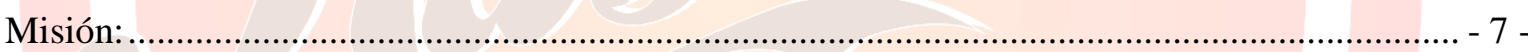

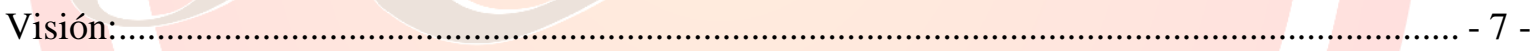

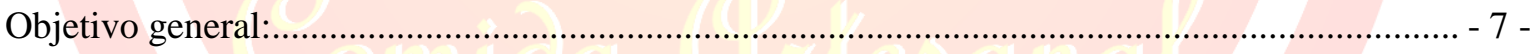

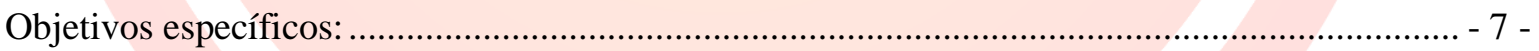

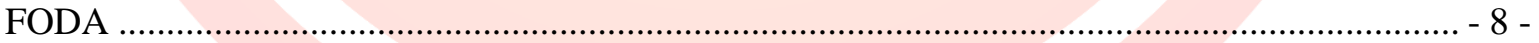

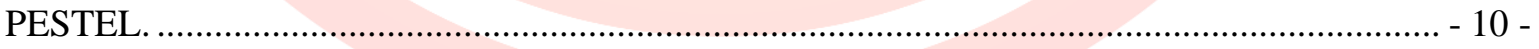

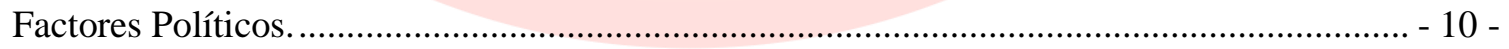

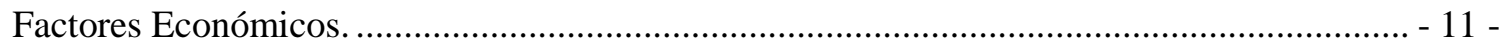

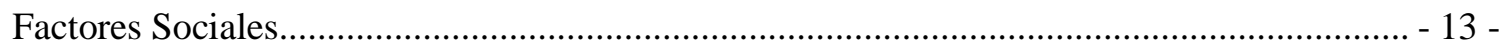

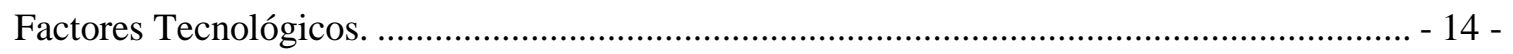

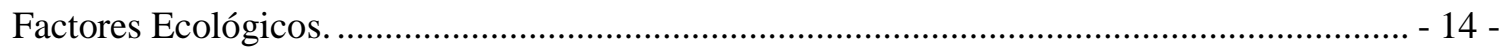




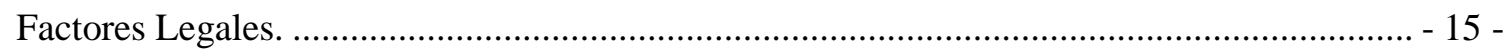

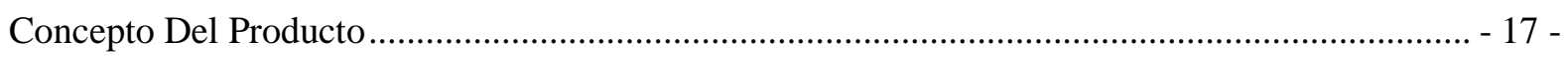

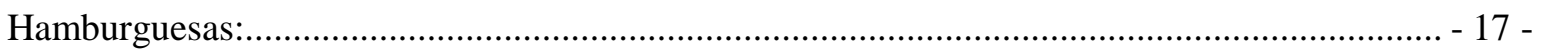

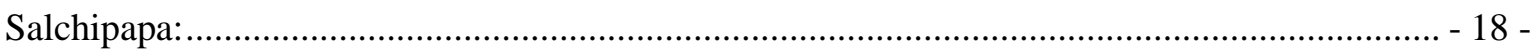

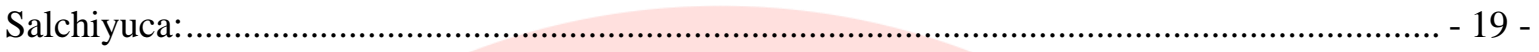

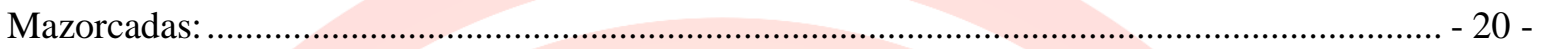

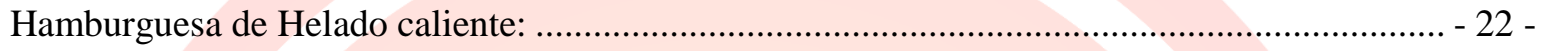

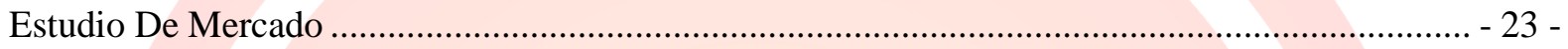

Características y comportamiento del grupo objetivo....................................................... - 23 -

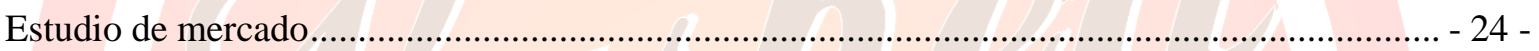

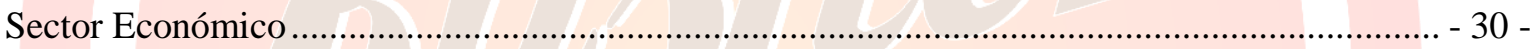

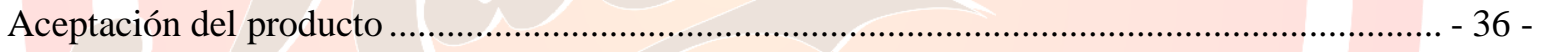

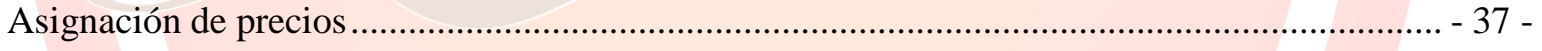

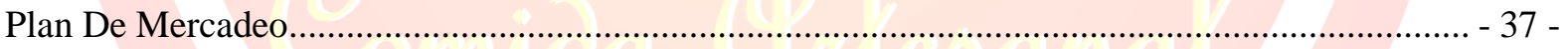

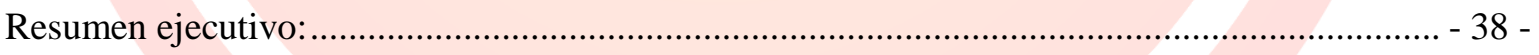

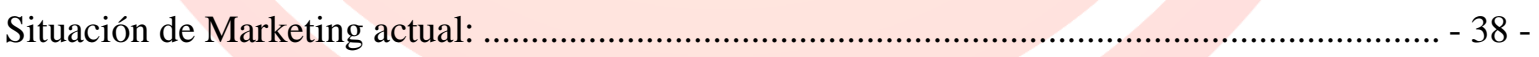

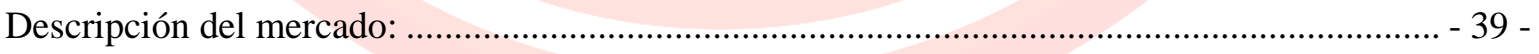

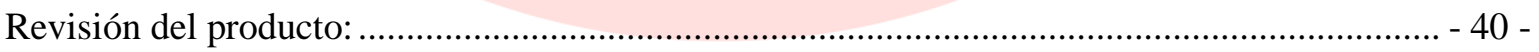

Revisión de Competencia: .................................................................................................... - 40 -

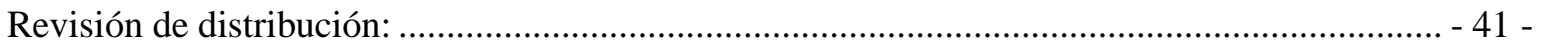

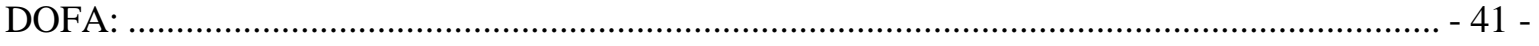




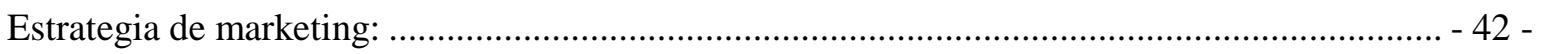

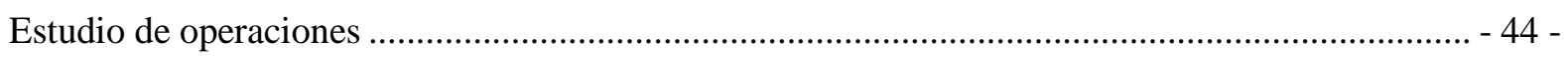

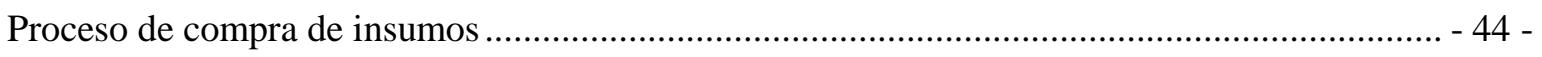

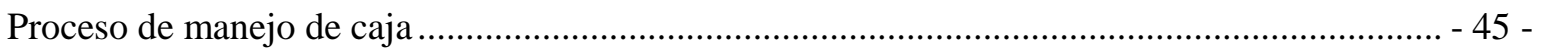

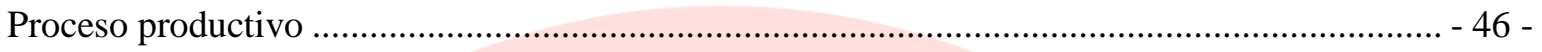

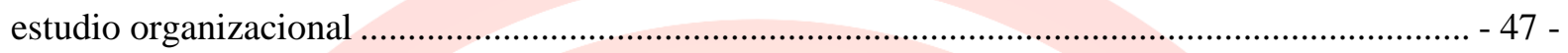

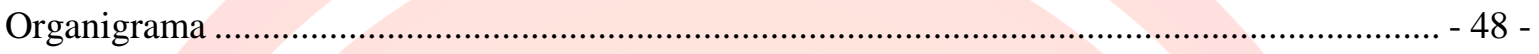

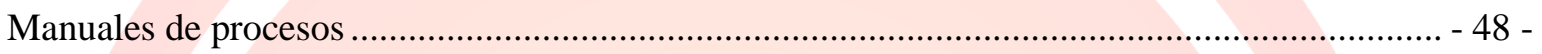

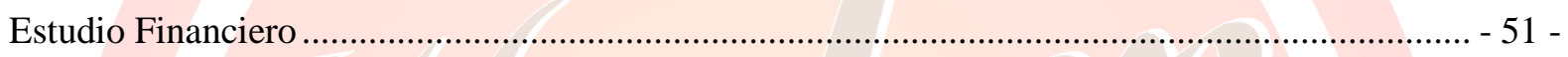

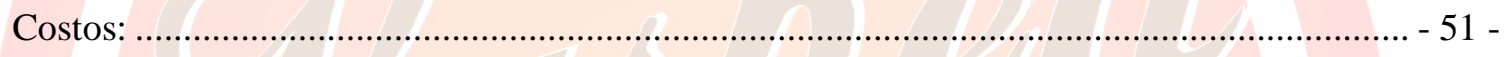

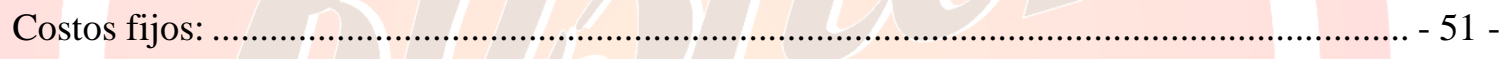

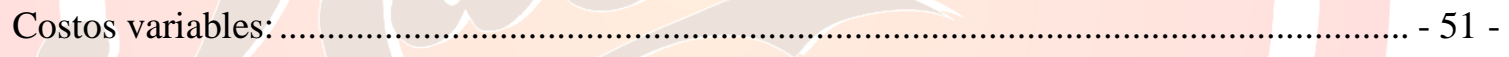

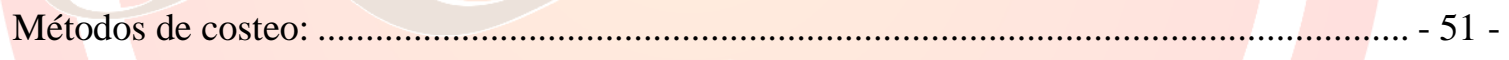

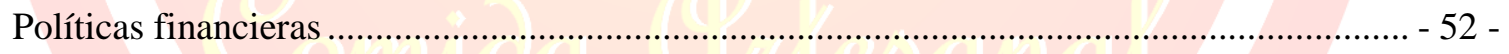

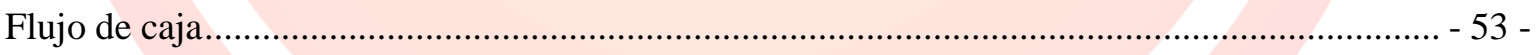

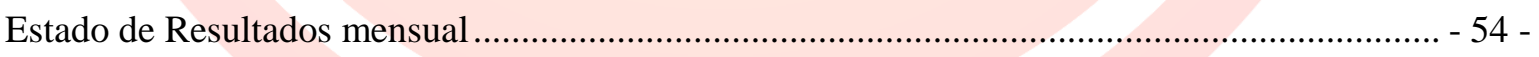

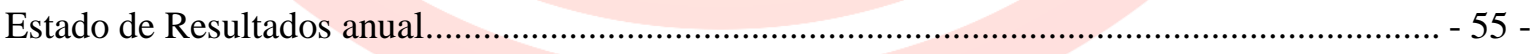

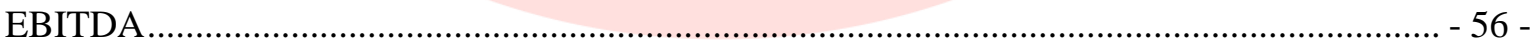

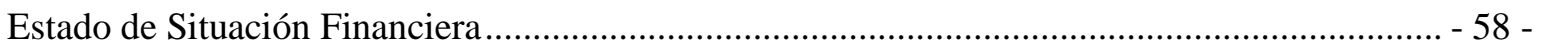

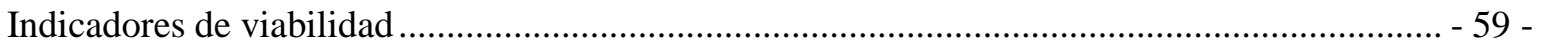

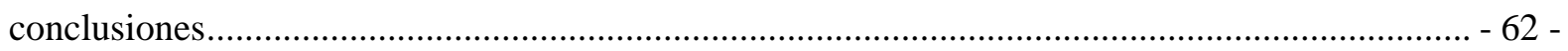




\section{LISTA DE TABLAS}

Tabla 1 FODA - 9 -

Tabla 2 Mercado Objetivo $-39-$

Tabla 3 Competidores Directos $-40-$

Tabla 4 DOFA $-41-$

Tabla 5 Manual de procesos Administrador $-48-$

Tabla 6 Manual de procesos Auxiliar de cocina. $-49-$

Tabla 7 Manual de procesos Domiciliario - 49 -

Tabla 8 Manual de procesos Contador $-50-$

\section{LISTA DE FIGURAS}

Figura 1 (Bogotá, 2016), mostrando el área delimita en la cual se centra el mercado del proyecto..... - 24 Figura 2 (SDP, 2011), mostrada anteriormente nombrando áreas y manzanas de cada localidad......... - 25 Figura 3 (SDP, 2011), mostrada anteriormente en la cual se encuentra el área de las UPZ de la localidad de Antonio Nariño. $-25-$

Figura 4 (SDP, 2011), mostrada anteriormente nombrando los barrios de cada UPZ...... $-26-$ Figura 5 (DANE, 2015), mostrada anteriormente y en la cual se encuentran la población por edades de la localidad Antonio Nariño. $-26-$ 
Figura 6 (DANE, 2015), mostrada anteriormente y en la cual se encuentran la población por edades de cada UPZ DE la localidad Antonio Nariño.

Figura 7 (SDP, 2011), mostrando los hogares encuestados por la secretaria distrital de planeación dentro de la localidad. $-28-$

Figura 8 (SDP, 2011), mostrando los hogares unipersonales dentro de la localidad. $-29-$

Figura 9 (campo, 2011), mostrando los sectores y tamaños de estos. $-29-$

Figura 10 (campo, 2011), mostrando el número de empresas y tamaño del sector en el que nos centramos. $-30-$

Figura 11 (DANE, 2016), donde se identifica el aumento del sector en lo corrido del año. $-32-$

Figura 12 (Finanzas personales, 2017), detallando los costos básicos para un local de comidas. $-34-$

Figura 13 (Finanzas personales, 2017) listando los requisitos para formalizar una pyme $-35-$

Figura 14 unidades de producto vendido por los competidores (elaboración propia) $-37-$

Figura 15 Tabla de precios de kushen (elaboración propia) $-37-$

Figura 16 flujograma de proceso de la compra de los insumos (elaboración propia) $-44-$

Figura 17 flujograma de proceso del manejo de caja (elaboración propia) $-45-$

Figura 18 flujograma de proceso productivo (elaboración propia) $-46-$

Figura 19 organigrama de Kushen (elaboración propia) $-48-$

Figura 20 flujo de caja mensual del primer año (elaboración propia) $-53-$

Figura 21 flujo de caja de los primeros cinco años (elaboración propia) $-54-$

Figura 22 estado de resultado del primer año (elaboración propia) $-55-$

Figura 23 estado de resultados de los primeros cinco años (elaboración propia) $-56-$

Figura 24 EBITDA del primer año mes a mes (elaboración propia) $-57-$

Figura 25 EBITDA de los primeros cinco años (elaboración propia) $-57-$

Figura 26 indicadores de viabilidad financiera (elaboración propia) $-59-$

Figura 27 indicadores de viabilidad financiera (elaboración propia) $61-$ 


\section{JUSTIFICACIÓN}

El presente emprendimiento corresponde a un restaurante de comidas rápidas situado en la localidad de Antonio Nariño, exactamente en el barrio San Antonio, De acuerdo con la Asociación Colombiana de la Industria Gastronómica (Acodres), “en el sector hubo un crecimiento superior a 22\% en todo el país” (Ortegón, 2015) Demostrando el gran potencial del proyecto ya que el sector se encuentra en constante crecimiento y la sociedad de la actualidad tienden a consumir mayormente en restaurantes cercanos a sus hogares.

Según Luis Fernando Jaramillo, director de Col franquicias menciona en la revista portafolio la importancia de que los negocios de comidas actualmente se están centrando en que los clientes necesitan algo más que una simple satisfacción del hambre, buscan obtener una mejor calidad del producto y servicio al cliente, generando nuevas experiencias y deleitando el paladar. La idea de negocio se centra en un restaurante de comidas rápidas, elaboradas con ingredientes $100 \%$ colombianos, naturales y procesados los colaboradores del restaurante, garantizando la calidad de los productos y que hacen que los clientes tengan una experiencia gastronómica especial, rodeados de un agradable ambiente para que las familias disfruten a la hora de comer.

La Evaluación del emprendimiento plasmado en el presente documento corresponde a la respuesta a una necesidad observada en la comunidad, en un segmento pobremente atendido, en lo referente a los restaurantes de comidas rápidas. 


\section{PLANTEAMIENTO DEL PROBLEMA}

- Carencia de restaurantes de comidas rápidas en la comunidad (se encuentra en el sector del barrio San Antonio, entre calles 4 hasta 12 sur y carrera 14 hasta la carrera 19 sur).

- Se encuentra la falta de restaurantes de comidas rápidas con una excepción la cual cuenta con buenos niveles de ventas, pero dicho restaurante no tiene un horario de atención fijo, adicional a esto no cuenta con la capacidad para responder con la demanda. Sus productos son hamburguesas, papas fritas, arepas rellenas, mazorcadas, estos productos son elaborados con pre cocidos y enlatados de marcas reconocidas.

- Se identifica otro problema el cual es la base del plan de negocio, se trata de la inconformidad que manifiesta la comunidad con respecto a la falta de otro restaurante ya que los clientes están agotados de comer lo mismo y en el mismo lugar.

- No se encuentra comida rápida hecha con ingredientes $100 \%$ naturales y frescos.

\section{Necesidad a Satisfacer:}

De acuerdo al problema ya planteado con respecto a la inconformidad de la comunidad sobre la falta de restaurantes de comidas rápidas, se considera que la necesidad primaria es satisfacer el hambre de una manera natural, creativa, variada, diferente, económica, rápida y con un muy buen servicio al cliente. 


\section{Oportunidad en el mercado:}

- El mercado de dicho sector es mayormente residencial, encontramos 3 conjuntos o unidades residenciales.

- La vía de acceso a este sector es la calle 12 ya que es la entrada única de la estación de Transmilenio (Estación Nariño) y vía principal de acceso al barrio Restrepo, con alta rotación de peatones y trasporte vehicular.

- Baja competencia directa.

- Alta demanda.

- Alto tráfico de peatones.

- Nivel socio económico medio.

\section{OBJETIVOS}

\section{Objetivo general}

Formular un plan de negocios para la creación de un restaurante de comidas rápidas, aplicando los conocimientos recopilados durante la carrera, aplicando los estudios necesarios para la elaboración del proyecto.

\section{Objetivos Específicos}

- Desarrollar un proceso de investigación, en la cual participa el estudiante, dirigido a solucionar problema del sector.

- Aplicar el estudio de mercadeo pertinente para obtener la proyección del negocio.

- Efectuar matrices por las cuales se determina información sobre el sector. 
- Evaluar los términos económicos, cuáles serán los resultados de la empresa y concluir con un estudio de la viabilidad del proyecto.

\section{Objetivos Técnicos}

Formular un plan de negocios para la creación de un restaurante de comidas rápidas cuya principal fortaleza es la elaboración de comida artesanal, natural y fresca, en la ciudad de Bogotá (Colombia) específicamente en la localidad Antonio Nariño, barrio San Antonio.

\section{Objetivos Específicos}

- Analizar el sector de restaurantes dentro de la zona establecida para avistar la posibilidad de crecimiento en el nicho de mercado que se describirá más adelante.

- Estudiar la situación de la competencia dentro del sector y elaborar el plan estratégico para ingresar en el mercado con la mayor seguridad.

- Determinar los costos operativos, de producción e infraestructura que se deben tener en cuenta para la puesta en marcha del proyecto.

- Evaluar los términos económicos, cuáles serán los resultados de la empresa y concluir con un estudio de la viabilidad del proyecto. 


\section{RESUMEN EJECUTIVO}

El negocio consiste en un Restaurante de comidas rápidas llamado Kushen House donde se elaboraran alimentos con ingredientes $100 \%$ naturales y procesados artesanalmente. Un lugar donde los clientes pueden compartir en familia ofreciéndoles un ambiente agradable, ubicado en la ciudad de Bogotá, en el barrio San Antonio de la Localidad Antonio Nariño.

El sector gastronómico y en especial el de las comidas rápidas tiene un incremento en Colombia a más del 15\% anual, lo cual nos muestra una atractiva oportunidad de negocio. El estudio de mercado realizado ha determinado que el cliente objetivo del restaurante está conformado por el segmento de población entre 20 y 50 años de edad de la localidad, que pertenecen a nivel socioeconómico medio, teniendo así un mercado objetivo de 9.495 personas, quienes en su mayoría se sienten insatisfechos por la poca oferta de restaurantes de éste tipo en el sector.

Mediante estrategias de marketing como el uso de material POP y BTL se busca llegar al grupo objetivo invitándolos a visitar el restaurante a probar los productos, los cuales con su calidad, precio, innovación y sumado al agradable ambiente del restaurante esperamos cautiven a dichos clientes.

El equipo de trabajo de Kushen House inicialmente estará conformado por un Administrador, un Auxiliar de cocina y un domiciliario, quienes con su servicio se encargarán junto a la calidad de los productos de fidelizar los clientes. 
La inversión inicial requerida para abrir Kushen House será de \$ 15.270.895, los cuales serán financiados con recursos propios por valor de $\$ 5.270 .895$ y con préstamo bancario por valor de $\$ 10.000 .000$. El punto de equilibrio acorde con los costos fijos y variables del restaurante es de 848 unidades distribuidas según el porcentaje de participación de cada producto en las ventas totales.

Acorde a las proyecciones financieras, se espera que al finalizar el quinto año de operación la utilidad neta ascienda a $\$ 18.694 .969$, contándose con una TIR de 56,93\% y una VPN de \$39.451.371 con una tasa de descuento del 5.17\%, por esta razón en el tercer año se habrá recuperado la inversión, permitiendo así mediante la reinversión de los recursos, cumplir con la meta de abrir una sucursal en el tercer año. Adicionalmente, las proyecciones financieras también nos indican que la rentabilidad que recibe el socio sobre la inversión es en promedio del $196 \%$.

Por tratarse de un negocio en el que sus ventas son $100 \%$ de contado, es posible mantener un flujo de efectivo alto que permite cumplir con todas las obligaciones y pagos que en su mayoría también son exigibles al contado, sin ninguna dificultad.

Este proyecto es muy viable según los indicadores que se reflejan en el estudio financiero, además de la planeación, el marketing y el exhaustivo estudio de mercado que se realizó con el fin de manifestar que el negocio tiene buenas bases y así mismo que el proyecto sea exitoso y rentable. 


\section{PLANEACIÓN ESTRATÉGICA}

\section{Misión:}

Ofrecer productos de comida rápida elaborados artesanalmente, con ingredientes $100 \%$ naturales, de buena calidad, frescos, con buen servicio y en un ambiente confortable.

\section{Visión:}

Kushen House busca para el 2019 lograr de la mano de los clientes y colaboradores abrir la primera sucursal en la localidad Antonio Nariño. Para el 2022 afianzar la compañía en dicho sector logrando 3 Sucursales dentro de la zona ya establecida para incrementar recordación de los clientes.

\section{Objetivo general:}

Ser una cadena de Restaurantes de comidas rápidas líder en el sector, ofreciendo a la comunidad comida artesanal y con ingredientes $100 \%$ naturales, donde los clientes puedan compartir, ofreciéndoles un ambiente agradable y que se sientan en confianza.

\section{Objetivos específicos:}

- Ofrecer productos naturales y de calidad a los clientes

- Liderar el mercado de comidas rápidas en el sector

- Ofrecer la mejor atención a los clientes de forma atenta y en un ambiente agradable

- Elaborar platos que cautiven a los clientes

- Dar los mejores precios y más adecuados para los platos

- Generar una fuente de empleo

- Crear estrategias de venta y campañas publicitarias para posicionar el restaurante

- Lograr un buen margen de rentabilidad para los inversionistas

- Incrementar un $15 \%$ en ventas los primeros 3 meses posteriores a la apertura. 


\section{FODA}

Definición La técnica de matriz FODA constituye un avance metodológico en la planeación, la cual envuelve procesos cualitativos y cuantitativos. Se define como el conjunto de fortalezas y oportunidades, debilidades y amenazas surgidas de la evaluación de un sistema organizacional que, al clasificarse, ordenarse y compararse, generan un conjunto de estrategias alternativas factibles para el desarrollo de dicho sistema organizacional. (Salazar, 2005, pág. 96)

El objetivo concreto de la matriz FODA es el análisis profundo de los factores que afectan positiva o negativamente al sistema organizacional, en el propósito de establecer comparaciones que permitan generar estrategias alternativas factibles, las cuales serán seleccionadas y priorizadas posteriormente (lo que significa determinar cuáles de ellas son las mejores estrategias) para identificar, finalmente, los objetivos socio-económicos básicos de la organización. (Salazar, 2005, pág. 96) 


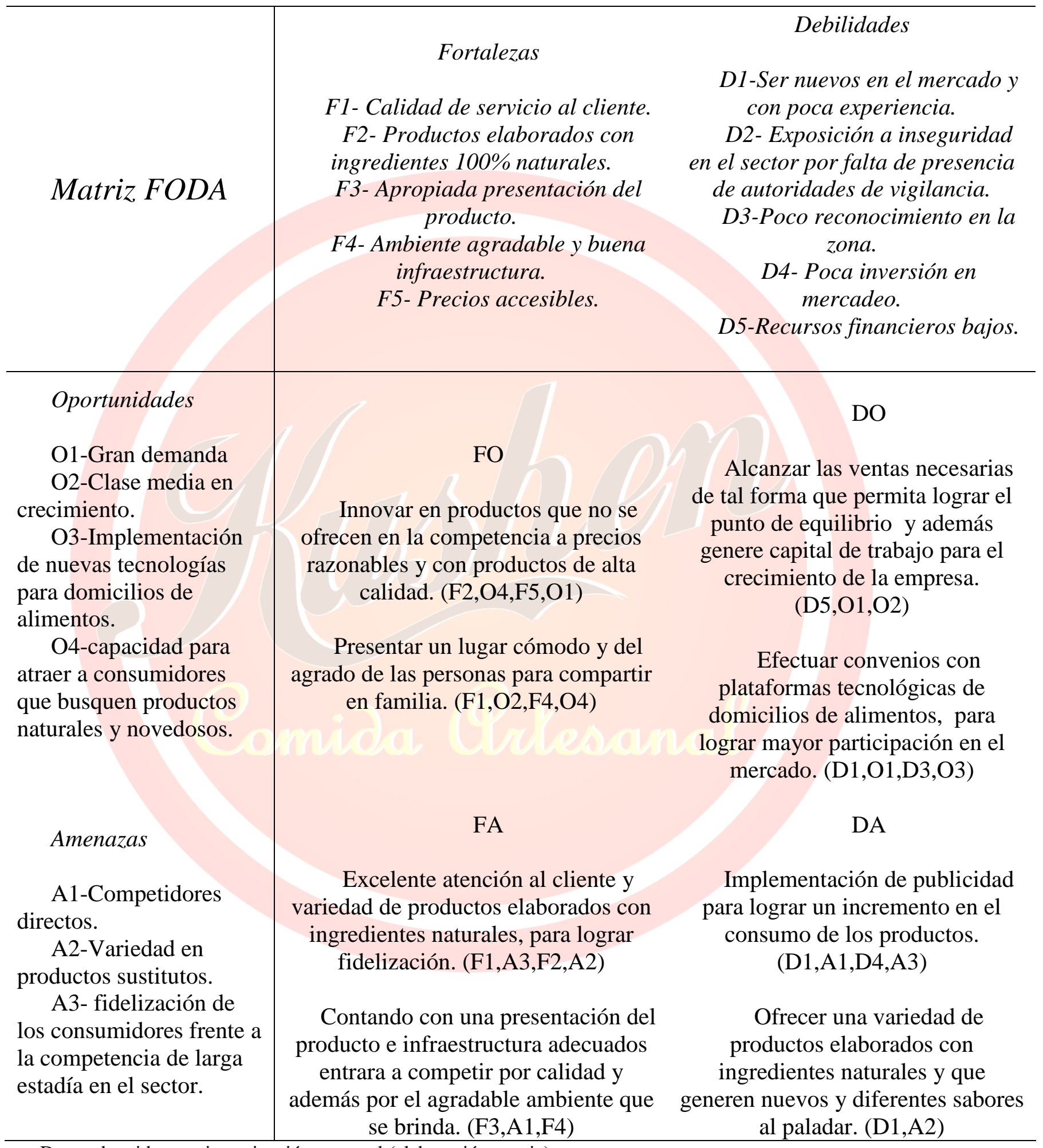

Datos obtenidos por investigación personal (elaboración propia) 


\section{PESTEL.}

Para realizar el análisis global utilizaremos el análisis PESTEL, una herramienta de gran utilidad para comprender el crecimiento o declive de un mercado y, en consecuencia, la tendencia que lleva un negocio en concreto. Los factores del entorno global que pueden ser identificados usando el análisis PESTEL son seis posibles: Políticos, Económicos, Sociales, Tecnológicos, Ecológicos y Legales. Aunque no inciden del mismo modo en toda estructura empresarial. Afectan a todas las empresas en mayor o menor medida independientemente de su tamaño, volumen de negocio, ubicación y estatus dentro de sector de actividad. (Giménez \& Espinosa, 2015, pág. 117)

La plantilla de análisis PESTEL promueve cl pensamiento proactivo, es decir, nos permite tener cierta anticipación en relación a lo que sucede en nuestro entorno global y nos ayuda a poder detectar amenazas y oportunidades con el propósito de poder tomar decisiones basadas en la reflexión y no en una reacción instintiva. Su utilización se vuelve más útil y relevante a medida que el sector de actividad se torna más complejo siendo importante este análisis para las pymes, puesto que puede proporcionar dato sobre oportunidades y amenazas que de otra forma seria complicado detectar. (Giménez \& Espinosa, 2015, pág. 117)

\section{Factores Políticos.}

En este apartado se mencionarán algunos factores de índole político que podrían afectar directa o indirectamente a la empresa, como lo es la Secretaria distrital de salud ${ }^{1}$ es la encargada de la normatividad que se tiene en manipulación de alimentos, son los encargados de la

\footnotetext{
${ }^{1}$ Secretaria de salud: "Un elemento fundamental de la Salud Pública, es la inocuidad de los alimentos. La gran diversidad de riesgos transmitidos a estos genera la posibilidad de ocurrencia de eventos en salud pública y también constituyen un obstáculo para el comercio de los mismos.” (MARTÍNEZ \& FERRO, 2017)
} 
vigilancia, inspección y control de los alimentos que se utilizan en el restáurate, además El Ministerio de industria y comercio ${ }^{2}$ apoya cualquier actividad comercial y de la mano de esta entidad Kushen podría garantizar que se entregan producto de calidad, novedoso y ayudar al crecimiento y competitividad de la empresa.

\section{Factores Económicos.}

En el análisis económico se pueden identificar algunos factores que influyen en el poder adquisitivo de las familias en Colombia y que determinaran el nivel de gasto de estos individuos en comidas fuera del hogar y en actividades recreativas. Existe evidencia empírica que a medida que el ingreso per cápita aumenta, se incrementa el gasto en restaurantes y actividades de recreación. Por lo tanto revisar algunos indicadores económicos será de suma importancia para la determinación de la estrategia y del presupuesto, entre otras actividades.

La compañía se ajustara a cualquier carga tributaria que se imponga según la actividad económica que brindara en la empresa para soportar gastos públicos y según la clasificación de contribuyente el cual se regirá bajo los lineamientos según su clasificación de contribuyente como persona natural constituida como una empresa, donde dicha persona se hace responsable de las obligaciones y deudas que adquiera la empresa y ejerciendo los derechos que esta tenga y garantizar el acatamiento de las obligaciones que establece la entidad responsable la cual es la DIAN $^{3}$ con trasparencia, cumpliendo a cabalidad las normas establecidas por esta entidad.

\footnotetext{
${ }^{2}$ Ministerio Industria y comercio: "El Ministerio de Comercio, Industria y Turismo apoya la actividad empresarial, productora de bienes, servicios y tecnología, así como la gestión turística de las regiones del país para mejorar su competitividad y su sostenibilidad e incentivar la generación de mayor valor agregado." (MinCIT, s.f.)

${ }^{3}$ DIAN: La Unidad Administrativa Especial Dirección de Impuestos y Aduanas Nacionales -DIAN- tiene como objeto coadyuvar a garantizar la seguridad fiscal del Estado colombiano y la protección del orden público económico nacional, mediante la administración y control al debido cumplimiento de las obligaciones tributarias,
} 
De la mano con la Cámara de Comercio ${ }^{4}$ se podrá tener apoyo en el crecimiento de la empresa y ayudar al crecimiento del sector de comidas rápidas de la zona donde se establecería el restaurante por otro lado se tendrán en cuenta las tasas de interés y demás datos estadísticos y estudios que servirán para posteriormente realizar tomas decisiones dentro de la empresa, la entidad que nos puede brindar esta información es el Banco de la Republica 5 .

Kushen contara con empleados dentro del restaurante y se tendrá en cuenta el salario mínimo legal vigente para establecer sueldo de dichos empleados, recibiendo este dinero de forma periódica ya sea mensual o quincenal por parte del empleador, por tiempo de trabajo o por tareas realizadas al elaborar los productos dentro del horario que se encuentre en atención al cliente. Además se debe tener en cuenta el PIB Per Cápita el cual permite ver el nivel de desarrollo económico que hay en el país frente a su población y así saber el nivel de riqueza y bienestar que se encuentra para determinar si la población tiene la capacidad monetaria de consumir alimentos en restaurantes.

El PIB Per cápita de Colombia en 2016 fue de 5.292€, 159€ menor que en 2015, cuando fue de 5.451€. Para ver la evolución del PIB per cápita resulta interesante mirar unos años atrás y comparar

aduaneras, cambiarias, los derechos de explotación y gastos de administración sobre los juegos de suerte y azar explotados por entidades públicas del nivel nacional y la facilitación de las operaciones de comercio exterior en condiciones de equidad, transparencia y legalidad. (DIAN, s.f.)

${ }^{4}$ Cámara de Comercio: Somos una entidad privada sin ánimo de lucro que busca construir una Bogotá - Región sostenible a largo plazo, promoviendo el aumento de la prosperidad de sus habitantes, a partir de servicios que apoyen las capacidades empresariales y que mejoren el entorno para los negocios con incidencia en la política pública. (CCB, s.f.)

${ }^{5}$ Banco de la Republica: "Según la Constitución, el principal objetivo de la política monetaria es preservar la capacidad adquisitiva de la moneda, en coordinación con la política económica general, entendida como aquella que propende por estabilizar el producto y el empleo en sus niveles sostenibles de largo plazo." (Banco de la República, s.f.) 
estos datos con los del año 2006 cuando el PIB per cápita en Colombia era de 2.987.

(Datosmacro.com, 2016)

según el DANE en grupo de alimentos reporta una variación menor al año 2015, lo que ayudaría a la elaboración de los productos finales aumentando el poder adquisitivo ya que los precios no se verían tan incrementados por la inflación de los insumos.

En los últimos doce meses el grupo Alimentos presentó una variación de 2,49\% menor a la registrada el año anterior cuando fue 12,63\%. Este grupo fue el que presentó la menor variación en los últimos doce meses. El grupo con la mayor variación en los últimos doce meses fue Salud con 7,81\%. Entre abril de 2015 y abril 2016 fue de 6,89\%. (DANE, 2017)

La compañía podría ayudar a disminuir la tasa de desempleo ofreciendo las bacantes necesarias para lograr que el restaurante ejerza las actividades con normalidad para satisfacer las necesidades de los clientes y el sector "En marzo de 2017 la tasa de desempleo se ubicó en 9,7\% y 486 mil personas más encontraron empleo. En marzo de 2017, 21 millones 932 mil personas se encontraban ocupadas, 486 mil personas más que marzo de 2016” (DANE, 2017).

\section{Factores Sociales.}

Dentro de los factores sociales encontramos que existe una entidad la cual permite encontrar datos e información oficial sobre población, hábitos de consumo, entre otros se encontró el $\mathrm{DANE}^{6}$ con la que se facilitara la planeación estratégica de Kushen. En cuanto a las tendencias

\footnotetext{
${ }^{6}$ DANE: “Contribuimos al desarrollo del país produciendo y difundiendo información confiable, relevante, oportuna y de calidad.” (DANE, s.f.)
} 
de consumo actualmente los consumidores están en búsqueda de alimentos elaborados con ingredientes $100 \%$ naturales, el gusto por alimentos que no tengan persevantes ni colorantes artificiales se ha dado a notar. Kushen cubriría esa necesidad en el sector de comidas rápidas ofreciendo productos novedosos y de excelente calidad.

Aunque en la zona se cuenta con el cuadrante de policía y la estación del CAI se encuentra aproximadamente a 3 cuadras del restaurante Kushen la zona en las horas de la noche se evidencia que hay poca vigilancia y seguridad por parte de las autoridades pertinentes, no se realizan recorridos por parte de los policías y no se cuenta con casetas de vigilancia cercanas.

\section{Factores Tecnológicos.}

Kushen pretende realizar la Implementación de tecnologías de domicilio como UberEATS, Rappi, Domicilios.com, etc. De modo que se fomentaría la marca y daría a conocer los productos en la cuidad de Bogotá aumentando las ventas y la utilidad que ingresaría al restaurante. Además de la Utilización de máquinas registradoras para garantizar el control de ventas e ingresos diarios de la empresa, con el cual se facilitaría temas de contabilidad e inventarios.

\section{Factores Ecológicos.}

El restaurante se compromete a seguir las regulaciones que establece el Ministerio de Ambiente y Desarrollo Sostenible ${ }^{7}$ para garantizar un buen desarrollo sostenible y un buen

\footnotetext{
${ }^{7}$ Ministerio de Ambiente y Desarrollo Sostenible: es el rector de la gestión del ambiente y de los recursos naturales renovables, encargado de orientar y regular el ordenamiento ambiental del territorio y de definir las políticas y regulaciones a las que se sujetarán la recuperación, conservación, protección, ordenamiento, manejo, uso y aprovechamiento sostenible de los recursos naturales renovables y del ambiente de la nación, a fin de asegurar el desarrollo sostenible, sin perjuicio de las funciones asignadas a otros sectores. (MINAMBIENTE, s.f.)
} 
manejo de residuos haciendo uso de los servicios que prestas diversas empresas de reciclaje o manejo de residuos grasos "Somos una empresa Colombiana, especializada en la recolección y reciclado de Aceite de Cocina Usado, conocido también como Aceite Vegetal Usado (AVU)” (Biogras S.A.S, s.f.). Como esta empresa hay diversas que prestan el servicio de recolección de aceites usados los cuales ayudarían a desechar correctamente los residuos grasos que se utilizan dentro del restaurante asegurando el correcto envío, tratamiento y aprovechamiento. Por otro lado Kushen contara con canecas para separar basuras y hacer la respectiva clasificación en cuanto a orgánico e inorgánico además no se hará uso de elementos desechables ni popotes a la hora de ofrecer y consumir los alimentos elaborados en el restaurante.

Dentro de la secretaria de salud se realizan ajustes para recibir certificaciones sobre manipulación de alimentos, autorizaciones sanitarias, expendio de alimentos, entre otras que son necesarios para lograr la certificación de la secretaria de salud para poder formar la empresa legalmente.

\section{Factores Legales.}

Kushen tiene afectación legal con todo lo concerniente a la legislación colombiana laboral (código sustantivo de trabajo), comercial (código de comercio), y en general todas las reglamentaciones emitidas por las entidades de vigilancia y control como la secretaria de salud, cámara de comercio, DIAN y el cuerpo oficial de Bomberos de Bogotá el cual revisa las condiciones de riesgos de incendios, seguridad humana, materiales peligrosos dentro del establecimiento y sistemas contra incendios que se instalen en el inmueble, si el restaurante 
cumple con todos los requerimientos establecidos se entregara un certificado el cual autoriza ejercer la actividad económica.

La reforma tributaria del año 2012 (Ley 1607) el impuesto nacional al consumo el cual grava la prestación o la venta al consumidor final de entre otros, el servicio de expendio de comidas y bebidas preparadas con "La tarifa aplicable al servicio es del ocho por ciento (8\%) sobre todo consumo" (El CONGRESO DE COLOMBIA , 2012). Definitivamente lo anterior puede ser un factor crítico para el restaurante dado que en caso de superar los topes permitidos para pertenecer al régimen simplificado, la estructura del PyG puede ser afectada por tener que pagar un $8 \%$ más de impuesto sobre el total de las ventas.

El plan de ordenamiento territorial (POT) es un factor de gran importancia debido a que es la norma que define cómo puede la ciudad hacer uso de su suelo y dónde están las áreas protegidas, en qué condiciones se puede ubicar vivienda, actividades productivas, culturales y de esparcimiento. Teniendo en cuenta lo anterior, el POT será crítico al momento de determinar la ubicación del restaurante y sus sucursales porque se podrá detectar el potencial de acuerdo con la zona o localidad. 


\section{CONCEPTO DEL PRODUCTO}

\section{Hamburguesas:}

\section{Carne de res:}

Paso 1: compra de la carne de res (Cogote y murillo)

Paso 2: se le agrega a la carne molida: $2 \mathrm{gr}$ de sal, $2 \mathrm{gr}$ de perejil picado, $15 \mathrm{gr}$ de cebolla picada, 2gr de pimienta, 30gr de miga de pan y $8 \mathrm{gr}$ de mantequilla.

Paso 3: se realiza la mezcla de los ingredientes y dejarlo reposar por 3 horas.

Paso 4: se pasa a la plancha y se asa cada porción para que suelte todo su sabor.

Se ofrecen porciones de carne de $200 \mathrm{gr}$.

\section{Verduras:}

Paso 1: se seleccionan $10 \mathrm{gr}$ de lechuga, $30 \mathrm{gr}$ de tomate y $10 \mathrm{gr}$ de cebolla.

Paso 2: limpieza de los ingredientes.

Paso 3: se procede a picar la lechuga, cortar en julianas el tomate y la cebolla en aros.

Paso 4: la cebolla se pasa por la plancha con $0,3 \mathrm{gr}$ de sal.

\section{Presentaciones:}

Paso 1: se da a conocer las 3 opciones en las que se puede entregar la hamburguesa las cuales son pan árabe, pan blanco o patacón. 
Paso 2: después que el cliente selecciona una de las presentaciones se procede a preguntar el gramaje de carne que desea.

Paso 3: se adiciona lechuga, tomate, cebolla grille, una tajada de jamón y queso.

\section{Salchipapa:}

\section{Papas:}

Paso 1: se selecciona de papas pastusa $\mathrm{R}-12^{8}$.

Paso 2: se procede a lavar la papa.

Paso 3: se pela y se retira cualquier pedazo en caso de tener yemas de crecimiento llamada comúnmente "ojos".

Pasó 4: luego de tener la papa arreglada se procede a picar a la mitad, después en cuartos y finalmente en tiras largas.

Paso 5: se coloca la porción de papa deseada por el cliente en la freidora a 160 grados centígrados.

Paso 6: se deja freír la papa en $400 \mathrm{ml}$ de aceite girasol por 8 minutos hasta que estén dorados y crujientes.

Se ofrecen porciones de papa de 500gr.

\section{Embutidos:}

Paso 1: se selecciona la salchicha y el chorizo.

\footnotetext{
${ }^{8}$ Papa pastusa R-12: Es la principal para elaborar las comidas por los colombianos, preparándolas mayormente en bastones "de buena aceptación para consumo en fresco, textura compacta al cocinar, adecuada para sopas y cocida o salada." (Ramos, s.f.)
} 
Paso 2: se coloca la salchicha o chorizo deseada por el cliente en la freidora a 160 grados centígrados por 1 minuto.

Paso 3: se deja freír la salchicha o chorizo en $400 \mathrm{ml}$ de aceite girasol.

Paso 4: luego de freídas se procede a sacar tajadas, para una porción se requiere de 1 unidad de salchicha o de chorizo.

\section{Presentaciones:}

Paso 1: se junta la papa y el embutido deseado por el cliente.

Paso 2: se le agrega sal y paprika.

Paso 3: se le agrega una tajada de queso doble crema y posteriormente al microondas por 1 min para que se gratine.

\section{Salchiyuca:}

\section{Yucas:}

Paso 1: se selecciona la yuca.

Paso 2: se procede a pelar la yuca y lavarla.

Paso 3: luego de tener la yuca arreglada se procede a picar a la mitad, después en cuartos y finalmente en tiras largas en el mismo estilo de las papas a la francesa.

Paso 4: se coloca la porción de yuca deseada por el cliente en la freidora a 160 grados centígrados.

Paso 5: se deja freír la papa en $400 \mathrm{ml}$ de aceite girasol por 7 minutos hasta que estén dorados y crujientes por fuera y suaves por dentro.

Se ofrecen porciones de yuca de 400gr. 


\section{Embutidos:}

Paso 1: se escoge la salchicha.

Paso 2: se coloca la salchicha en la freidora a 160 grados centígrados por 1 minuto.

Paso 3: se deja freír la salchicha en $400 \mathrm{ml}$ de aceite girasol.

Paso 4: luego de freídas se procede a sacar tajadas, para una porción se requiere de 1 unidad de salchicha.

\section{Presentaciones:}

Paso 1: se junta la yuca y la salchicha.

Paso 2: se le agrega $0,3 \mathrm{gr}$ de sal, $2 \mathrm{gr}$ de mantequilla o $5 \mathrm{gr}$ de suero costeño según lo prefiera el consumidor.

Paso 3: se le agrega una tajada de queso doble crema y posteriormente al microondas por 1 min para que se gratine.

\section{Mazorcadas:}

\section{Mazorca:}

Paso 1: se seleccionan la mazorca tierna desgranada.

Paso 2: se lavan los granos de mazorca.

Paso 3: se cocina la mazorca en 250ml de agua natural con $5 \mathrm{gr}$ de azúcar por 30 minutos.

Paso 4: se saltea a la plancha con $5 \mathrm{ml}$ de aceite por 3 minutos.

Paso 5: cuando esté lista la sacamos de la plancha directo al plato. 
Se ofrecen porciones de mazorcada de 200gr.

\section{Carne:}

Paso 1: se seleccionan $75 \mathrm{gr}$ de carne res (pecho) para desmechar.

Paso 2: se realiza una limpieza a la carne la cual consta de retirarle todos los excesos de grasa.

Paso 3: se pone a cocinar en olla a presión en $166 \mathrm{ml}$ de agua natural con $2 \mathrm{gr}$ de sal por 30 minutos.

Paso 4: una vez cocinada la carne, se puede desmechar y consiste en ir sacando las hebras de la carne.

\section{Pollo:}

Paso 1: se seleccionan $75 \mathrm{gr}$ de pechuga de pollo para desmechar.

Paso 2: se realiza una limpieza al pollo la cual consta de retirarle todos los excesos de grasa y la piel de la pechuga.

Paso 3: se pone a cocinar en $166 \mathrm{ml}$ de agua natural con $2 \mathrm{gr}$ de sal por 30 minutos.

Paso 4: una vez cocinado el pollo, se puede desmechar y consiste en ir sacando las hebras de la carne.

\section{Guiso:}

Paso 1: se lava $16 \mathrm{gr}$ de cebolla y $50 \mathrm{gr}$ de tomate.

Paso 2: se licua la cebolla, tomate, hasta obtener una pasta.

Paso 3: se le agrega $1 \mathrm{gr}$ de ajo en pasta, $0,2 \mathrm{gr}$ de azúcar, $1 \mathrm{gr}$ de sal y $0,4 \mathrm{gr}$ de mantequilla. 
Paso 4: se coloca todo en una olla con $16 \mathrm{ml}$ de agua y se deja cocinar por $20 \mathrm{~min}$.

Paso 5: se deja sofreír junto a la carne o el pollo por 5 minutos hasta que la preparación esta lista para servir.

\section{Presentaciones:}

Paso 1: se junta la mazorca con la carne, el pollo y el guiso sobre una cama de papas en chip.

Paso 2: 3 tajadas de queso doble crema.

Paso 3: se mete al microondas por 1 minuto para que gratine el queso.

\section{Hamburguesa de Helado caliente:}

\section{Presentación:}

Paso 1: selección de pan de hamburguesa.

Paso 2: se pone la base de pan de hamburguesa.

Paso 3: se coloca una capa de $70 \mathrm{ml}$ de helado.

Paso 4: se adiciona $15 \mathrm{ml}$ de mermelada de frutos rojos.

Paso 5: se coloca la tapa de pan de hamburguesa.

\section{Caramelizado:}

Paso 1: en un sartén se coloca 20 gr de azúcar blanca y se cocina hasta que esta que caramelice.

Paso 2: se toma la hamburguesa y se pasa 30 segundos por cada lado del pan hasta que este absorba el azúcar. 


\section{ESTUDIO DE MERCADO}

\section{Características y comportamiento del grupo objetivo.}

El mercado que va a ser atendido está localizado en el barrio San Antonio el cual es mayormente residencial, donde encontramos 3 conjuntos residenciales (Luna park etapa I, etapa II, etapa III) con alta población donde la mayoría de la población se encuentra entre 20 y 50 años y un nivel socioeconómico medio. A demás que hay gran afluencia de estudiantes universitarios que llegan desde las $8 \mathrm{pm}$ hasta las $11 \mathrm{pm}$, el comportamiento de la comunidad es muy tradicional con trabajos de horarios $8 \mathrm{am}-5 \mathrm{pm}$ de lunes a viernes y los fines de semana disponen de tiempo y dinero para salir a comer en restaurantes con familia y/o amigos. El sector es reconocido por las pescaderías que se localizan sobre la calle 12 sur pero así mismo no se hallan muchos lugares de comidas rápidas.

El día a día de una persona que vive dentro del sector delimitado es muy tradicional, inician alrededor de las 6 am, normalmente salen de sus casas sin desayunar y se dirige a su lugar de trabajo, algunos en moto, carro o por el contrario sube por la calle 12 sur para ingresar a la estación de Transmilenio, cumplen con su horario de oficina normal es decir de 8 am a 5 pm con 1 hora de almuerzo que normalmente es a la $1 \mathrm{pm}$, a las $5 \mathrm{pm}$ algunos listos para dirigirse a sus casas llegando alrededor de las 6 a sus hogares y otros se dirigen a sus universidades ya que estudian en jornada nocturna cumpliendo un horario de 6 pm a 10 pm después de terminar su jornada se destinan a sus hogares llegando alrededor de las $11 \mathrm{pm}$, con este movimiento regular 
en la zona se da a notar la afluencia de peatones que circulan por la 12 sur entre las 5 pm y 11 pm el cual sería el horario en el que se atendería en la idea de negocio, los fines de semana normalmente el sábado trabajan medio día y llegan tipo 2 pm a sus hogares con la idea de salir a comer en restaurantes con sus familias y los domingos las personas descansan y buscan domicilios para no salir de casa.

\section{Estudio de mercado}

Kushen es un restaurante de comidas rápidas el cual estará dirigido a la localidad Antonio Nariño en el sector del barrio San Antonio, entre calles 4 hasta 12 sur y carrera 14 hasta la carrera 19 sur.

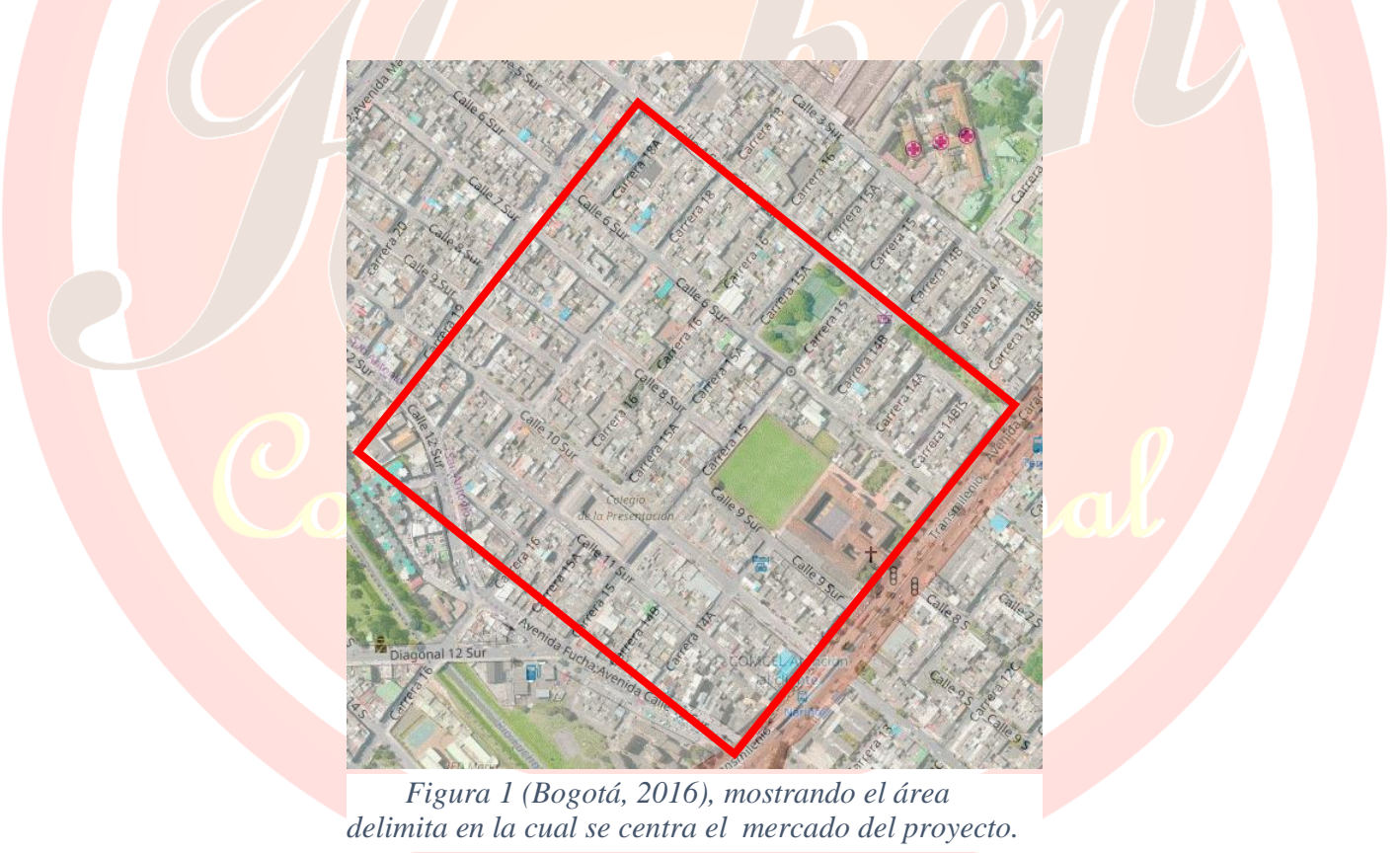

Dentro del sector delimitado se encontró por método de observación que se cuentan con aproximadamente 38 manzanas residenciales las cuales están compuestas por un promedio de 27 casas por manzana lo cual daría como resultado 1.026 casa dentro del sector delimitado, las casas están adaptadas mayormente con 2 o 3 apartamentos independientes para un total de 2.565 hogares aproximadamente. Además se cuenta con 3 conjuntos residenciales cercanos a la zona 
por tanto representaría alrededor de 600 hogares para un total de 3.165 hogares que en su mayoría la conforman 3 personas para obtener un resultado de 9.495 personas a los que estaría dirigido el restaurante.

El área total de la localidad de Antonio Nariño es de 488 hectáreas, en el siguiente cuadro de indica la cantidad de manzanas. El área urbana de la localidad está conformado por 602 manzanas y ocupan 329,4 hectáreas.

\begin{tabular}{|c|c|c|c|c|c|}
\hline & Localidad & Área total (ha) & $\begin{array}{l}\text { Área suelo } \\
\text { urbano (ha) }\end{array}$ & $\begin{array}{c}\text { Manzanas suelo } \\
\text { urbano }\end{array}$ & $\begin{array}{l}\text { Area manzanas } \\
\text { suelo urbano } \\
\text { (ha) }\end{array}$ \\
\hline 1 & Usaquén & $6.531,6$ & $3.525,1$ & 2417 & $2.625,2$ \\
\hline 2 & Chapinero & $3.815,6$ & $1.307,9$ & 1078 & 954,6 \\
\hline 3 & Santa Fe & $4.517,1$ & 696,4 & 778 & 506,9 \\
\hline 4 & San Cristóbal & $4.909,9$ & $1.649,0$ & 2951 & $1.231,5$ \\
\hline 5 & Usme & $21.506,7$ & $2.120,7$ & 3482 & $1.738,4$ \\
\hline 6 & Tunjuelito & 991,1 & 991,1 & 848 & 651,5 \\
\hline 7 & Bosa & $2.393,3$ & $1.932,5$ & 3258 & $1.375,5$ \\
\hline 8 & Kennedy & $3.859,0$ & $3.606,4$ & 4861 & $2.606,6$ \\
\hline 9 & Fontibón & $3.328,1$ & $3.052,8$ & 1643 & $2.475,4$ \\
\hline 10 & Engativá & $3.588,1$ & $3.439,2$ & 4344 & $2.595,5$ \\
\hline 11 & Suba & $10.056,0$ & $5.800,7$ & 4882 & $4,473,8$ \\
\hline 12 & Barrios Unidos & $1.190,3$ & $1.190,3$ & 1224 & 802,6 \\
\hline 13 & Teusaquillo & $1.419,3$ & $1.419,3$ & 1029 & 991,2 \\
\hline 14 & Los Martires & 651,4 & 651,4 & 707 & 433,2 \\
\hline 15 & Antonio Nariño & 488,0 & 488.0 & 601 & 326.9 \\
\hline 16 & Puente Aranda & $1.731,1$ & $1.731,1$ & 1868 & $1.159,5$ \\
\hline 17 & La Candelaria & 206,0 & 206,0 & 185 & 162,9 \\
\hline 18 & Rafael Uribe Uribe & $1.383,4$ & $1.383,4$ & 2860 & 911,7 \\
\hline 19 & Ciudad Bolivar & $13.000,3$ & $3.239,8$ & 5393 & $2.525,5$ \\
\hline \multirow{2}{*}{\multicolumn{2}{|c|}{ Total }} & $78.096,9$ & & & \\
\hline & & 163.663 .1 & 38.431 .2 & 44.409 & 28.548 .4 \\
\hline
\end{tabular}

Antonio Nariño contiene dos UPZ: 035 Ciudad Jardín y 038 Restrepo.

\begin{tabular}{llrrrr}
\multicolumn{1}{c}{ UPZ } & \multicolumn{1}{c}{ Clasificación } & $\begin{array}{c}\text { Area total } \\
\text { (ha) }\end{array}$ & $\%$ & $\begin{array}{c}\text { Cantidad } \\
\text { manzanas }\end{array}$ & $\begin{array}{c}\text { Area } \\
\text { manzanas (ha) }\end{array}$ \\
\hline 35 Cludad Jardin & Residencial Consolidado & 133,2 & 27,3 & 168 & 87,8 \\
38 Restrepo & Con Centralidad Urbana & 354,7 & 72,7 & $\mathbf{4 3 4}$ & 241,5 \\
\hline Total & & 488.0 & $\mathbf{1 0 0 . 0}$ & $\mathbf{6 0 2}$ & $\mathbf{3 2 9 . 4}$ \\
\hline
\end{tabular}

Figura 3 (SDP, 2011), mostrada anteriormente en la cual se encuentra el área de las UPZ de la localidad de Antonio Nariño.

Antonio Nariño tiene un total de 17 sectores catastrales que ocupan una superficie de 501,6 hectáreas, el cual uno de ellos es el barrio san Antonio en él se centra la idea de negocio.

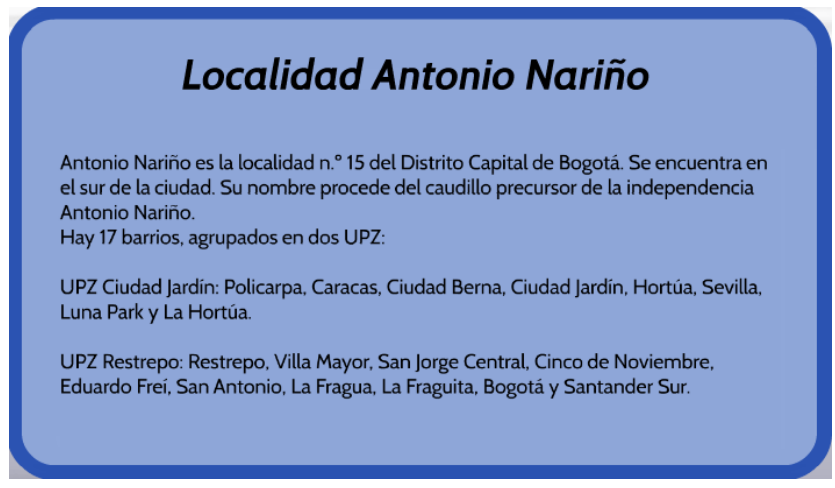


Figura 4 (SDP, 2011), mostrada anteriormente nombrando los barrios de cada UPZ.

La UPZ Restrepo se ubica en el costado occidental de la localidad Antonio Nariño, tiene una extensión de 354,7 hectáreas, equivalentes al 72,7\% del total del área de las UPZ de la localidad. Esta UPZ limita, por el norte, con las UPZ Muzú y Ciudad Montes de la localidad Puente Aranda; por el oriente, con la UPZ Ciudad Jardín; por el sur, con la UPZ Quiroga de la localidad Rafael Uribe; y por el occidente, con la UPZ Tunjuelito, de la localidad del mismo nombre. (SDP, 2011)

La población para 2015 de la localidad Antonio Nariño es de 108.941, el cual se muestra a continuación:

\begin{tabular}{|c|c|c|c|c|}
\hline \multirow{2}{*}{ Codigo } & \multirow{2}{*}{$\begin{array}{l}\text { Grupos de } \\
\text { edad }\end{array}$} & \multirow{2}{*}{$\begin{array}{l}2015 \\
\text { Total }\end{array}$} & \multirow[b]{2}{*}{ Hombres } & \multirow[b]{2}{*}{ Mujeres } \\
\hline & & & & \\
\hline TOTAL BOGOTÁ D.C. & total & & & \\
\hline \multirow[t]{19}{*}{15} & $\begin{array}{l}\text { Antonio } \\
\text { Nariño }\end{array}$ & & & \\
\hline & Total & 108.941 & 53.103 & 55.838 \\
\hline & $0-4$ & 8.070 & 4.186 & 3.884 \\
\hline & $5-9$ & 7.604 & 3.941 & 3.663 \\
\hline & $10-14$ & 7.950 & 4.118 & 3.832 \\
\hline & $15-19$ & 8.803 & 4.517 & 4.286 \\
\hline & $20-24$ & 9.173 & 4.699 & 4.474 \\
\hline & $25-29$ & 7.975 & 4.056 & 3.919 \\
\hline & $30-34$ & 7.928 & 3.833 & 4.095 \\
\hline & $35-39$ & 7.436 & 3.599 & 3.837 \\
\hline & $40-44$ & 6.943 & 3.349 & 3.594 \\
\hline & $45-49$ & 7.561 & 3.597 & 3.964 \\
\hline & $50-54$ & 7.462 & 3.497 & 3.965 \\
\hline & $55-59$ & 6.066 & 2.792 & 3.274 \\
\hline & $60-64$ & 4.779 & 2.172 & 2.607 \\
\hline & $65-69$ & 3.954 & 1.775 & 2.179 \\
\hline & $70-74$ & 2.827 & 1.244 & 1.583 \\
\hline & $75-79$ & 2.058 & 841 & 1.217 \\
\hline & 80 Y MAS & 2.352 & 887 & 1.465 \\
\hline
\end{tabular}

Figura 5 (DANE, 2015), mostrada anteriormente y en la cual se encuentran la población por edades de la localidad Antonio Nariño.

"Por estrato socioeconómico se tiene que del total de habitantes de Antonio Nariño para el 2011, el 93,0\% se encuentra en el estrato medio-bajo, el 4,6\% en el bajo y el 2,4\% clasificado sin estrato" (SDP, 2011). 
La localidad de Antonio Nariño está conformada por dos UPZ las cuales presentan la siguiente distribución de población.

\begin{tabular}{|c|c|c|c|c|}
\hline \multirow[t]{2}{*}{035} & \multicolumn{4}{|c|}{ Ciudad Jardín } \\
\hline & Total & 30.543 & 14.892 & 15.651 \\
\hline & $0-4$ & 1.842 & 958 & 884 \\
\hline & $5-9$ & 1.748 & 912 & 836 \\
\hline & $10-14$ & 1.852 & 971 & 881 \\
\hline & $15-19$ & 2.183 & 1.127 & 1.056 \\
\hline & $20-24$ & 2.414 & 1.257 & 1.157 \\
\hline & $25-29$ & 2.215 & 1.130 & 1.085 \\
\hline & $30-34$ & 2.319 & 1.125 & 1.194 \\
\hline & $35-39$ & 2.222 & 1.068 & 1.154 \\
\hline & $40-44$ & 2.157 & 1.037 & 1.120 \\
\hline & $45-49$ & 2.372 & 1.128 & 1.244 \\
\hline & $50-54$ & 2.267 & 1.064 & 1.203 \\
\hline & $55-59$ & 1.845 & 854 & 991 \\
\hline & $60-64$ & 1.484 & 689 & 795 \\
\hline & $65-69$ & 1.245 & 570 & 675 \\
\hline & $70-74$ & 914 & 407 & 507 \\
\hline & $75-79$ & 673 & 278 & 395 \\
\hline & 80 Y MAS & 791 & 317 & 474 \\
\hline 038 & \multicolumn{4}{|l|}{ Restrepo } \\
\hline & Total & 78.398 & 38.211 & 40.187 \\
\hline & $0-4$ & 6.228 & 3.228 & 3.000 \\
\hline & $5-9$ & 5.856 & 3.029 & 2.827 \\
\hline & $10-14$ & 6.098 & 3.147 & 2.951 \\
\hline & $15-19$ & 6.620 & 3.390 & 3.230 \\
\hline & $20-24$ & 6.759 & 3.442 & 3.317 \\
\hline & $25-29$ & 5.760 & 2.926 & 2.834 \\
\hline & $30-34$ & 5.609 & 2.708 & 2.901 \\
\hline & $35-39$ & 5.214 & 2.531 & 2.683 \\
\hline & $40-44$ & 4.786 & 2.312 & 2.474 \\
\hline & $45-49$ & 5.189 & 2.469 & 2.720 \\
\hline & $50-54$ & 5.195 & 2.433 & 2.762 \\
\hline & $55-59$ & 4.221 & 1.938 & 2.283 \\
\hline & $60-64$ & 3.295 & 1.483 & 1.812 \\
\hline & $65-69$ & 2.709 & 1.205 & 1.504 \\
\hline & $70-74$ & 1.913 & 837 & 1.076 \\
\hline & $75-79$ & 1.385 & 563 & 822 \\
\hline & 80 Y MAS & 1.561 & 570 & 991 \\
\hline
\end{tabular}

Figura 6 (DANE, 2015), mostrada anteriormente y en la cual se encuentran la población por edades de cada UPZ DE la localidad Antonio Nariño.

Restrepo de 78.398 habitantes delimitados en esta UPZ, “el 96,7\% se ubican en el estrato medio-bajo y el 2,4\% restante, corresponde a población clasificada sin estrato" (SDP, 2011). 
En la localidad de Antonio Nariño se evidencia las siguientes reparticiones de tipos de hogares:

43,5\% de los hogares encuestados están conformados por tres o cuatro personas, siendo éstos los tamaños de hogar con participaciones mayores. Un 18,4\% de los hogares son unipersonales, un $20,1 \%$, están conformados por dos integrantes, un $10,8 \%$ por cinco y $7,2 \%$ por seis o más. (SDP, 2011)

Antonio Nariño ocupa el quinto lugar entre las localidades con la mayor proporción de hogares encuestados con dos integrantes, con el 20,1\%. En valores absolutos, de los 803.620 hogares encuestados en Bogotá, 1.956 pertenecen a la localidad de Antonio Nariño. Entre estos, 455 de los 187.719 hogares con tres integrantes encuestados en Bogotá, habitan en esta localidad. (SDP, 2011)

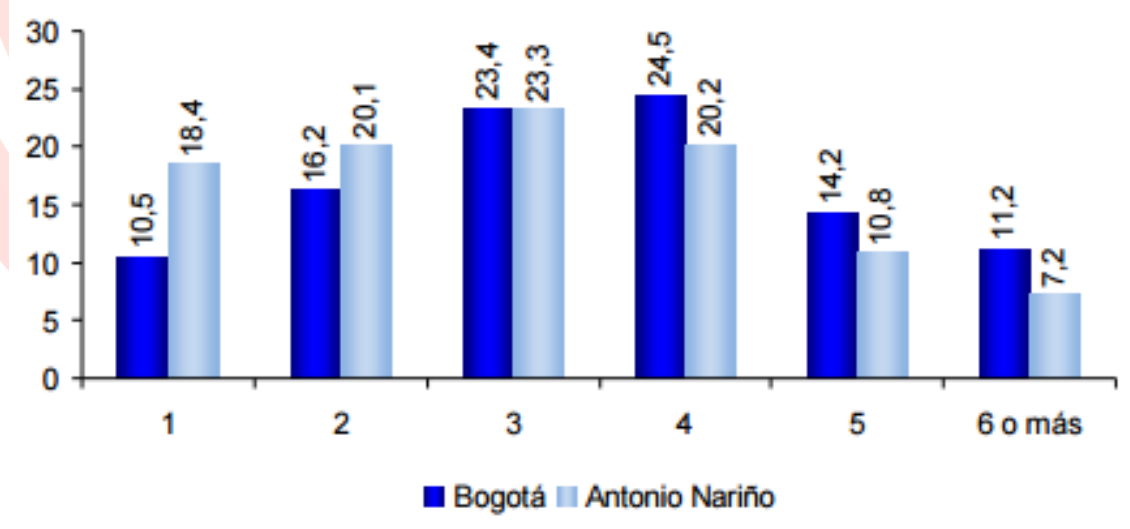

Figura 7 (SDP, 2011), mostrando los hogares encuestados por la secretaria distrital de planeación dentro de la localidad.

Antonio Nariño ocupa el sexto lugar entre todas las localidades con mayor participación de hogares tipo unipersonal que encuesto la secretaria distrital de planeación “(...) con el 18,4\%. En 
valores absolutos, de los 513.438 hogares nucleares encuestados en Bogotá, 1.128 pertenecen a la localidad de Antonio Nariño" (SDP, 2011).

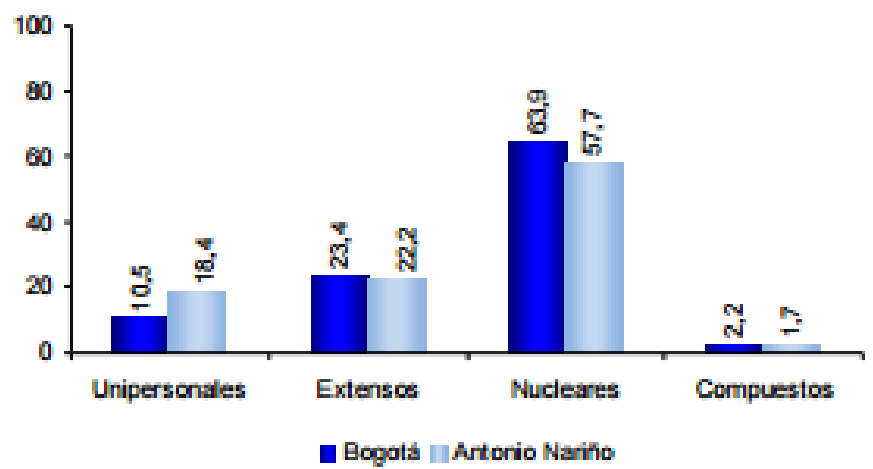

Figura 8 (SDP, 2011), mostrando los hogares unipersonales dentro de la localidad.

La estructura empresarial de la localidad Antonio Nariño se concentró en el sector de los servicios (74\%) y la industria (23\%). La mayor participación de los servicios se explica por el comercio (45\% de las empresas) que es el eje de la economía local y en menor medida por los hoteles y restaurantes (9\%), los servicios inmobiliarios y de alquiler (7\%), transporte, almacenamiento y comunicaciones (5\%), y otros servicios comunitarios (5\%). (campo, 2011)

\begin{tabular}{|l|r|r|r|r|r|}
\hline \multicolumn{1}{|c|}{ Sector } & Microempresa & Pequefia & Medliana & Grande & Total \\
\hline No informa & 17 & - & - & - & 17 \\
Agricultura & 14 & 2 & - & - & 16 \\
Pesca & 1 & - & - & - & 1 \\
Explotación de minas y canteras & 7 & 2 & 1 & - & 10 \\
Industrias manufactureras & 1.008 & 124 & 10 & 1 & 1.143 \\
Suministro de electricidad, gas y agua & 5 & - & - & - & 5 \\
Construción & 72 & 8 & - & - & 80 \\
Comercio y reparación de vehículos automotores & 2.046 & 138 & 7 & 1 & 2.192 \\
Hoteles y restaurantes & 415 & 6 & 1 & - & 422 \\
Transporte,almacenamiento y comunicaciones & 230 & 11 & 1 & 1 & 243 \\
Intermediación financiera & 58 & 8 & 7 & 2 & 75 \\
Actividades inmobiliarias, empresariales y de alquiler & 315 & 23 & 4 & - & 342 \\
Administración pública y defensa & 1 & - & - & - & 1 \\
Educación & 33 & 5 & - & - & 38 \\
Servicios sociales y de salud & 77 & 1 & 1 & - & 79 \\
Otras actividades de servicios comunitarios, sociales & 228 & 4 & - & 1 & 233 \\
Hogares con servicio doméstico & - & - & - & - & \\
Organizaciones y organos extraterritoriales & - & - & - & - & - \\
Total & $\mathbf{4 . 5 2 7}$ & $\mathbf{3 3 2}$ & $\mathbf{3 2}$ & $\mathbf{6}$ & $\mathbf{4 . 8 9 7}$ \\
\hline
\end{tabular}

Figura 9 (campo, 2011), mostrando los sectores y tamaños de estos. 
La actividad de Hoteles y Restaurantes cuenta con el 9\%de las empresas existentes en la localidad. En el 2004, el sector obtuvo el 2,2\% de los activos, mostró ventas que alcanzaron el 2\% de las registradas en ese año y ocupó al 4\%del personal reportado por las firmas. (campo, 2011)

Las empresas de la localidad que se dedican a la actividad de restaurantes y hotelería tienen mayor fuerza en la distribución y en la venta de alimentos elaborados dentro del mismo sitio de venta para un total de 289 empresas de las cuales 288 son microempresas y 1 es una pequeña empresa.

\begin{tabular}{|c|c|c|c|c|c|}
\hline Sulbector & Miresennesa & Penerial & Mediana & Grando & Total \\
\hline $\begin{array}{l}\text { Alojamientos en hoteles, campamentos y otros tipos de } \\
\text { hospedaje no permanente }\end{array}$ & 23 & 5 & 1 & 0 & 29 \\
\hline Expendio de alimentos preparados en el sitio de venta & 288 & 1 & 0 & 0 & 289 \\
\hline Expendio de bebidas alcohólicas para el consumo dentro & & & & & \\
\hline del establecimiento & 104 & 0 & 0 & 0 & 104 \\
\hline Total & 415 & 6 & 1 & $\mathbf{0}$ & 422 \\
\hline
\end{tabular}

Figura 10 (campo, 2011), mostrando el número de empresas y tamaño del sector en el que nos centramos.

\section{Sector Económico}

El sector económico de las comidas rápidas tienen una viabilidad alta ya que desde sus inicios ha sido de gran éxito, así como lo menciona la revista Dinero en el artículo Comidas rápidas: Una industria con gran apetito refiriéndose al significado de lo que son realmente las comidas rápidas y sus inicios:

Desde 1912, cuando se inició en Estados Unidos la práctica de despachar alimentos de fácil cocción por una ventanilla a los trabajadores de las fábricas, que solo tenían algunos minutos para almorzar, 
esta industria ha buscado los mejores argumentos para mantenerse en pie, y a un ritmo de importante de crecimiento. (Dinero, 2016)

El sector gastronómico muestra una dinámica positiva y particularmente los restaurantes de comidas rápidas se encuentran actualmente en un sector bastante competitivo, por lo que se hace necesario que las marcas generen un valor agregado y diferenciador como:

expandir sus menús con la introducción de alguna receta que se ajuste a las tendencias, de sorprender a los clientes con locales más modernos, con una atención más eficiente y hasta con un sistema de pedidos y de publicidad que incluye los nuevos canales o medios de comunicación, como las redes sociales. (Dinero, 2016)

Lo anterior obtener reconocimiento y satisfacer las necesidades que los nuevos clientes están pidiendo actualmente.

El sector económico en el que se centra la idea de negocio es el de comidas rápidas, es un negocio que se ve en constante crecimiento, según la revista dinero menciona que "El negocio de comidas por fuera del hogar crece a más de $15 \%$ anual y ya vende $\$ 30$ billones. Los grandes conglomerados se están moviendo para dominar uno de los mercados más sólidos de la economía colombiana” (Dinero, 2015). Viéndose aquí un gran potencial para este sector, además, “De acuerdo con la firma Raddar, el mercado de las comidas fuera del hogar representó en el país $\$ 30,7$ billones durante el año pasado. Esto equivale a un consumo per cápita anual de $\$ 646.000$; con un robusto crecimiento de 15\%" (Dinero, 2015).

En la página web del periódico portafolio, en los aportes del director de Col franquicias, Luis Fernando Jaramillo, indico que: 
Cada día están apareciendo nuevos y diferentes conceptos para atraer al consumidor y que están haciéndolo con los mejores estándares como respuesta a un cambio de actitud en el consumidor, el cual está dispuesto a conocer, explorar y comprar estos alimentos. Asimismo, hay interés en recibir una mejor calidad y servicio. Existe mucho negocio informal que no llena las expectativas del cliente, y ello hace exitoso el caso de estas nuevas marcas que aterrizan. (Iglesias, 2014)

Según el DANE, “Entre enero y septiembre de 2016 la rama aumentó en 1,4\% respecto al mismo periodo de 2015, explicado por los servicios de reparación de automotores que crecieron en $5,4 \%$; comercio en $1,2 \%$; y servicios de hoteles, restaurantes y bares en 0,3\%" (DANE, 2016).

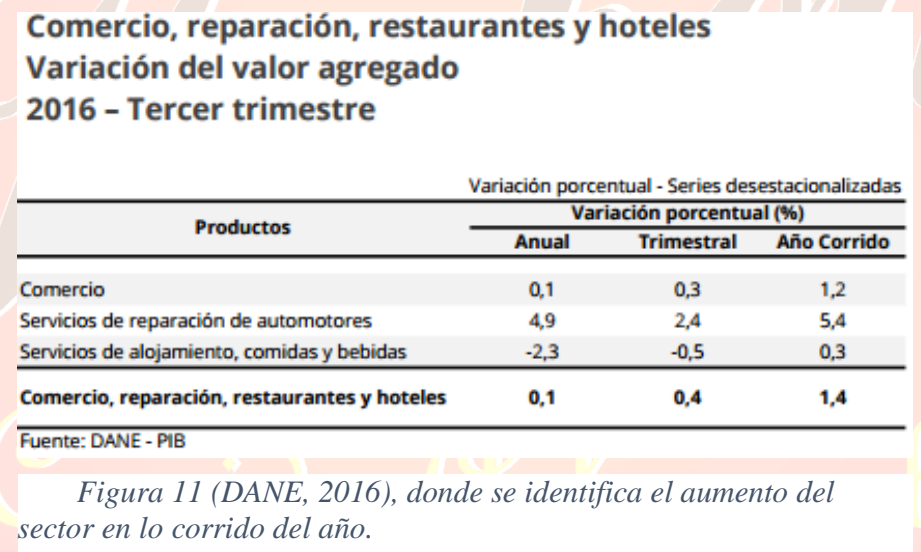

La Asociación Colombiana de la Industria Gastronómica ACODRES, es una Federación la cual propende por los intereses locales de sus afiliados y por el desarrollo sostenible de su región. A nivel nacional cuenta con una presidencia ejecutiva nacional encargada de ejecutar las políticas trazadas por la Asamblea General de Delegados y por la Junta Directiva Nacional, en beneficio de la totalidad de afiliados del país. Para el logro de estos propósitos, la Asociación cuenta con un equipo humano comprometido con los valores del trabajo en equipo y el logro de los resultados. (ACODRES, 
De acuerdo con la Asociación Colombiana de la Industria Gastronómica (Acodres), en el sector hubo un crecimiento superior a $22 \%$ en todo el país, pero en regiones como el Caribe en las que se registró un incremento mayor a 40\% para el 2015. Adicional la página web de La Republica encuentra que el sector gastronómico ha tenido un crecimiento significativo en Colombia durante los últimos años “cerca de 90.000 restaurantes registrados en 2014 ventas por \$30,7 billones” (Ortegón, 2015).

La población joven cada vez ve más viable una cadena de comidas rápidas como una empresa sin embargo mantener, diseñar y realizar una idea de negocio con rentabilidad y factibilidad no es tan fácil como parece. Para ayuda de este estudio se investigó en finanzas personales así pues es una guía sobre cómo empezar un negocio propio.

Para un negocio de cadena de comidas rápidas se debe contar con elementos los cuales son: Equipo básico explicado en el gráfico con el numero 4 (horno, estufa, nevera, congelador, microondas, utensilios de cocina, vajilla, vasos y caja de seguridad), un mobiliario explicado en el gráfico con el numero 3 (sillas y mesas), que alcanza los $\$ 3.8$ millones. El sitio debe contar, además, con capacidad para reproducir música y distribuir pedidos en caso que se vayan a realizar domicilios. (Finanzas personales , 2017) 


\begin{tabular}{|r|l|l|r|}
\hline No. & \multicolumn{1}{|c|}{ Inversión inicial } & \multicolumn{1}{c|}{ Detalle } & \multicolumn{1}{c|}{$\begin{array}{c}\text { Monto } \\
\text { (Mínimo) }\end{array}$} \\
\hline 1 & Publicidad y promoción & Volante, logo, menú y avisos & 1.000 .000 \\
\hline 2 & Adecuación & Pintura, decoración y adecuación normas sanitarios & 700.000 \\
\hline 3 & Mobiliario & Mesas y sillas & 800.000 \\
\hline 4 & Equipo & $\begin{array}{l}\text { Horno y estufa, nevera, congelador, horno micro } \\
\text { ondas, utensilios de cocina, vajilla, vasos }\end{array}$ & 3.000 .000 \\
\hline 5 & Sonido & Equipo, parlantes e instalación & 250.000 \\
\hline 6 & Capacidad distribución & Bicicleta & 180.000 \\
\hline & \multicolumn{1}{|c|}{ Total } & 5.930 .000 \\
\hline
\end{tabular}

Figura 12 (Finanzas personales, 2017), detallando los costos básicos para un local de comidas.

La Confederación Colombiana de Cámaras de Comercio (Confecamaras) facilita por medio de internet en su portal www.crearempresa.com.co, por el cual se lograrán realizar todos los trámites para poder constituir su empresa online. 


\begin{tabular}{|c|c|c|}
\hline No: & Pasos & Detalle \\
\hline 1 & Definir el tipo de persona que va a constituir & $\begin{array}{l}\text { Conocer las características y responsabilidades que implica } \\
\text { cada uno de los tipos de empresa, dependiendo si se trata de } \\
\text { una persona natural o juridica. }\end{array}$ \\
\hline 2 & $\begin{array}{l}\text { Consultar si el nombre que va a utilizar para } \\
\text { su empresa ha sido registrado }\end{array}$ & $\begin{array}{l}\text { Revisar el nombre para su nueva empresa se hace a nivel } \\
\text { nacional, gracias al Registro Único Empresarial (RUE). }\end{array}$ \\
\hline 3 & $\begin{array}{l}\text { Consultar si la marca está disponible en la } \\
\text { Superintendencia de Industria y Comercio }\end{array}$ & $\begin{array}{l}\text { 1. Identificar los productos o servicios que desea proteger con } \\
\text { la marca, de acuerdo con la clasificación NIZA: } 2 \text {. Verificar que } \\
\text { la Superintendencia de Industria y Comercio no se encuentra } \\
\text { registrada o en trámite una marca parecida o similar mediante } \\
\text { la consulta de antecedentes marcarios o figurativos; } 3 \text {. Tener en } \\
\text { cuenta para la verificación de la marca la configuración NIZA; } 4 \text {. } \\
\text { Una vez este seguro diligencie el formulario (petitorio) que } \\
\text { existe para ello. }\end{array}$ \\
\hline 4 & $\begin{array}{l}\text { Consultar la actividad económica que se va } \\
\text { a realizar }\end{array}$ & $\begin{array}{l}\text { H552100 Expendio a la mesa de comidas preparadas, en } \\
\text { restaurantes. }\end{array}$ \\
\hline 5 & Consultar el uso del suelo & $\begin{array}{l}\text { Verificar en la Secretaría de Planeación de cada ciudad si la } \\
\text { actividad que se va a iniciar puede desarrollarse en el lugar } \\
\text { previsto para su funcionamiento. }\end{array}$ \\
\hline 6 & $\begin{array}{l}\text { Realizar inscripción en el Registro Único } \\
\text { Tributario (RUT) }\end{array}$ & En la página Web de la DIAN. \\
\hline 7 & Elaborar documento de constitución & $\begin{array}{l}\text { Escritura pública de constitución de empresa (sólo para persona } \\
\text { jurídica) o documento privado (art. } 22 \text { Ley } 1014 \text { de 2006). }\end{array}$ \\
\hline 8 & $\begin{array}{l}\text { Diligenciar formulario de Registro Único } \\
\text { Empresarial }\end{array}$ & Disponible en la cámara de comercio de su ciudad. \\
\hline 9 & Presentar la solicitud de matricula mercantil & $\begin{array}{l}\text { En la cámara de comercio con jurisdicción en el lugar donde van } \\
\text { a tener su domicilio. }\end{array}$ \\
\hline 10 & $\begin{array}{l}\text { Pagar derechos de Autor y Conexos } \\
\text { en Sayco y Acinpro }\end{array}$ & $\begin{array}{l}\text { Los propietarios de establecimientos que en forma permanente } \\
\text { u ocasional comuniquen la música para sus clientes, en forma } \\
\text { directa o indirecta, deben pagar derechos de autor. Este pago } \\
\text { se realiza anualmente }\end{array}$ \\
\hline 11 & $\begin{array}{l}\text { Solicitar concepto técnico del cuerpo oficial } \\
\text { de bomberos }\end{array}$ & $\begin{array}{l}\text { Si al momento de su solicitud la evaluación de bomberos } \\
\text { determina que el establecimiento es de bajo riesgo, se hace } \\
\text { una capacitación de las normas en seguridad industrial y se } \\
\text { entrega un formulario de "auto-revisión". Si la clasificación es } \\
\text { de moderado o alto riesgo se le asigna una visita de campo al } \\
\text { negocio para obtener el concepto respectivo. }\end{array}$ \\
\hline 12 & Solicitar concepto sanitario & $\begin{array}{l}\text { El concepto sanitario es gratuito y tiene vigencia anual. El } \\
\text { concepto de la visita según las condiciones de su } \\
\text { establecimiento será favorable, pendiente o desfavorable. }\end{array}$ \\
\hline 13 & Hacer curso de manipulación de alimentos & Revisar regulación de cada ciudad. \\
\hline
\end{tabular}

Figura 13 (Finanzas personales, 2017) listando los requisitos para formalizar una pyme.

Por último, para la financiación del proyecto se encuentra el Fondo Emprender del SENA, los ciudadanos que sean aprendices, universitarios o profesionales que no haya pasado más dos años de haberse graduado se puede solicitar el prestamos presentando el plan de negocios y los lineamiento para el estudio de viabilidad del negocio. 


\section{Aceptación del producto}

Se realizó un trabajo de observación a los 4 competidores directos que están en la zona con mayor participación del mercado con el objetivo de definir la rotación de clientes y un promedio de los productos vendidos por cada uno de los competidores durante la semana. La observación se realizó en el mes de junio del día 5 al 11 cubriendo los restaurantes de las 6:00pm a 11:00pm identificando lo siguiente:

\begin{tabular}{|l|r|r|r|r|r|r|r|}
\hline \multicolumn{7}{|c|}{ UNIDADES DE PRODUCTOS VENDIDOS EN UNA SEMANA } & \\
\hline Competidores & Hamburguesas & Perros & Carnes & Salchipapa & $\begin{array}{c}\text { Arepa } \\
\text { s }\end{array}$ & $\begin{array}{c}\text { Total de } \\
\text { Unid. }\end{array}$ & $\begin{array}{c}\text { Total del } \\
\text { mes }\end{array}$ \\
\hline KEBAB & 52 & 21 & 12 & 32 & 135 & 252 & 1008 \\
\hline $\begin{array}{l}\text { HOMERO COMIDAS } \\
\text { RAPIDAS }\end{array}$ & 109 & 62 & 59 & 63 & 0 & 293 & $\mathbf{1 1 7 2}$ \\
\hline HAMBURGUESAS CALI & 184 & 36 & 24 & 43 & 44 & 331 & $\mathbf{1 3 2 4}$ \\
\hline BULLDOG'S GOURMET & 228 & 23 & 15 & 38 & 0 & 304 & $\mathbf{1 2 1 6}$ \\
\hline \hline
\end{tabular}

\begin{tabular}{|l|r|r|r|r|r|}
\hline $\begin{array}{c}\text { Promedio de servicios por día de la } \\
\text { semana }\end{array}$ & KEBAB & $\begin{array}{c}\text { HOMERO } \\
\text { COMIDAS } \\
\text { RAPIDAS }\end{array}$ & $\begin{array}{c}\text { HAMBURGUESAS } \\
\text { CALI }\end{array}$ & $\begin{array}{c}\text { BULLDOG'S } \\
\text { GOURMET }\end{array}$ & $\begin{array}{c}\text { Promedio } \\
\text { de } \\
\text { servicios }\end{array}$ \\
\hline Lunes - Jueves (sevicios) & 8 & 12 & 9 & 10 & $\mathbf{9 , 7 5}$ \\
\hline Viernes - Domingo (servicios) & 14 & 21 & 15 & 18 & $\mathbf{1 7}$ \\
\hline \hline
\end{tabular}




\section{Asignación de precios}

La asignación de precios se realiza mediante la observación anteriormente mencionada además se hizo un análisis de precios y productos de iguales características que ofrece la competencia, de tal forma se llega a la conclusión que para ser competitivos ya que somos un negocio nuevo nos vamos a ajustar a los precios del mercado, de tal forma que al contrastarlos con los costos da como resultad o que el margen de contribución es de $60 \%$ para la hamburguesa, mazorcada y hamburguesa de helado y con una utilidad del $61 \%$ para el salchipapa y salchiyuca.

\begin{tabular}{|l|r|r|r|}
\hline \multicolumn{2}{c}{ PRECIO } & \multicolumn{1}{c|}{$\begin{array}{c}\text { Impuesto al } \\
\text { consumo }\end{array}$} & Precio total \\
\hline Hamburguesa & 7.248 & 580 & 7.800 \\
\hline Salchipapa & 6.914 & 553 & 7.500 \\
\hline Salchiyuca & 7.397 & 592 & 8.000 \\
\hline Mazorcada & 12.023 & 962 & 13.000 \\
\hline Hamburguesa de helado & 3.487 & 279 & 3.800 \\
\hline
\end{tabular}

figura 15 Tabla de precios de kushen (elaboración propia)

\section{PLAN DE MERCADEO}

El plan de mercadeo se sujeta a la metodología que ofrece Philip Kotler en el libro Marketing versión para Latinoamérica del año 2007 en la sección de apéndice 1 páginas A3-A6 donde el indica que los pasos básicos para hacer un plan de mercadeo de un negocio radica en los 
siguientes apartados: Resumen ejecutivo, Situación de Marketing actual, Descripción del mercado, Revisión del producto, Revisión de Competencia, Revisión de distribución, DOFA y Estrategia de marketing.

\section{Resumen ejecutivo:}

Kushen House es una empresa la cual está preparada para hacer lanzamiento de su primer establecimiento de comidas rápidas artesanales en el sector de Luna Park y San Antonio comprendido entre las carreras 14 a 19 y calles 4 a 12, de modo que puede competir con establecimientos de comidas rápidas que llevan más de 10 años en dicho sector como líderes (Kebab parrilla, Homero comidas rápidas). La empresa se dirige a este sector y segmento sabiendo que cuenta con la capacidad de ofrecer productos innovadores, frescos, artesanales, de buena calidad, confort y un buen servicio, características que se sabe, no son cualidades de la competencia.

Los principales objetivos de mercadeo es lograr participación en el mercado local de 3\% durante el primer semestre y lograr fidelización de los clientes posicionados como los numero uno en comidas rápidas de dicho sector. Los objetivos financieros, lograr punto de equilibrio al cumplir 18 meses de funcionamiento, ventas mensuales de entre 10 y 12 millones de pesos.

\section{Situación de Marketing actual:}

Es una empresa que tiene como lanzamiento proyectado agosto del año 2017, es una empresa que iniciará con recursos limitados, préstamos bancarios y ahorros familiares, lo cual hace que la 
situación de marketing sea lenta y deba tener un proceso de crecimiento a medida del retorno de la inversión.

\section{Descripción del mercado:}

El mercado de Kushen House está compuesto por personas habitantes del sector ya delimitado, estudiantes universitarios, trabajadores y familias, estas personas en su gran mayoría están entre 25 y 40 años de edad, las necesidades de este grupo de personas son alimentarse bien, rápido, en un buen espacio, ser bien atendidos y con productos innovadores.

Tabla 2

Mercado Objetivo

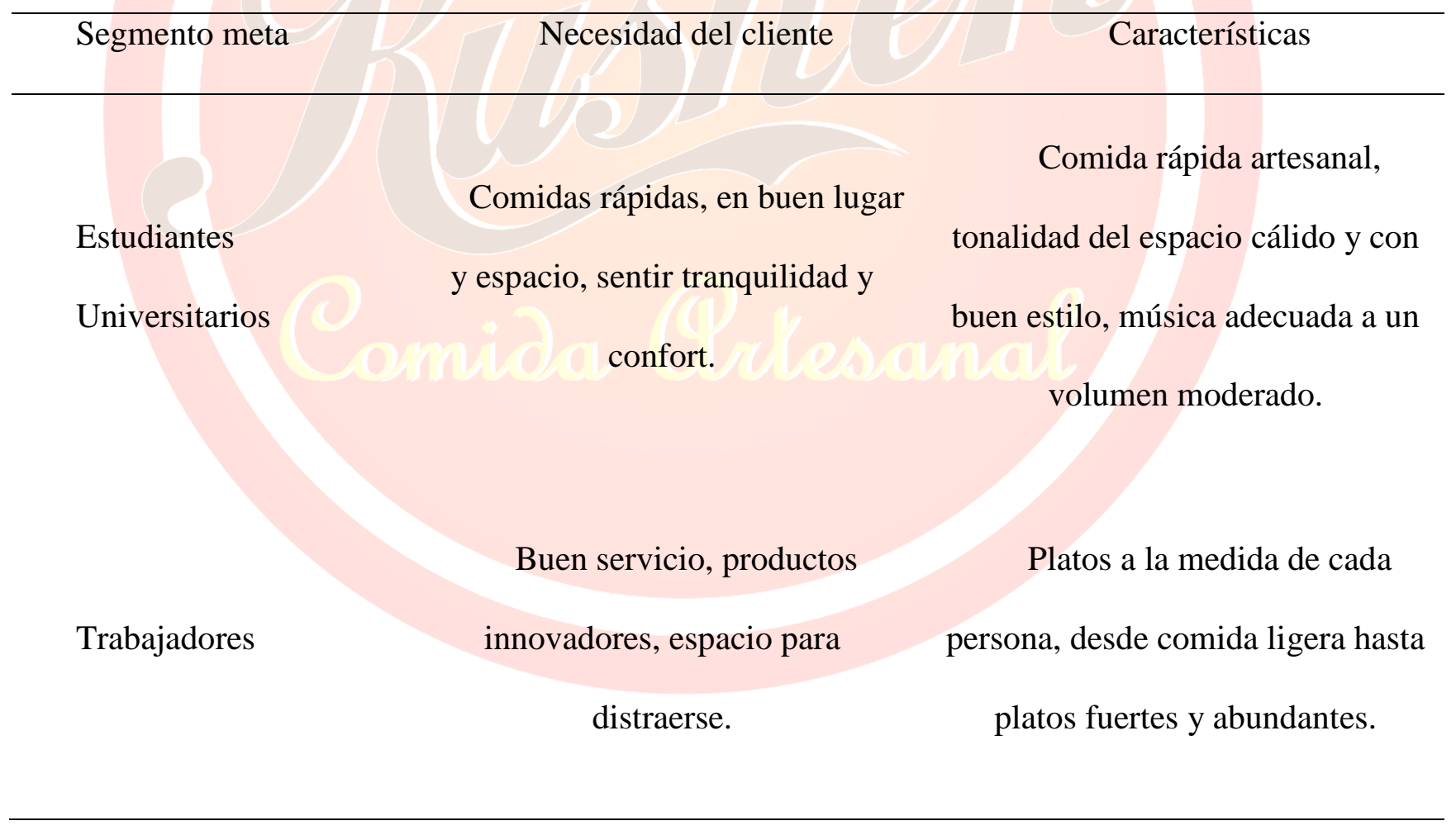


Espacio para compartir en

Familias familia, no cocinar en casa,

distracción.
Espacio cerca a su hogar, económico, hogareño, con un buen

estilo.

Datos obtenidos por investigación personal (elaboración propia)

\section{Revisión del producto:}

El producto estrella de kushen house es la hamburguesa, el cual presenta las siguientes características:

- Carne $100 \%$ de res combinada con especias que dan un toque inigualable en su sabor.

- La carne es de muy buen sabor y a la hora de asar suelta todos sus jugos generando una combinación de sabores al paladar.

- La cebolla grille es poco utilizada en la zona y esta salteada con sal dando un sabor especial a la hamburguesa acompañado del tomate y la lechuga.

\section{Revisión de Competencia:}

Dentro del sector encontramos a la competencia con sus respectivos productos estrella, algunos con más de 10 años de antigüedad en la zona, los cuales ya están bien establecidos y tienen sus clientes fidelizados con algunos de los competidores son:

Tabla 3

Competidores Directos 


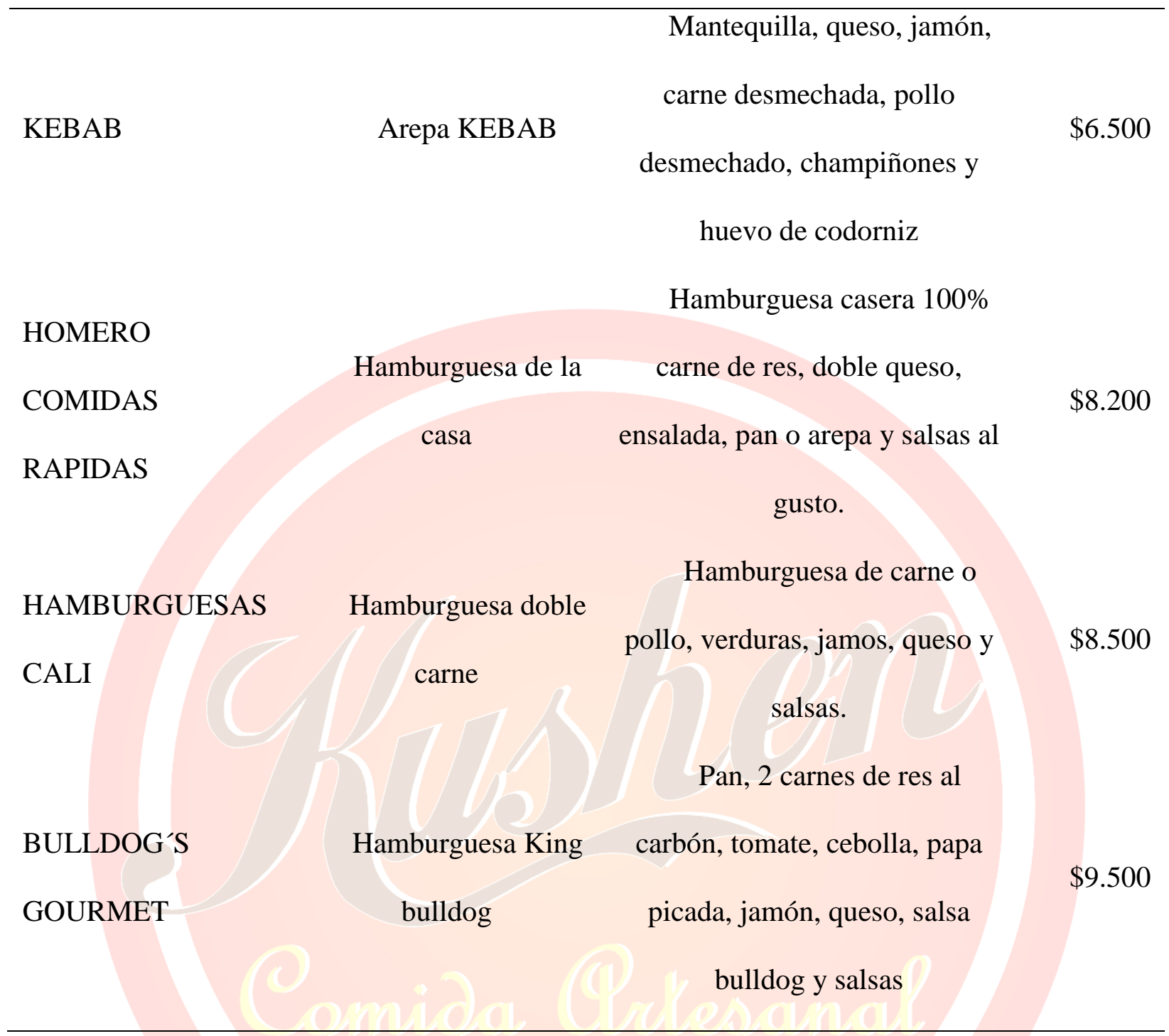

Datos obtenidos por investigación personal (elaboración propia)

\section{Revisión de distribución:}

La distribución de los productos inicialmente se realiza por medio del punto de venta evolucionando a mensajeros motorizados para servicio domiciliario puerta a puerta.

\section{DOFA:}

Tabla 4

DOFA 
- Alta calidad del producto.

- Carne $100 \%$ de res.

- Precio del producto.
- Poco reconocimiento del

producto.

- Inflación de los ingredientes.
Oportunidades:

- Impactar en el mercado por el

sabor de la hamburguesa.

- Fidelización de clientes

\section{Amenazas:}

- Competencia de la zona.

- Productos sustitutos.

- Imitación de la hamburguesa.

Datos obtenidos por investigación personal (elaboración propia)

\section{Estrategia de marketing:}

La estrategia de marketing está dividida en dos partes:

La primera va a ser material $\mathrm{POP}^{9}$ (punto de compra) Se pretende llegar al grupo objetivo por medio de volanteo, informando sobre la variedad de productos que se ofrecerán, invitándolos a que visiten el punto de venta y puedan probar los alimentos elaborados artesanalmente, además se realizaran brigadas por la zona que se quiere impactar brindando la información sobre productos y sus precios, entregando el imán para los domicilios y una carta de precios en forma de volantes, por otro lado se adecuar el restaurante con fotografías de los platos de comidas que se ofrecerán para que los peatones sepan que alimentos podrán encontrar dentro del restaurante y los diferentes ingredientes naturales que se utilizaran para cada plato.

${ }^{9}$ POP: por sus siglas en ingles Point of Purchase, es una categoría del Marketing que recurre a la publicidad puesta en los puntos de venta, busca generar una permanencia de la marca recurriendo a una gran variedad de objetos donde se puede imprimir o estampar información del producto.” (Red Gráfica Latinoamérica, s.f.) 
La segunda parte del plan de mercadeo es con materiales de BTL $^{10}$ que consta de es un Rompe tráfico "es un estilo de publicidad habitualmente utilizada en los pasillos de supermercados y tiendas. Su diseño es un arte que resalta en la góndola para dar a conocer las promociones y productos" (PAGOMA S.A, s.f.). El cual consiste en un carrito de perros informando sobre los alimentos elaborados con ingredientes $100 \%$ naturales y procesados artesanalmente, que se ubicará frente a la entrada del local y por medio de la cual se buscará llamar la atención de tanto los peatones, como los que circulan en vehículos particulares y de transporte público.

${ }^{10}$ BTL: (Below The Line o "debajo de la línea") se conoce como una técnica de marketing que se caracteriza por tener un contacto más directo con las personas. El BTL se dirige a segmentos de mercado específicos mediante estrategias de comunicación no masivas en las cuales los mensajes son transmitidos de una manera diferente y poco convencional, lo cual logra sorprender y sacar de la rutina a quien los mira." (Bojórquez, 2008) 


\section{ESTUDIO DE OPERACIONES}

Proceso de compra de insumos

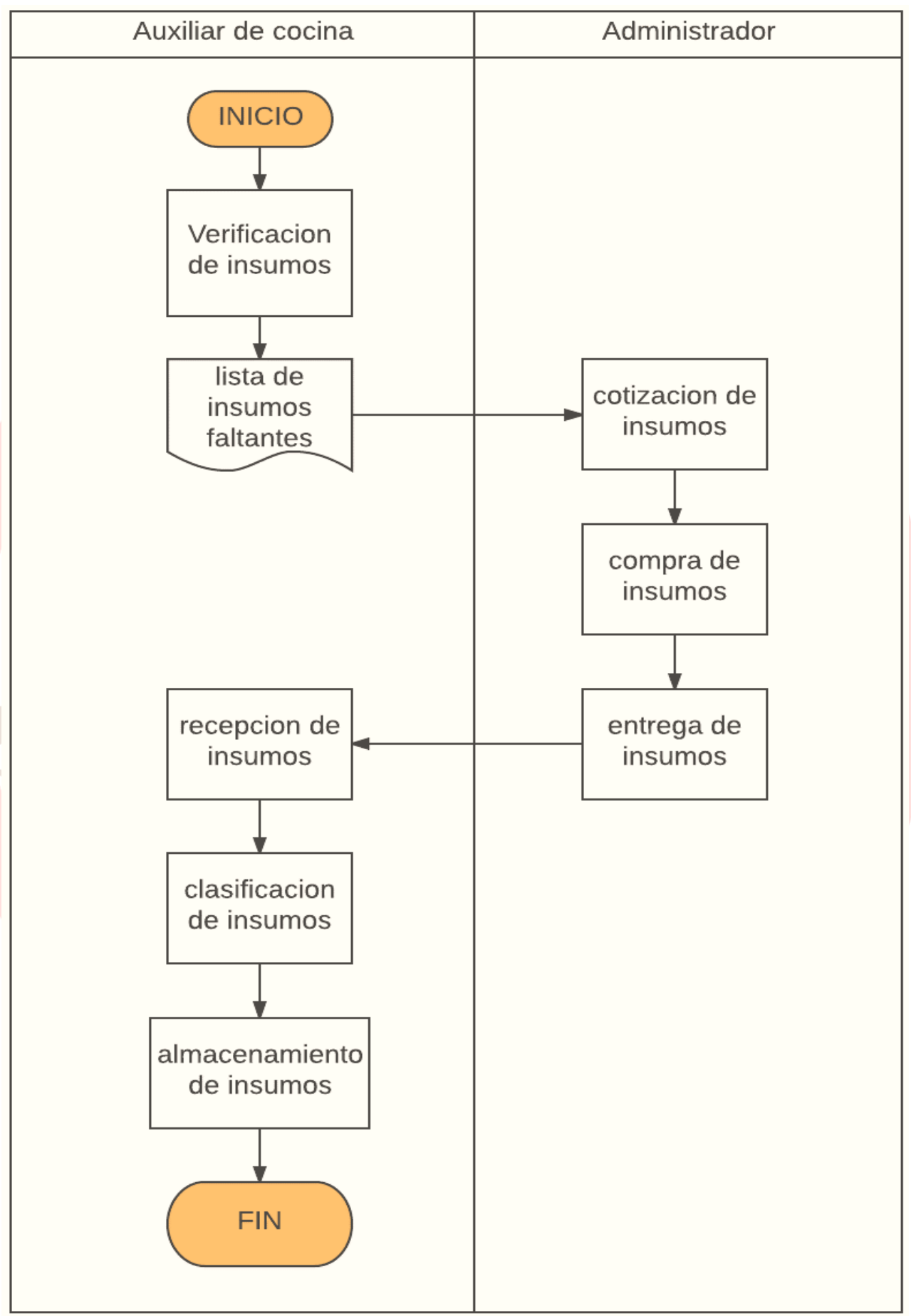

Figura 16 flujograma de proceso de la compra de los insumos (elaboración propia) 
Proceso de manejo de caja

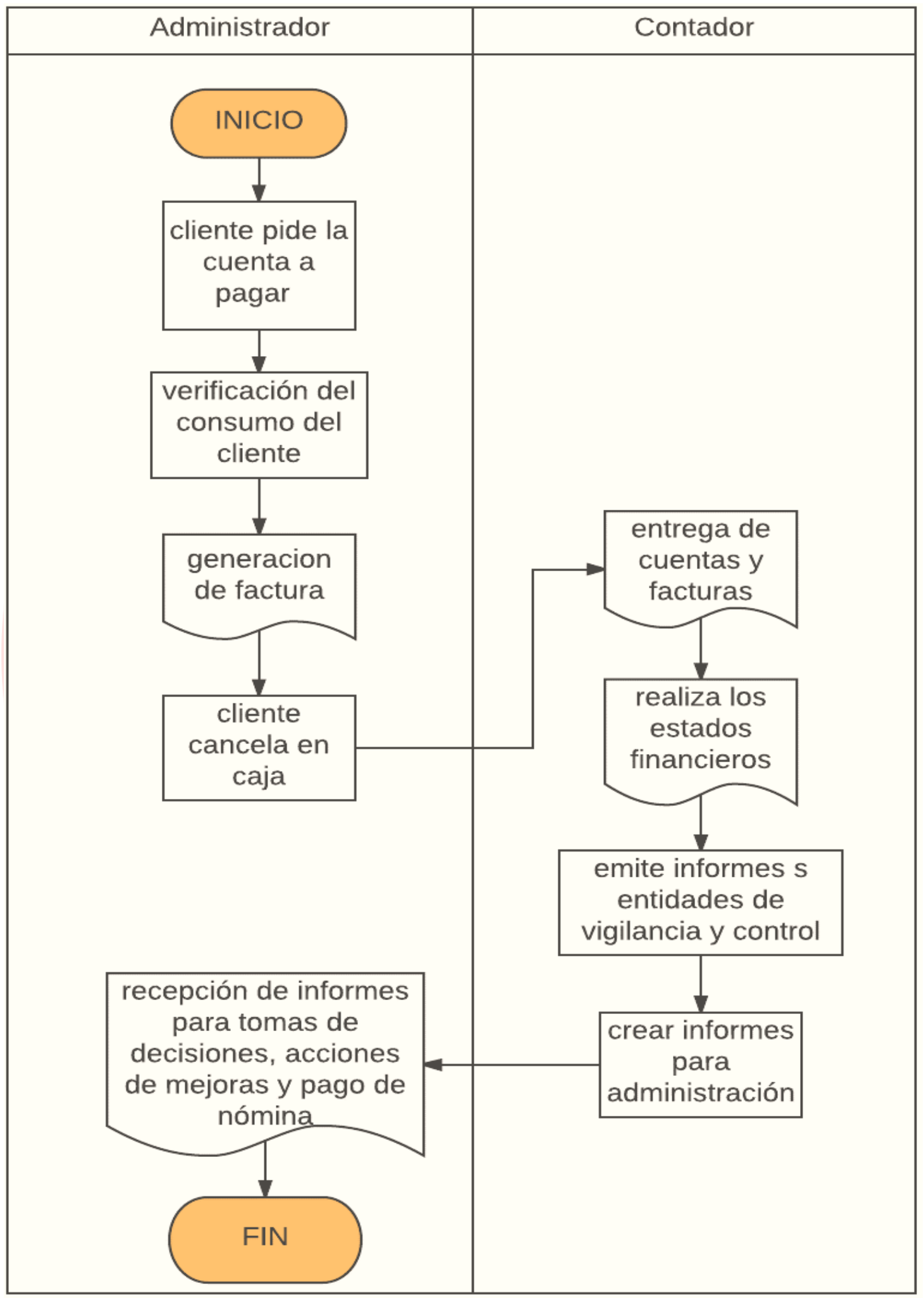

Figura 17 flujograma de proceso del manejo de caja (elaboración propia) 


\section{Proceso productivo}

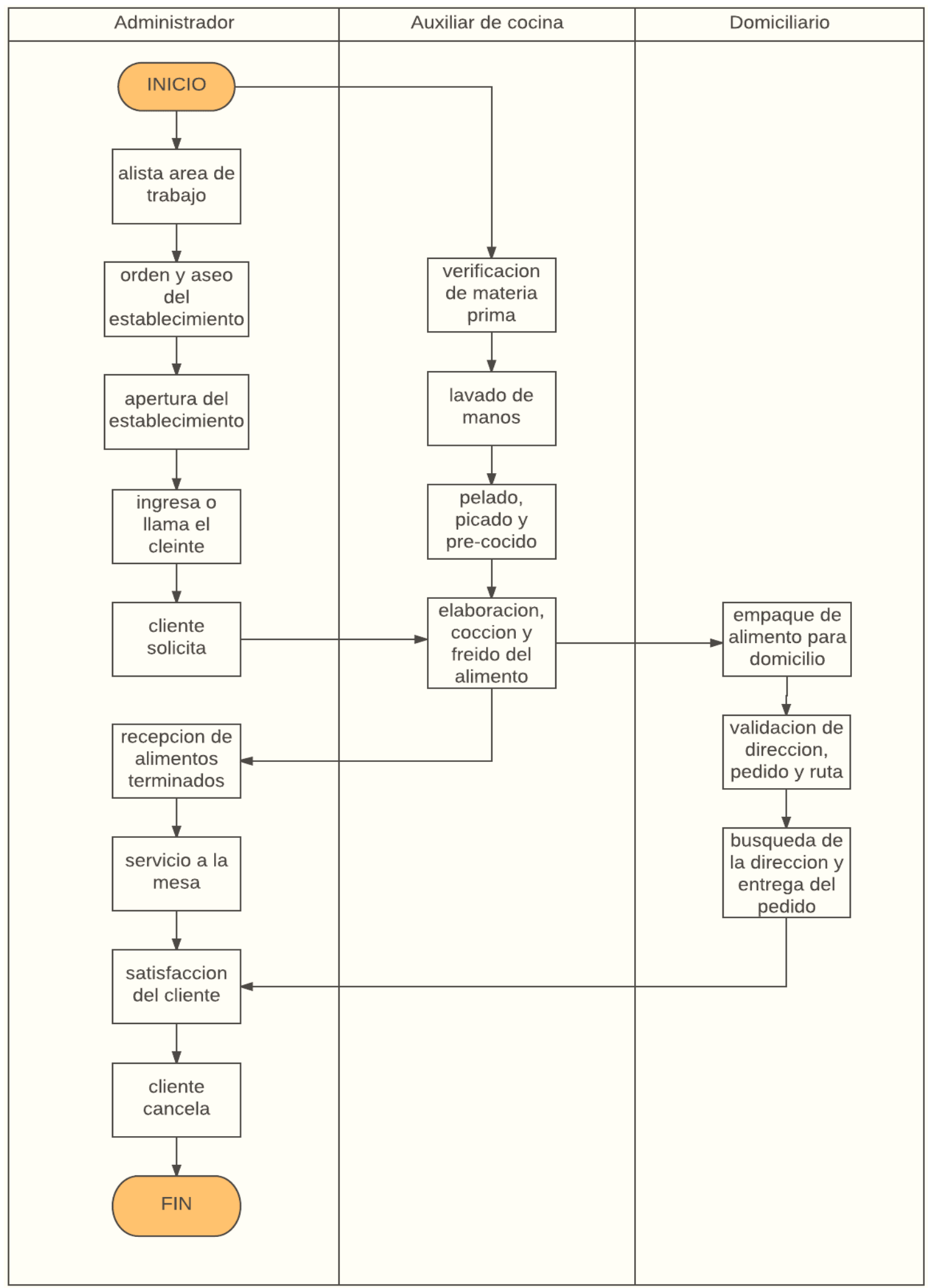

Figura 18 flujograma de proceso productivo (elaboración propia) 


\section{ESTUDIO ORGANIZACIONAL}

La estructura organizacional de KUSHEN HOUSE es Lineo-Funcional ${ }^{11}$, se observa que el organigrama está conformado por líneas verticales, se caracteriza por la autoridad y división del trabajo, se conserva la especialización de cada área en su función específica. La empresa se establecerá como régimen común, como un tipo de sociedad SAS (sociedad por acciones simplificadas) la cual estará constituida por una persona natural, realizando una actividad comercial.

La estructura organizacional se divide de la siguiente manera se tiene proyectado que durante los dos primeros años se contará con un administrador, un auxiliar de cocina y un domiciliario. Para el tercer año se tiene proyectada la apertura de una nueva sucursal por esta razón los empleados se duplicaran y al final del quinto año se lograra alcanzar una nómina de dos administradores, cuatro auxiliares de cocina y dos domiciliarios para lograr cubrir la demanda que se tendría para este año.

\footnotetext{
${ }^{11}$ Lineo-funcional: "se combinan los tipos de organización lineal y funcional, aprovechando las ventajas y evitando las desventajas inherentes a cada una, conservándose de la funcional la especialización de cada actividad en una función, y de la lineal la autoridad y responsabilidad que se transmite a través de un sólo jefe por cada función en especial." (Valencia, s.f.)
} 


\section{Organigrama}

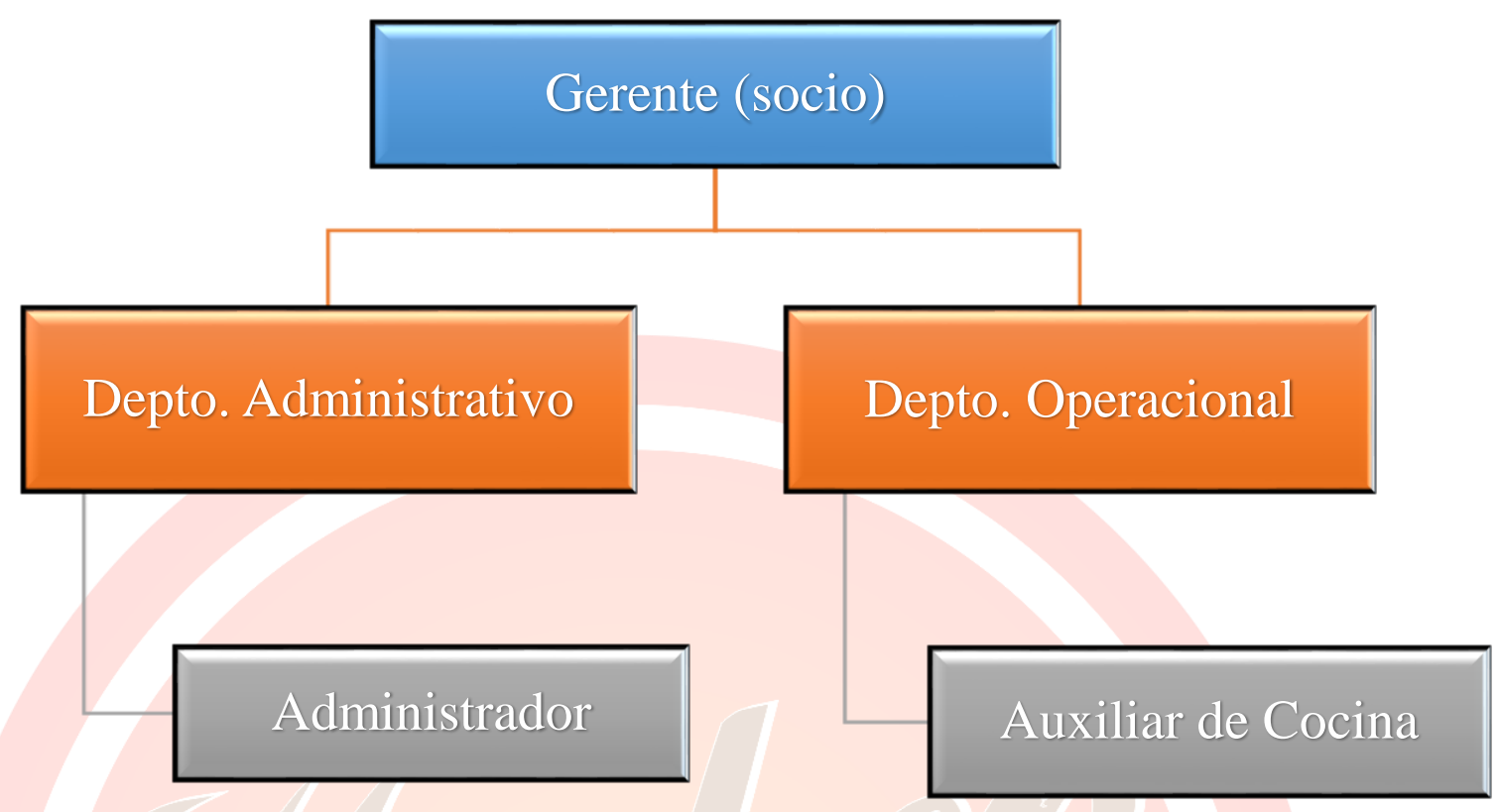

Figura 19 organigrama de Kushen (elaboración propia)

Manuales de procesos

Tabla 5

Manual de procesos Administrador

Identificación de Cargo

Nombre del cargo:

Administrador

Dependencia:

Depto. Administrativo

Número de cargos:

Dos (2)

Reporta a (nombre del cargo):

Gerente (socio)

\begin{tabular}{cc}
\hline $\mathrm{N}^{\circ}$ & Funciones \\
\hline 1 & Responsable de llevar en niveles óptimos todos los recursos del punto de venta. \\
& Organizar, planificar y realizar la compra de materia prima para la producción de los \\
& alimentos. \\
\hline
\end{tabular}


3 Encargado de la caja, atención al cliente y verificación el despacho de los pedidos.

4 Atiende solicitudes, quejas y reclamos de los clientes.

5 Ayuda a determinar mejores estrategias de promoción que se brinden dentó del restaurante y fidelización del cliente.

Datos obtenidos por investigación personal (elaboración propia)

Tabla 6

Manual de procesos Auxiliar de cocina

Identificación de Cargo

Nombre del cargo:

Auxiliares de cocina

Dependencia:

Depto. Operacional

Número de cargos:

Cuatro (4)

Reporta a (nombre del cargo):

Gerente(socio)

$\mathrm{N}^{\circ}$

Funciones

1

Verificar la rotación de materia prima al administrador para que este realice la compra y suministro de los ingredientes necesarios

2

Está al mando de la cocina con el conocimiento y habilidad para preparar los platos que se ofrecen en el restaurante.

3

Repartición a la mesa de los alimentos preparados.

4

Optimizar los procesos de producción de los alimentos para que se despachen más rápido.

Datos obtenidos por investigación personal (elaboración propia)

Tabla 7

Manual de procesos Domiciliario 
Identificación de Cargo

Nombre del cargo:

Domiciliario

Dependencia:

Depto. Operacional

Número de cargos:

$\operatorname{Dos}(2)$

Reporta a (nombre del cargo):

Auxiliares de cocina

\begin{tabular}{cc}
\hline $\mathrm{N}^{\circ}$ & Funciones \\
\hline 1 & Verificación de la orden de compra del cliente. \\
2 & Encargado de llevar hasta la puerta de la casa los alimentos pedidos por los clientes.
\end{tabular}

Datos obtenidos por investigación personal (elaboración propia)

Tabla 8

Manual de procesos Contador

Identificación de Cargo

Nombre del cargo:

Contador

Dependencia:

Depto. Administrativo

Número de cargos:

Uno (1)

Reporta a (nombre del cargo):

Gerente (socio)

\begin{tabular}{lc}
\hline $\mathrm{N}^{\circ}$ & Funciones \\
\hline 1 & Será contratado como staff, producirá y verificara la información contable \\
& mensualmente. \\
& Estará encargado del control de los gastos e ingresos, obligaciones con entidades de \\
& vigilancia y control. \\
\hline
\end{tabular}

Datos obtenidos por investigación personal (elaboración propia) 


\section{ESTUDIO FINANCIERO}

Costos: "los contadores definen al costo como un recurso sacrificado o perdido para alcanzar un objetivo específico" (Horngren, Datar, \& Foster, 2007, pág. 27). Los costos se miden por 3 elementos los cuales son: materiales, mano de obra y costos indirectos de fabricación, estos brindan la información necesaria para realizar la medición de ingresos y la fijación de los precios de cada producto

Costos fijos: "permanece sin cambios en total por un periodo dado, pese a grandes cambios en el nivel relacionado con la actividad o volumen totales" (Horngren, Datar, \& Foster, 2007, pág. 30). Son aquellos en los que incurre la empresa pero no depende de la cantidad de la producción que se realice.

Costos variables: "cambia en total en producción a los cambios en el nivel relacionado del volumen o actividad total" (Horngren, Datar, \& Foster, 2007, pág. 30). Son aquellos en los que incurre la empresa y sí depende de la cantidad de la producción que realice la empresa.

Métodos de costeo: los métodos de costeo más utilizados en contabilidad son:

Costos por órdenes de fabricación

Costos por procesos o departamentales

Costos directos o variables

Costo por absorción

Costos ABC 
Según la compañía el costeo que más aplicaría dentro de los métodos es el de Costos por órdenes de fabricación "se refieren a los materiales, la mano de obra y la carga fabril necesarios para completar una orden o lote específicos de productos terminados. En esta clase de costos se ha de fabricar una cantidad definida en una orden de fabricación específica” (HERRERA, 2011). Ya que en un restaurante se maneja por pedidos de comidas que se realicen y es más fácil realizar el costeo con este método y hallar un punto de equilibrio y determinar el precio de venta de los productos.

\section{Políticas financieras}

- Dada el tipo de empresa las ventas se realizan de contado e igualmente las compras de materiales para la elaboración de los productos se realizan de contado.

- Es una empresa de régimen común por esta razón está sujeto a declarar a la DIAN y maneja un impuesto de renta del $33 \%$ anual.

- Se tiene en cuenta el IPC (índice de precios al consumo) de alimentos para la ejecución de las proyecciones.

- La financiación se realiza de aportes familiares y préstamo bancario. 


\section{Flujo de caja}

Se observa que en términos de efectivo la compañía es líquida manteniendo los niveles de efectivo necesarios para ser eficiente y cubrir su capital de trabajo. A su vez se ve el incremento de efectivo desde el primer año, excepto el año 3 debido a que se realiza la inversión en una nueva sucursal.

\section{Flujo de Caja mensual Año 1}

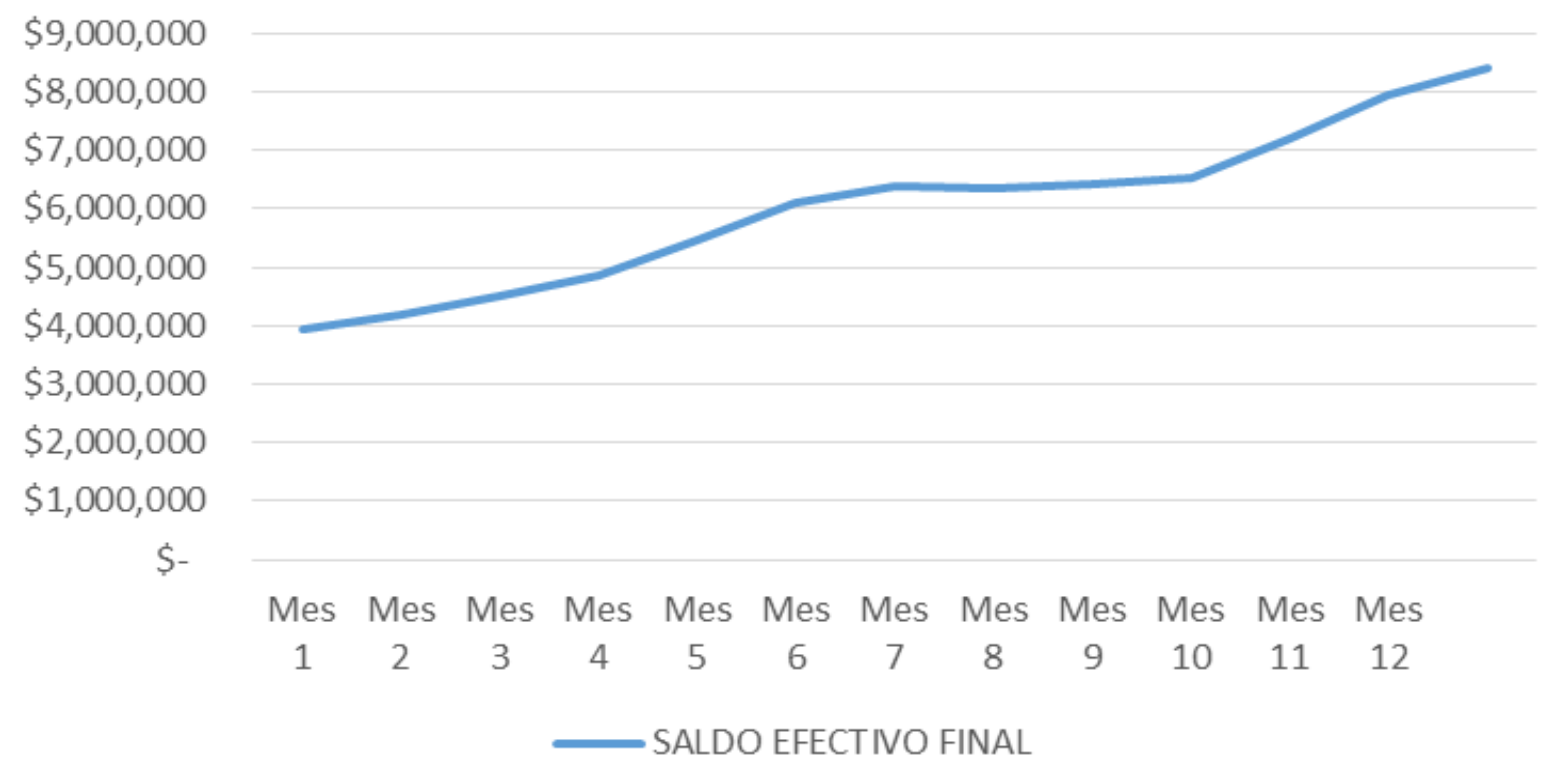

Figura 20 flujo de caja mensual del primer año (elaboración propia) 


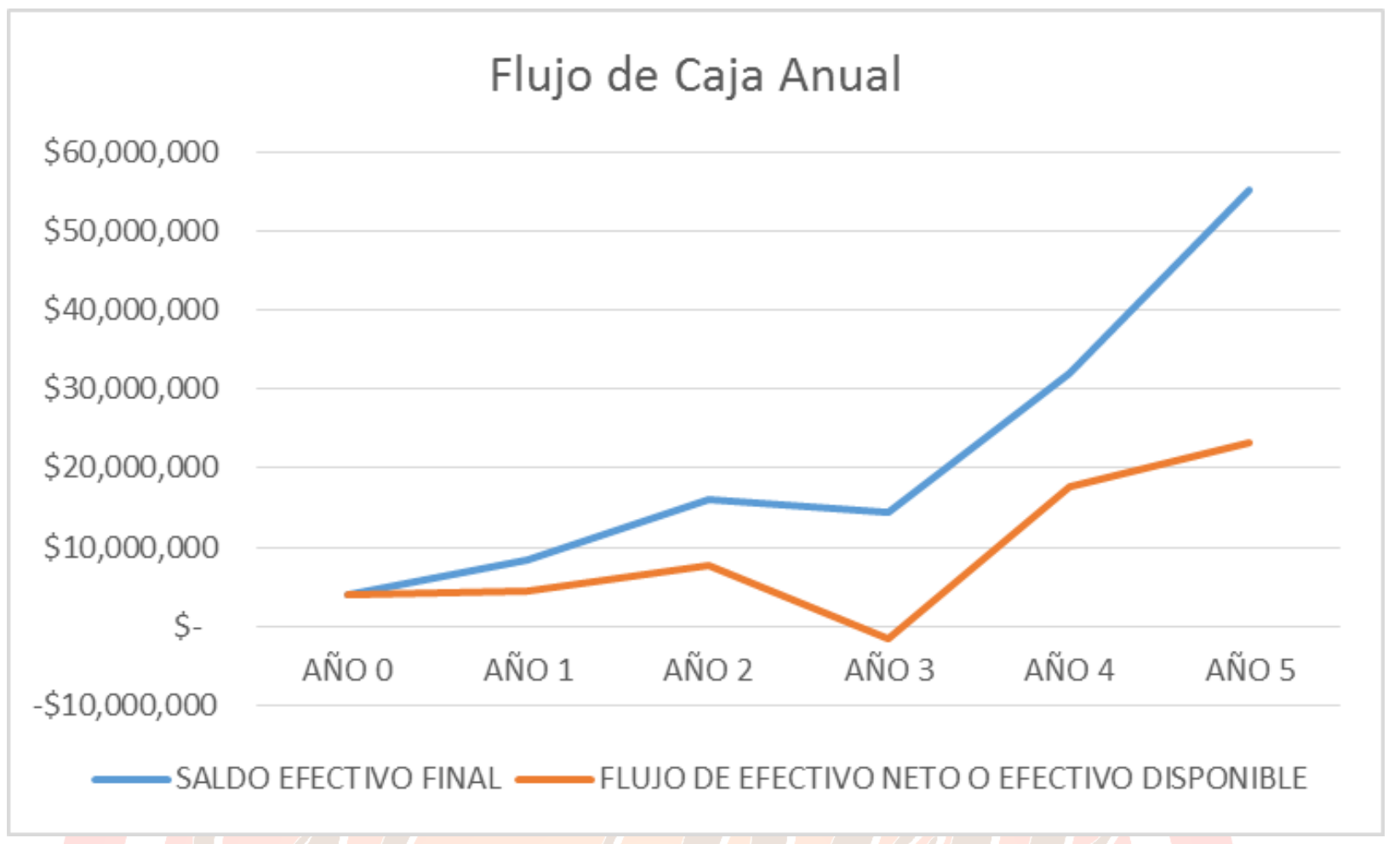

\section{Estado de Resultados mensual}

Partimos de unas ventas en el primer mes que superan en un $10 \%$ el punto de equilibrio, y cada mes se van incrementando, en algunos meses tenemos incrementos más altos debido a que vamos a hacer publicidad, por esta razón se impulsaría el volumen de ventas. De la misma forma se comporta la utilidad bruta a consecuencia de que la mayoría del costo de la venta es variable, es decir que va ligado a la cantidad de productos vendidos. Se puede observar que a partir del primer mes se obtiene utilidad neta, lo cual demuestra que es un proyecto rentable desde el principio. 


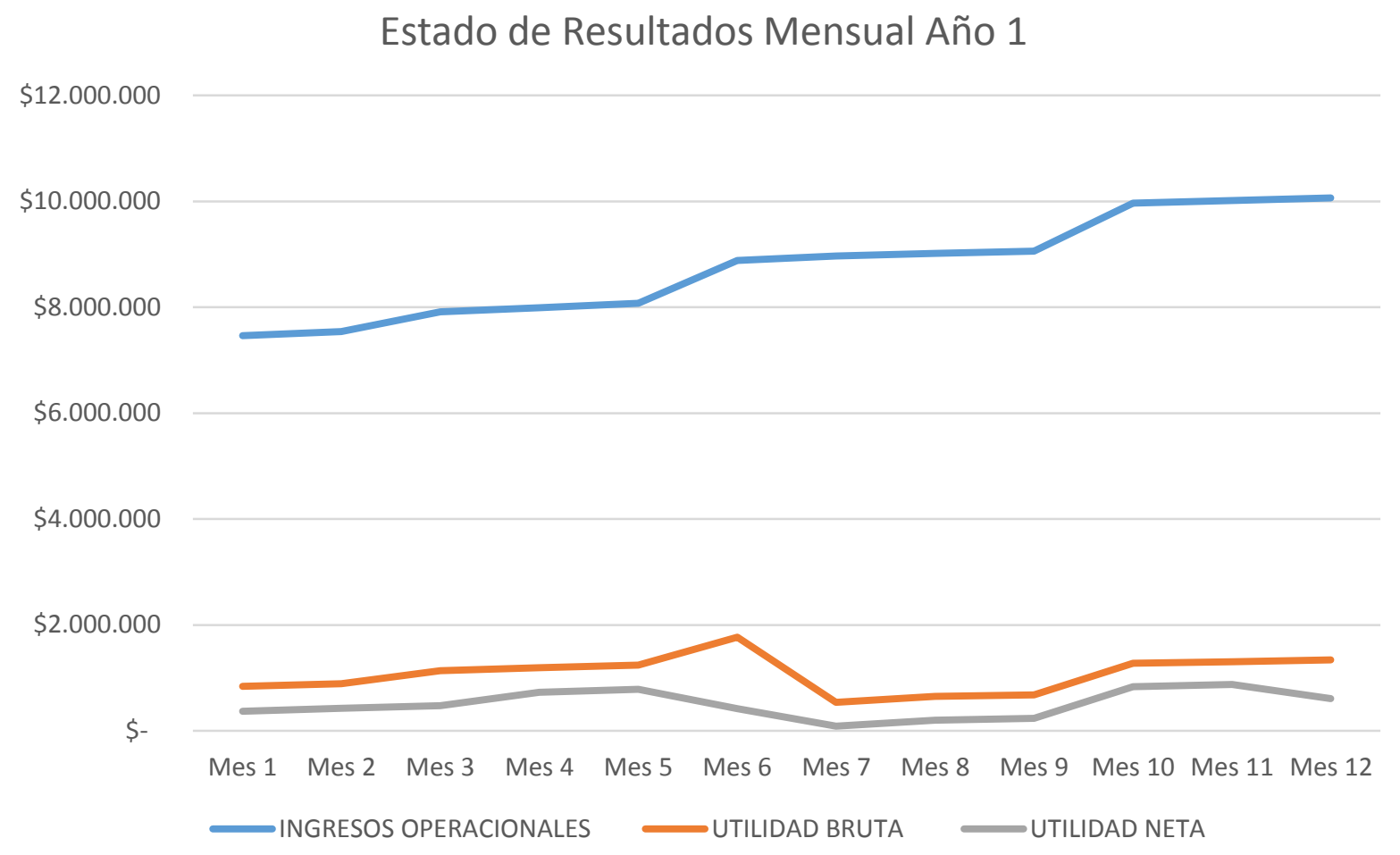

Figura 22 estado de resultado del primer año (elaboración propia)

\section{Estado de Resultados anual}

La proyección de los ingresos de Kushen está con incrementos de: $41 \%$ el primer año, 15\% segundo año, $80 \%$ tercer año con la apertura de una nueva sucursal, $10 \%$ para los años cuarto y quinto, logrando estos incrementos con publicidad y alianzas con plataformas tecnológicas de domicilios de comidas. Al igual que los ingresos, la utilidad bruta se va incrementando cada año, en la misma proporción a causa de que los costos de ventas en su mayoría son variables.

Se puede notar que el proyecto es rentable desde su comienzo, puesto que a partir del momento que empieza a generar ingresos se empieza a obtener utilidad neta, la cual tiene una pequeña caída en el año 3 debido a la apertura de la nueva sucursal, por este motivo trae unos gastos de puesta en marcha adicionales a la operación normal del restaurante. 


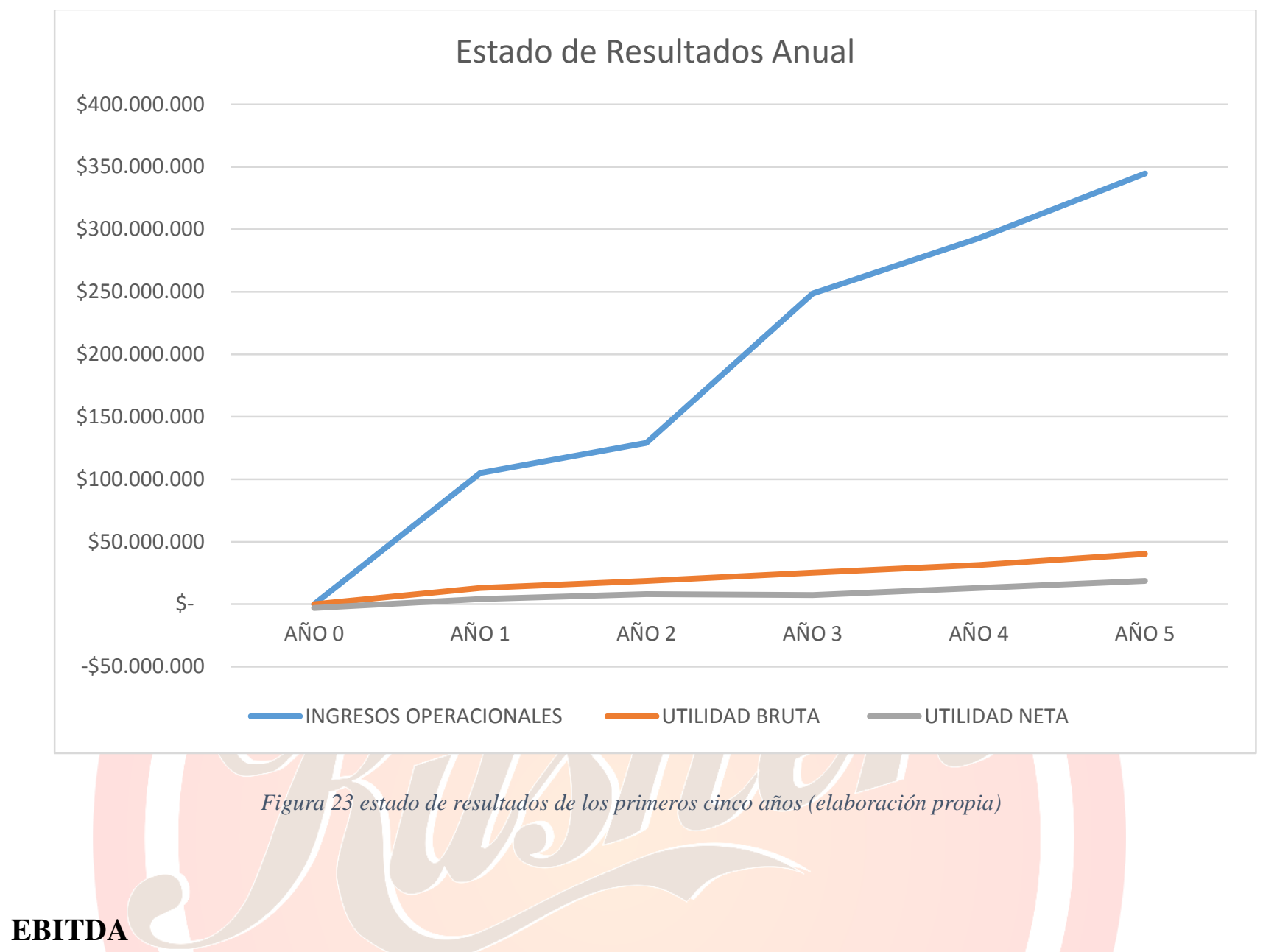

Se puede contemplar que a partir del primer mes Kushen genera EBITDA positivo, lo que quiere decir que el proyecto es rentable desde sus inicios, en el año 3 cae un poco debido a los gastos de puesta en marcha, pero aun así genera EBITDA positivo, y los años siguientes sigue en crecimiento. 


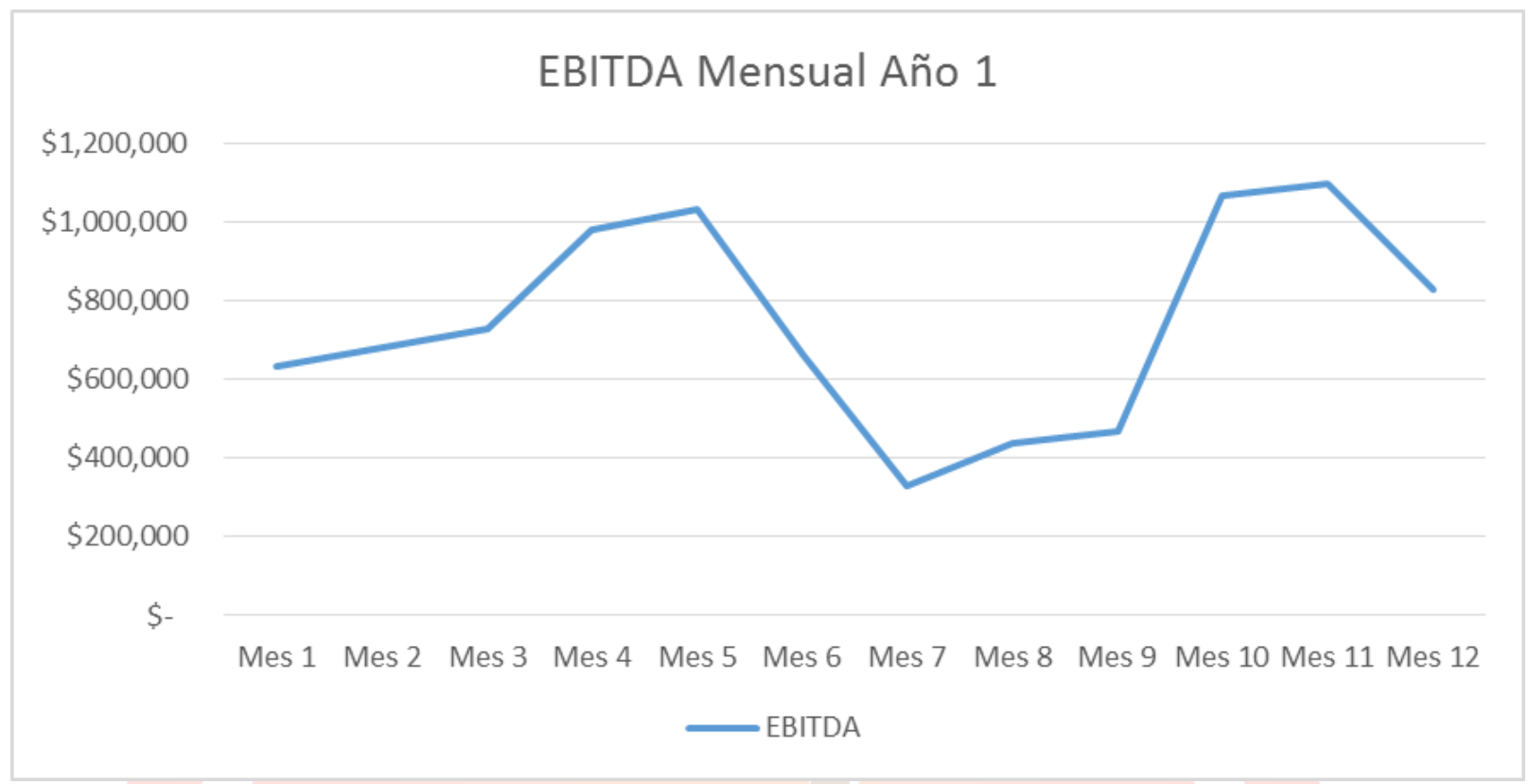

Figura 24 EBITDA del primer año mes a mes (elaboración propia)

\section{EBITDA Anual}

$\$ 35,000,000$

$\$ 30,000,000$

$\$ 25,000,000$

$\$ 20,000,000$

$\$ 15,000,000$

$\$ 10,000,000$

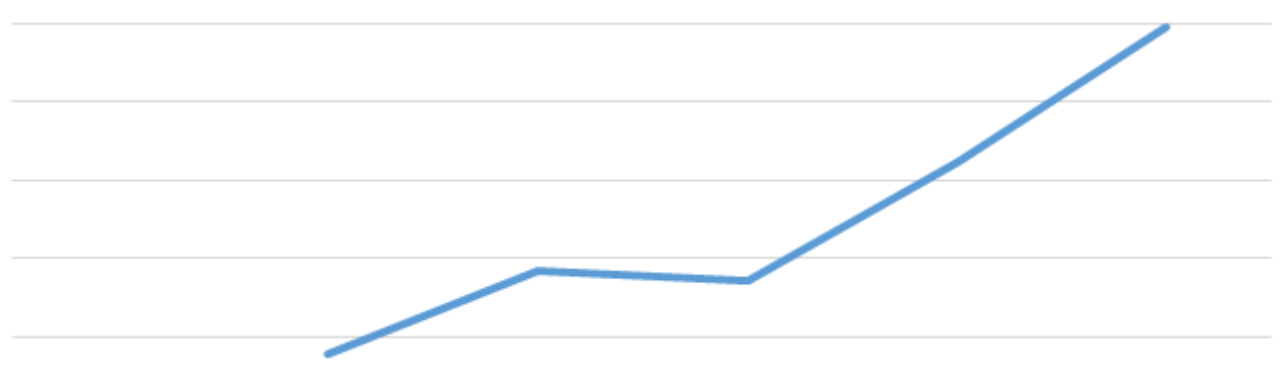

$\$ 5,000,000$

$\$-$

\begin{tabular}{|c|c|c|c|c|}
\hline AÑO 0 & AÑO 1 & AÑO 2 & AÑO 3 & AÑO 4 \\
\hline
\end{tabular}

Figura 25 EBITDA de los primeros cinco años (elaboración propia) 


\section{Estado de Situación Financiera}

\section{Activos}

Las ventas en Kushen serán $100 \%$ de contado, debido a esto no se tienen cuentas por cobrar de clientes así, el efectivo (explicación flujo de caja) es el único activo corriente.

Las materias primas (ingredientes) utilizados en Kushen, son productos perecederos, adicionalmente, al ofrecer productos naturales y frescos, es necesario comprar a diario los alimentos, por lo cual no se tienen inventarios en stock.

La propiedad, planta y equipo son recursos controlados de los cuales se espera obtener beneficios económicos futuros, para Kushen son las maquinarias y equipos que se requieren para la operación como por ejemplo: Estufa, nevera, freidor, horno, campana extractora, etc., se observa que en el año 3 se incrementa este rubro debido a la compra de nueva maquinaria y equipo debido a que se hará la inversión para la apertura de una nueva sucursal.

\section{Pasivos}

Las compras de materiales se realizan $100 \%$ de contado, por lo tanto no se tiene pasivo por pagar a proveedores

Kushen está obligado a presentar declaración de renta, a la tarifa del 34\% para el año 2017 y $33 \%$ para los años siguientes, impuesto que al finalizar cada año se presenta como un pasivo por impuestos que se pagan en el corto plazo.

Para tener los recursos necesarios para iniciar el proyecto, se solicitará préstamo bancario por valor de \$10.000.000 pagaderos en tres años, por lo que es una obligación de largo plazo, valor que se va disminuyendo con los respectivos pagos, como se observa en los saldos de cada año. 
Se puede observar que Kushen genera suficiente liquidez para poder desarrollar su objeto social de forma eficiente, ya que sus activos corrientes son mucho más altos que sus pasivos corrientes, abriendo así la posibilidad de poder realizar en el año 3 la inversión en una nueva sucursal y soportar las operaciones sin recurrir a préstamos bancarios o con terceros, sólo con las reinversión de sus utilidades.

Al ser Kushen una sociedad unipersonal, el único socio decide no recibir dividendos durante los 3 primeros años para tener el flujo de caja suficiente para cumplir la meta de abrir la nueva sucursal en el año 3.

\section{Indicadores de viabilidad}

\section{INDICADORES DE RENTABILIDAD}

Margen Bruto

Margen Operativo

Margen Neto

EBITDA

Margen Ebitda

ROE

ROA

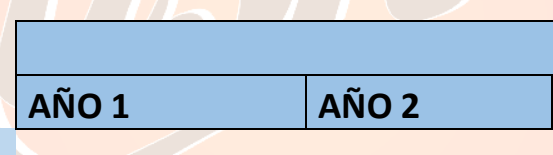

AÑO 3

$11,76 \%$

$7,00 \%$

$3,50 \%$

8.451 .278

$8,05 \%$

$69,66 \%$

$18,83 \%$

$14,40 \%$

$10,15 \%$

$6,19 \%$

14.219 .815

$11,00 \%$

$151,67 \%$

$29,52 \%$
$69,73 \%$

$48,68 \%$

$40,65 \%$

$36,33 \%$

$31,83 \%$

\section{INDICADORES DE LIQUIDEZ}

Capital de Trabajo

$\$ \quad 2.722 .413$ 
En general los márgenes de rentabilidad son positivos, en el año 3 se observa una ligera disminución debido a la apertura de la sucursal, lo que hace que se tengan algunos gastos extraordinarios y disminuyen éstos indicadores, se evidencia que además según el EBITDA se refleja el buen desempeño operativo visto que en todos los periodos es positivo. En el margen de EBITDA $^{12}$ se encuentra en promedio en $8 \%$, en el año 3 con una ligera disminución por la apertura de la sucursal.

El $\mathrm{ROE}^{13}$ es en promedio del $196 \%$ por esta razón es muy atractivo para el inversionista, dado que es la rentabilidad sobre su inversión y con relación al $\mathrm{ROA}^{14}$ es en promedio de $24 \%$, lo cual quiere decir que por cada peso invertido en activos se obtiene una rentabilidad del $24 \%$. El endeudamiento en activos en promedio es el $45 \%$ es financiado por terceros, en los 3 primeros años por bancos para la inversión inicial y en cuanto al capital de trabajo el proyecto genera suficiente liquidez para poder desarrollar su actividad económica eficientemente.

\section{TASA INTERNA DE RETORNO - TIR}

$\begin{array}{lr}\text { Flujo inicial } & -\$ 15.270 .895 \\ \text { Flujo año 1 } & \$ 7.613 .502 \\ \text { Flujo año 2 } & \$ 8.628 .379 \\ \text { Flujo año 3 } & \$ 3.250 .788 \\ \text { Flujo año 4 } & \$ 20.003 .088 \\ \text { Flujo año 5 } & \$ 26.424 .018 \\ \text { TIR } & \mathbf{5 6 , 9 3 \%}\end{array}$

\footnotetext{
${ }^{12}$ EBITDA: Es la utilidad en términos de efectivo, refleja el buen desempeño operativo ya que en todos los periodos es positivo.

${ }^{13}$ ROE: (Return of Equity) rentabilidad sobre capital.

${ }^{14}$ ROA: (Return of Assets) rentabilidad sobre activos.
} 


TIR $>$ TO ACEPTA

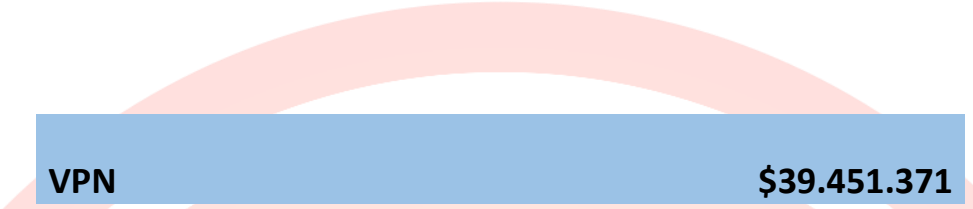

VPN Positivo

VIABLE

Figura 27 indicadores de viabilidad financiera (elaboración propia)

La TIR del proyecto es del $57 \%$, la cual es muy superior a la tasa de oportunidad, que para éste ejercicio es del $5.17 \%$ correspondiente a la tasa que le pagarían los bancos al inversionista, si coloca su dinero en un CDT, por lo tanto es conveniente aceptar el proyecto. EL VPN del proyecto con una tasa de descuento del $5.17 \%$, correspondiente a la tasa de oportunidad explicada en el punto anterior, es positivo, por lo que es viable invertir en Kushen. 


\section{CONCLUSIONES}

El resultado del trabajo elaborado muestra el análisis del mercado, del sector y la viabilidad al ejecutar el proyecto, de esta manera se pudo evidenciar que el sector está en crecimiento y tiene un amplio mercado a su favor debido a que no se encuentran muchos competidores y la población que transita por la zona, el énfasis el productos elaborados artesanalmente, naturales, frescos y una buena atención al cliente, brindando un ambiente agradable son los pilares que garantizan un buen flujo de efectivo.

La viabilidad financiera, denota que el proyecto es sostenible y realizable, genera buenas utilidades para realizar su actividad, dando paso a un crecimiento corporativo volviéndose un restaurante fuerte en el sector de comidas rápidas. El resultado muestra una tasa de retorno del $40 \%$ lo cual es bueno y demuestra que los flujos generados por la empresa son positivos. Además de un VPN que se registra positivo sobre una tasa de descuento del $5 \%$.

La estrategia competitiva de KUSHEN es ofrecer comida rápida elaborada artesanal, con ingredientes $100 \%$ naturales y preparados a la vista del cliente y con la posibilidad que este personalice el producto a su gusto, es un producto únicos en el sector (Papas artesanal, yuca artesanal, entre otros) además de esto, Construir fuertes relaciones, clientes satisfechos y un grato ambiente para que los clientes se sientan en confianza.

Como conclusión general se puede afirmar que es en negocio rentable, porque los ingresos sobre las ventas siempre se ven en aumento al pasar los años generando buenas utilidades y la 
posibilidad de lograr la apertura de una nueva sucursal al tercer año además que es un sector en crecimiento y el potencial del proyecto es muy alto.

\section{ANEXOS ECONÓMICOS}

- Anexo 1: Costos.

- Anexo 2: Costos Fijos Mensuales.

- Anexo 3: Lista de ingredientes.

- Anexo 4: Costo de materiales.

- Anexo 5: Costos de mano de obra.

- Anexo 6: Orden de producción hamburguesa.

- Anexo 7: Orden de producción salchipapa.

- Anexo 8: Orden de producción salchiyuca.

- Anexo 9: Orden de producción mazorcada.

- Anexo 10: Orden de producción hamburguesa de helado.

- Anexo 11: Lista de precios.

- Anexo 12: Inversión inicial.

- Anexo 13: Inversión inicial de sucursal.

- Anexo 14: Cálculo depreciación activos fijos.

- Anexo 15: Cálculo financiación de la inversión.

- Anexo 16: Punto de equilibrio.

- Anexo 17: Supuestos económicos.

- Anexo 18: Ingresos.

- Anexo 19: Modelo proyección costos.

- Anexo 20: Modelo proyección mano de obra.

- Anexo 21: Modelo de proyección de gastos.

- Anexo 22: Estado de resultados proyectado mensual.

- Anexo 23: Estado de resultados proyectado anual.

- Anexo 24: Balance general proyectado mensual.

- Anexo 25: Balance general proyectado anual.

- Anexo 26: Flujo de caja proyectado mensual.

- Anexo 27: Flujo de caja proyectado anual. 


\section{BIBLIOGRAFÍA}

ACODRES . (2013). ACODRES . Obtenido de ACODRES : http://acodres.com.co/quienessomos/\#objetivos

Banco de la República. (s.f.). Banco de la República. Obtenido de Banco de la República: http://www.banrep.gov.co/es/el-banco/que-hacemos

Biogras S.A.S. (s.f.). biograssas. Obtenido de biograssas: http://www.biograssas.com/quienessomos.html

bogota, a. m. (2016). Obtenido de http://mapacallejero.bogota.gov.co/mad/vm.php Bojórquez, A. (02 de 07 de 2008). autentica wordpress. Obtenido de https://autentica.wordpress.com/2008/07/02/btl-y-atl-\%C2\%BFcual-es-tu-estrategia/

campo, m. f. (02 de 2011). empresario.com.co. Obtenido de http://empresario.com.co/recursos/page_flip/compromiso_colectivo/Perfil_economico_e mpresarial_localidad_Antonio_Narino/index.html\#/39/zoomed

CCB. (04 de 2016). camara de comercio de bogota. Obtenido de camara de comercio de bogota: http://www.ccb.org.co/Clusters/Cluster-Lacteo-de-BogotaRegion/Noticias/2016/Abril/Conozca-los-requisitos-para-abrir-un-nuevo-negocio-deproductos-alimenticios

CCB. (s.f.). Cámara de Comercio. Obtenido de La Cámara de Comercio: http://www.ccb.org.co/La-Camara-CCB

DANE. (2015). SECRETARIA DE PLANEACION. Obtenido de http://www.sdp.gov.co/PortalSDP/InformacionTomaDecisiones/Estadisticas/ProyeccionP oblacion 
DANE. (25 de 11 de 2016). DANE. Obtenido de DANE:

https://www.dane.gov.co/files/investigaciones/boletines/pib/bol_PIB_IIItrim16_oferta.pd f

DANE. (ABRIL de 2017). DANE. Obtenido de DANE:

https://www.dane.gov.co/index.php/estadisticas-por-tema/precios-y-costos/indice-deprecios-al-consumidor-ipc

DANE. (Marzo de 2017). DANE. Obtenido de DANE:

http://www.dane.gov.co/index.php/estadisticas-por-tema/mercado-laboral/empleo-ydesempleo

DANE. (s.f.). DANE. Obtenido de DANE: http://www.dane.gov.co/index.php/acerca-deldane/informacion-institucional/generalidades

Datosmacro.com. (2016). datosmacro.com. Obtenido de datosmacro.com: http://www.datosmacro.com/pib/colombia

DIAN. (s.f.). La Dirección de Impuestos y Aduanas Nacionales. Obtenido de DIAN: http://www.dian.gov.co/DIAN/12SobreD.nsf/pages/Laentidad?OpenDocument

Dinero. (31 de 03 de 2015). Dinero. Obtenido de Dinero: http://www.dinero.com/edicionimpresa/caratula/articulo/negocio-comidas-colombia/207247

Dinero. (15 de 12 de 2016). Dinero. Obtenido de Dinero: http://www.dinero.com/edicionimpresa/negocios/articulo/el-negocio-de-la-comida-rapida-en-colombia/240022

El CONGRESO DE COLOMBIA . (26 de DICIEMBRE de 2012). DIAN. Obtenido de DIAN: http://www.dian.gov.co/descargas/normatividad/2012/Leyes/Ley_1607_2012_Congreso_ de_la_Republica.pdf 
Finanzas personales . (2017). finanzas personales . Obtenido de finanzas personales :

http://www.finanzaspersonales.com.co/ahorro-e-inversion/articulo/lo-debe-saber-antesmontar-restaurante/38064

Giménez, A. O., \& Espinosa, J. L. (14 de ENERO de 2015). Plan de internacionalización empresarial. Manual práctico (Primera ed.). españa: ESIC. Recuperado el 15 de 05 de 2017, de emprendices:

https://books.google.com.co/books?id=9KjkBgAAQBAJ\&pg=PA132\&dq=matriz+pestel \&hl=es419\&sa=X\&ved=0ahUKEwj_7MaErPPTAhWE1CYKHdiWBoMQ6AEINTAD\#v=onep age $\& \mathrm{q}=$ matriz $\% 20$ pestel $\& \mathrm{f}=$ false

HERRERA, D. A. (17 de 06 de 2011). blogger. Obtenido de CONTABILIDAD DE COSTOS, METODOS Y APLICACIONES:

http://wwwcontabilidaddecostosmetodos.blogspot.com.co/2011/06/contabilidad-decostos-metodos-y.html

Horngren, C. T., Datar, S. M., \& Foster, G. (2007). contabilidad de costos (decimosegunda edicion ed.). (J. L. Servin, Trad.) mexico: pearson educacion. Recuperado el 31 de 05 de 2017, de https://books.google.com.co/books?id=zDCb9fDzNgC\&pg=PA30\&dq=definicion + de + costos \&hl=es419\&sa=X\&ved=0ahUKEwj3r_W1zZvUAhXB6SYKHSp0BQUQ6AEINTAE\#v=onepa ge $\& \mathrm{q}=$ definicion $\% 20 \mathrm{de} \% 20 \operatorname{costos} \& \mathrm{f}=$ false

Iglesias, I. (21 de 11 de 2014). Portafolio. Obtenido de Portafolio: http://www.portafolio.co/negocios/empresas/mercado-comidas-rapidas-potencialexplotar-58492 
MARTÍNEZ, M. C., \& FERRO, M. H. (marzo de 2017). SECRETARIA DISTRITAL DE SALUD. Obtenido de SECRETARIA DISTRITAL DE SALUD:

http://www.saludcapital.gov.co/VSP/Caja_de_herramientas/2_Estrategias/V_SALUD_A MBIENTAL/ALI_SAN_SEG.pdf\#search=restaurantes\%20de\%20comidas\%20rapidas

MINAMBIENTE. (s.f.). ministerio de ambiente y desarrollo sostenible. Obtenido de ministerio de ambiente y desarrollo sostenible: http://www.minambiente.gov.co/index.php/ministerio/objetivos-y-funciones

MinCIT. (s.f.). Ministerio de Comercio Industria y Turismo. Obtenido de http://www.mincit.gov.co/publicaciones/34613/conozca_el_mincomercio

Ortegón, D. G. (16 de 06 de 2015). la republica. Obtenido de la republica: http://www.larepublica.co/el-sector-gastron\%C3\%B3mico-creci\%C3\%B3-22-en-el\%C3\%BAltimo-a\%C3\%B1o-con-90000-restaurantes_266206

PAGOMA S.A. (s.f.). PAGOMA S.A. Obtenido de http://pagoma.com.co/index.php/es/empaque/p-o-p/rompetraficos

Ramos, N. E. (s.f.). grupo de investigacion de la papa. Obtenido de universidada nacional de colombia: http://www.papaunc.com/catalogoExtendido.shtml?x=26

Red Gráfica Latinoamérica. (s.f.). Red Gráfica Latinoamérica. Obtenido de http://redgrafica.com/El-Material-P-O-P-y-su-utilidad

Salazar, H. Z. (12 de mayo de 2005). Planeación estratégica aplicada a cooperativas y demás formas asociativas y solidarias. (primera edicion ed.). colombia: universidad cooperativa de colombia. Recuperado el 15 de 05 de 2017, de ABOUT EN ESPAÑOL: https://accounts.google.com/Login?service=print $\&$ continue $=$ https $\% 3 \mathrm{~A} \% 2 \mathrm{~F} \% 2 \mathrm{Fbooks}$. go ogle.com.co\%2Fbooks\%3Fid\%3DXW1kXEr1jlwC\%26printsec\%3Dfrontcover\%26dq\% 
3Dmatriz\%2Bdofa\%26hl\%3Des-

419\%26sa\%3DX\%26sqi\%3D2\%26redir_esc\%3Dy\&hl=en

SDP. (31 de 12 de 2011). SECRETARÍA DISTRITAL DE PLANEACIÓN. Obtenido de 21 monografias de las localidades:

http://www.sdp.gov.co/portal/page/portal/PortalSDP/InformacionTomaDecisiones/Estadi sticas/Documentos/An\%E1lisis/DICE077-MonografiaAntonioNarino31122011.pdf

Valencia, G. (s.f.). 7 Sistemas y Modelos de Estructuras Organizacionales. Obtenido de http://www.academia.edu/9227866/7_Sistemas_y_Modelos_de_Estructuras_Organizacio nales 
Anexo 1: COSTOS

\section{COSTOS VARIABLES}

Materiales

Envases y empaques

\section{COSTOS FIJOS}

Sueldos

Arriendo

Servicios públicos

Otros costos (Aseo, papelería)

\section{Anexo 2: COSTOS FIJOS MENSUALES}

Sueldos

Arriendo

Servicios públicos

Otros costos (Aseo, papelería)

Depreciación
$\$ 2.830 .895,00$

$800.000,00$

$300.000,00$

$50.000,00$

$91.388,89$

\$ 4.072.283,89 


\section{Anexo 3: LISTADO DE INGREDIENTES}

\begin{tabular}{|l|lr|r|l|lr|}
\hline & \multicolumn{2}{|l|}{ Precio } & Un & Un medida & \multicolumn{2}{|l|}{ Vr. Unitario } \\
\hline Carne molida & $\$$ & 5.000 & 500 & $\mathrm{gr}$ & $\$$ & 10,00 \\
\hline Pan hamb. & $\$$ & 4.300 & 12 & un & $\$$ & 358,33 \\
\hline Salsas & $\$$ & 4.300 & 1000 & $\mathrm{gr}$ & $\$$ & 4,30 \\
\hline Aceite & $\$$ & 25.000 & 5000 & $\mathrm{ml}$ & $\$$ & 5,00 \\
\hline Queso tajado & $\$$ & 12.000 & 50 & tajada & $\$$ & 240,00 \\
\hline Cebolla & $\$$ & 2.200 & 500 & $\mathrm{gr}$ & $\$$ & 4,40 \\
\hline Tomate & $\$$ & 1.000 & 500 & $\mathrm{gr}$ & $\$$ & 2,00 \\
\hline Lechuga & $\$$ & 500 & 500 & $\mathrm{gr}$ & $\$$ & 1,00 \\
\hline Salchichas & $\$$ & 10.500 & 15 & un & $\$$ & 700,00 \\
\hline Pollo & $\$$ & 6.000 & 500 & $\mathrm{gr}$ & $\$$ & 12,00 \\
\hline Carne desmechada & $\$$ & 6.500 & 500 & $\mathrm{gr}$ & $\$$ & 13,00 \\
\hline Mazorca & $\$$ & 4.000 & 500 & $\mathrm{gr}$ & $\$$ & 8,00 \\
\hline perejil & $\$$ & 500 & 1000 & $\mathrm{gr}$ & $\$$ & 0,50 \\
\hline Miga de pan & $\$$ & 1.000 & 500 & $\mathrm{gr}$ & $\$$ & 2,00 \\
\hline Mantequilla & $\$$ & 1.000 & 125 & $\mathrm{gr}$ & $\$$ & 8,00 \\
\hline sal & $\$$ & 1.000 & 1000 & $\mathrm{gr}$ & $\$$ & 1,00 \\
\hline Pimienta & $\$$ & 2.500 & 1000 & $\mathrm{gr}$ & $\$$ & 2,50 \\
\hline Platano & $\$$ & 600 & 1 & un & $\$$ & 600,00 \\
\hline Empaque & $\$$ & 100.000 & 1000 & un & $\$$ & 100,00 \\
\hline Palillo & $\$$ & 800 & 100 & un & $\$$ & 8,00 \\
\hline Servilleta & $\$$ & 1.100 & 200 & un & $\$$ & 5,50 \\
\hline Jamon & $\$$ & 12.000 & 50 & un & $\$$ & 240,00 \\
\hline Papa & $\$$ & 500 & 500 & $\mathrm{gr}$ & $\$$ & 1,00 \\
\hline yuca & $\$$ & 700 & 500 & $\mathrm{gr}$ & $\$$ & 1,40 \\
\hline huevo de codorniz & $\$$ & 40 & 1 & un & $\$$ & 40,00 \\
\hline papa chip & $\$$ & 1.000 & 500 & $\mathrm{gr}$ & $\$$ & 2,00 \\
\hline cebolla guiso & $\$$ & 1.500 & 500 & $\mathrm{gr}$ & $\$$ & 3,00 \\
\hline chorizo & $\$$ & 1.000 & 1 & un & $\$$ & $1.000,00$ \\
\hline helado & $\$$ & 16.000 & 6000 & $\mathrm{ml}$ & $\$$ & 2,67 \\
\hline mermelada & $\$$ & 3.000 & 500 & $\mathrm{ml}$ & $\$$ & 6,00 \\
\hline azucar blanca & $\$$ & 3.500 & 500 & $\mathrm{gr}$ & $\$$ & 7,00 \\
\hline
\end{tabular}




\section{Anexo 4: COSTO DE MATERIALES}

\begin{tabular}{|c|c|c|c|c|c|c|}
\hline Producto: & & & RGI & & & \\
\hline Ingredientes & Cantidad & $\mathbf{U}$ & & ario & & Total \\
\hline Pan hamb. & 1 & un & $\$$ & 358 & $\$$ & 358 \\
\hline Carne molida & 100 & $g r$ & $\$$ & 10 & $\$$ & 1.000 \\
\hline Salsas & 50 & $g r$ & $\$$ & 4 & $\$$ & 215 \\
\hline Aceite & 10 & $g r$ & $\$$ & 5 & $\$$ & 50 \\
\hline Queso tajado & 1 & tajada & $\$$ & 240 & $\$$ & 240 \\
\hline Cebolla & 10 & $g r$ & $\$$ & 4 & $\$$ & 44 \\
\hline Tomate & 30 & $g r$ & $\$$ & 2 & $\$$ & 60 \\
\hline Lechuga & 10 & $g r$ & $\$$ & 1 & $\$$ & 10 \\
\hline Perejil & 2 & $g r$ & $\$$ & 1 & $\$$ & 1 \\
\hline Miga de pan & 30 & $g r$ & $\$$ & 2 & $\$$ & 60 \\
\hline Sal & 2 & $g r$ & $\$$ & 1 & $\$$ & 2 \\
\hline Pimienta & 2 & $g r$ & $\$$ & 3 & $\$$ & 5 \\
\hline Mantequilla & 8 & $g r$ & $\$$ & 8 & $\$$ & 64 \\
\hline cebolla guiso & 15 & $g r$ & $\$$ & 3 & $\$$ & 45 \\
\hline Empaque & 1 & $g r$ & $\$$ & 100 & $\$$ & 100 \\
\hline Servilleta & 5 & $g r$ & $\$$ & 6 & $\$$ & 28 \\
\hline- & & & & & & \\
\hline TOTAL COSTO INGRED & (MATERIAL & & & & $\$$ & 2.282 \\
\hline
\end{tabular}

\begin{tabular}{|l|r|l|lr|rr|}
\hline Producto: & \multicolumn{5}{c|}{ SALCHIPAPA } \\
\hline \multicolumn{1}{|c|}{ Ingredientes } & Cantidad & & Un & \multicolumn{2}{c|}{ Vr. Unitario } & \multicolumn{2}{c|}{ Vr. Total } \\
\hline papa & 750 & un & $\$$ & 1 & $\$$ & 750 \\
\hline Salchichas & 1 & $\mathrm{gr}$ & $\$$ & 700 & $\$$ & 700 \\
\hline Salsas & 50 & $\mathrm{gr}$ & $\$$ & 4 & $\$$ & 215 \\
\hline Aceite & 40 & $\mathrm{ml}$ & $\$$ & 5 & $\$$ & 200 \\
\hline Sal & 4 & $\mathrm{gr}$ & $\$$ & 1 & $\$$ \\
\hline Empaque & 1 & $\mathrm{gr}$ & $\$$ & 100 & $\$$ & 100 \\
\hline Servilleta & 5 & $\mathrm{gr}$ & $\$$ & 6 & $\$$ & 28 \\
\hline & & & & & & \\
\hline TOTAL COSTO INGREDIENTES (MATERIALES) & & & & 1.997 \\
\hline
\end{tabular}




\begin{tabular}{|c|c|c|c|c|c|c|}
\hline Producto: & \multicolumn{6}{|c|}{ SALCHIYUCA } \\
\hline Ingredientes & Cantidad & Un & \multicolumn{2}{|c|}{ Vr. Unitario } & \multicolumn{2}{|c|}{ Vr. Total } \\
\hline Yuca & 750 & $g r$ & $\$$ & 1,40 & $\$$ & 1.050 \\
\hline salchichas & 1 & $g r$ & $\$$ & 700 & $\$$ & 700 \\
\hline Salsas & 50 & $g r$ & $\$$ & 4 & $\$$ & 215 \\
\hline Aceite & 40 & $\mathrm{ml}$ & $\$$ & 5 & $\$$ & 200 \\
\hline Sal & 4 & $g r$ & $\$$ & 1 & $\$$ & 4 \\
\hline Empaque & 1 & $g r$ & $\$$ & 100 & $\$$ & 100 \\
\hline Servilleta & 5 & gr & & 6 & $\$$ & 28 \\
\hline & & & & & & \\
\hline 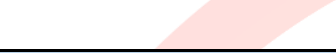 & & & & & & \\
\hline \multicolumn{3}{|c|}{ TOTAL COSTO INGREDIENTES (MATERIALES) } & & & $\$$ & 2.297 \\
\hline
\end{tabular}

\begin{tabular}{|c|c|c|c|c|c|c|}
\hline Producto: & \multicolumn{6}{|c|}{ MAZORCADA } \\
\hline & & & & & & \\
\hline Ingredientes & \multirow{2}{*}{$\begin{array}{r}\text { Cantidad } \\
200 \\
\end{array}$} & Un & \multicolumn{2}{|c|}{ Vr. Unitario } & \multicolumn{2}{|c|}{ Vr. Total } \\
\hline Mazorca & & un & $\$$ & 8 & $\$$ & 1.600 \\
\hline salchichas & 1 & $g r$ & $\$$ & 700 & $\$$ & 700 \\
\hline Salsas & 50 & $g r$ & $\$$ & 4 & $\$$ & 215 \\
\hline Aceite & 40 & $\mathrm{ml}$ & $\$$ & 5 & $\$$ & 200 \\
\hline Sal & 4 & tajada & $\$$ & 1 & $\$$ & 4 \\
\hline Carne desmechada & 150 & $\mathrm{gr}$ & $\$$ & 13 & $\$$ & 1.950 \\
\hline papa chip & 150 & $g r$ & $\$$ & 2 & $\$$ & 300 \\
\hline huevo de codorniz & 3 & un & $\$$ & 40 & $\$$ & 120 \\
\hline Empaque & 1 & $g r$ & $\$$ & 100 & $\$$ & 100 \\
\hline Servilleta & 5 & $\mathrm{gr}$ & & 6 & $\$$ & 28 \\
\hline \multicolumn{3}{|c|}{ TOTAL COSTO INGREDIENTES (MATERIALES) } & & & $\$$ & 5.217 \\
\hline
\end{tabular}

\begin{tabular}{|c|c|c|c|c|c|c|}
\hline \multirow[t]{2}{*}{ Producto: } & \multicolumn{6}{|c|}{ HAMBURGUESA DE HELADO } \\
\hline & & & & & & \\
\hline Ingredientes & Cantidad & Un & & ario & & otal \\
\hline Pan hamb. & & un & $\$$ & 358 & $\$$ & 358 \\
\hline mermelada & 15 & $\mathrm{ml}$ & $\$$ & 6 & $\$$ & 90 \\
\hline helado & 70 & $\mathrm{ml}$ & $\$$ & 3 & $\$$ & 187 \\
\hline azucar blanca & 20 & $\mathrm{gr}$ & $\$$ & 7 & $\$$ & 140 \\
\hline \multicolumn{3}{|c|}{ TOTAL COSTO INGREDIENTES (MATERIALES) } & & & $\$$ & 775 \\
\hline
\end{tabular}




\section{Anexo 5: COSTOS DE MANO DE OBRA}

\section{Valores mensuales}

\begin{tabular}{|c|c|c|c|c|}
\hline \multicolumn{3}{|c|}{ Auxiliar Cocina } & & \\
\hline Sueldo & $\$$ & $737.717,00$ & \multirow[b]{2}{*}{$53 \%$} & \\
\hline Carga prestacional & $\$$ & $393.498,00$ & & \\
\hline Aux. Transporte & $\$$ & $83.140,00$ & \multirow[b]{3}{*}{240} & \\
\hline Valor mensual & $\$$ & $1.214 .355,00$ & & \\
\hline Valor hora & $\$$ & $5.059,81$ & & \\
\hline \multicolumn{3}{|c|}{ Administrador } & \multirow{5}{*}{$53 \%$} & \\
\hline Sueldo & $\$$ & $1.000 .000,00$ & & \\
\hline Carga prestacional & $\$$ & $533.400,00$ & & \\
\hline Aux. Transporte & $\$$ & $83.140,00$ & & \\
\hline Valor mensual & $\$$ & $1.616 .540,00$ & & \\
\hline \multirow[t]{8}{*}{ Valor hora } & $\$$ & $6.735,58$ & \multicolumn{2}{|c|}{240} \\
\hline & \multicolumn{4}{|c|}{ Proyeccion de empleados } \\
\hline & \multicolumn{4}{|c|}{ Domiciliario } \\
\hline & & & $\$$ & $737.717,00$ \\
\hline & pre & ional & $\$$ & $393.498,00$ \\
\hline & & & $\$$ & $83.140,00$ \\
\hline & me & & $\$$ & $1.214 .355,00$ \\
\hline & $r h$ & & $\$$ & $5.059,81$ \\
\hline
\end{tabular}

FACTOR PRESTACIONAL

\begin{tabular}{lr} 
Cesantías & $8,33 \%$ \\
Intereses/Cesantías & $1,00 \%$ \\
Prima & $8,33 \%$ \\
Vacaciones & $4,18 \%$ \\
Salud & $8,50 \%$ \\
Pensión & $12,00 \%$ \\
ARL & $2,00 \%$ \\
SENA & $4,00 \%$ \\
ICBF & $3,00 \%$ \\
Caja Comp & $\mathbf{2 , 0 0 \%}$ \\
\cline { 2 - 2 } & $\mathbf{5 3 , 3 4 \%}$ \\
\hline Prestaciones sociales & $\mathbf{2 1 , 8 4 \%}$ \\
Seguridad social & $31,50 \%$ \\
\cline { 2 - 2 } & $\mathbf{5 3 , 3 4 \%}$ \\
\cline { 2 - 2 } &
\end{tabular}

\begin{tabular}{lcr}
\multicolumn{3}{c}{ Auxiliar Cocina II } \\
Sueldo & $\$$ & $737.717,00$ \\
Carga prestacional & $\$$ & $393.498,00$ \\
Aux. Transporte & $\$$ & $83.140,00$ \\
Valor mensual & $\mathbf{\$}$ & $\mathbf{1 . 2 1 4 . 3 5 5 , 0 0}$ \\
\hline Valor hora & $\mathbf{\$}$ & $\mathbf{5 . 0 5 9 , 8 1}$ \\
\hline
\end{tabular}




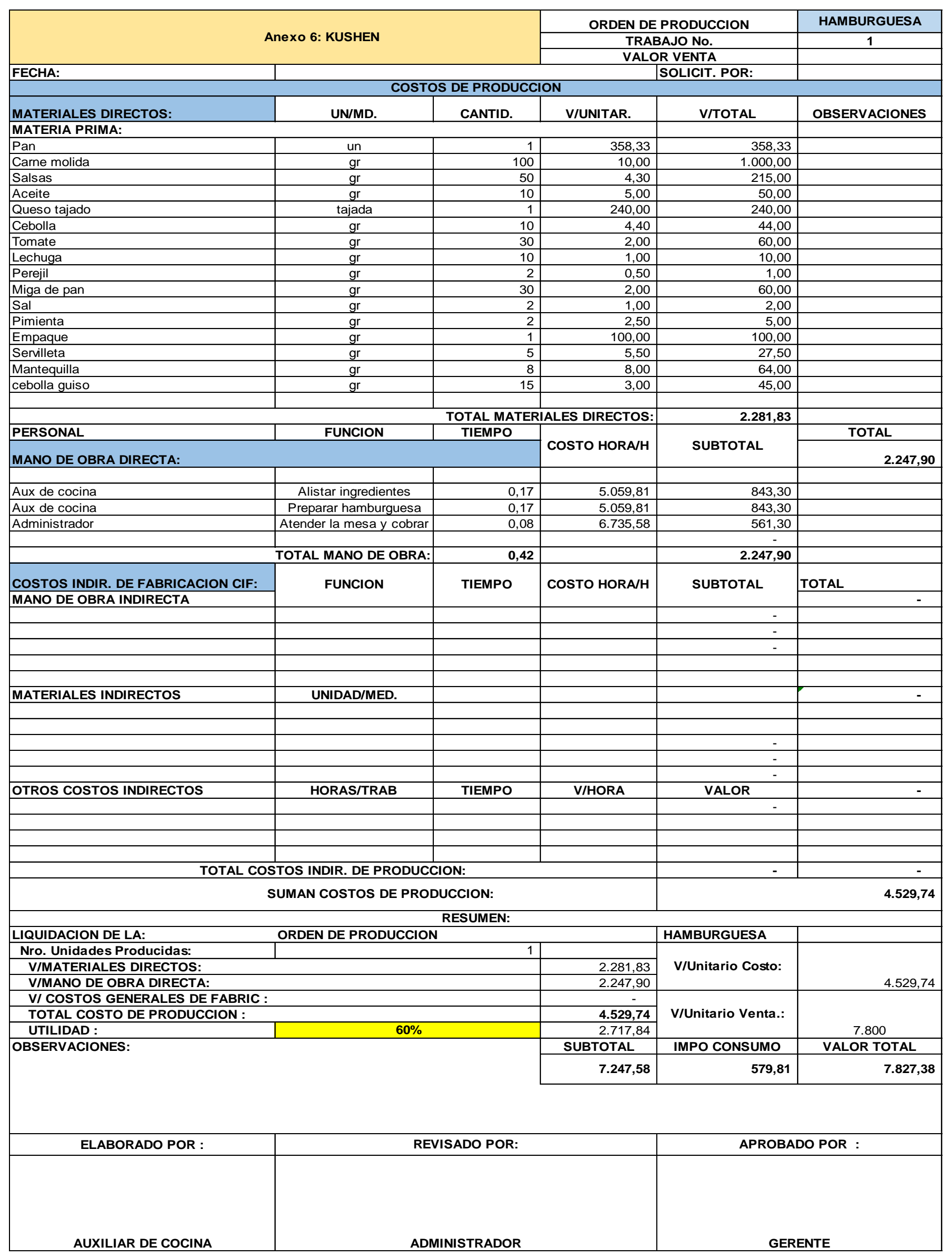




\begin{tabular}{|c|c|c|c|c|c|}
\hline \multirow{3}{*}{\multicolumn{3}{|c|}{ Anexo 7: KUSHEN }} & \multicolumn{2}{|c|}{ ORDEN DE PRODUCCION } & SALCHIPAPA \\
\hline & & & \multicolumn{2}{|c|}{ TRABAJO No. } & 2 \\
\hline & & & \multicolumn{2}{|c|}{ VALOR VENTA } & \\
\hline FECHA: & & & & SOLICIT. POR: & \\
\hline MATERIALES DIRECTOS: & UN/MD. & CANTID. & V/UNITAR. & V/TOTAL & OBSERVACIONES \\
\hline \multicolumn{6}{|l|}{ MATERIA PRIMA: } \\
\hline papa & un & 750 & 1,00 & 750,00 & \\
\hline Aceite & $\mathrm{ml}$ & 40 & 5,00 & 200,00 & \\
\hline Sal & $\mathrm{gr}$ & 4 & 1,00 & 4,00 & \\
\hline Empaque & gr & 1 & 100,00 & 100,00 & \\
\hline \multirow[t]{2}{*}{ Servilleta } & gr & 5 & 5,50 & 27,50 & \\
\hline & & & & - & \\
\hline Aux de cocina & Alistar ingredientes & $1 / 6$ & $5.059,81$ & 843,30 & \\
\hline Aux de cocina & Preparación & $1 / 6$ & $5.059,81$ & 843,30 & \\
\hline Administrador & Atender la mesa y cobrar & $1 / 12$ & $6.735,58$ & 561,30 & \\
\hline & & & & - & \\
\hline & TOTAL MANO DE OBRA: & 0,42 & & $2.247,90$ & \\
\hline COSTOS INDIR. DE PRODUCCION: & \multirow{2}{*}{ FUNCION } & \multirow{2}{*}{ TIEMPO } & \multirow{2}{*}{ COSTO HORA/H } & \multirow{2}{*}{ SUBTOTAL } & TOTAL \\
\hline \multirow[t]{4}{*}{ MANO DE OBRA INDIRECTA } & & & & & - \\
\hline & & & & - & \\
\hline & & & & - & \\
\hline & & & & - & \\
\hline & & & & & - \\
\hline MATERIALES INDIRECTOS & UNIDAD/MED. & & & & - \\
\hline \multicolumn{4}{|c|}{ TOTAL COSTOS INDIR. DE PRODUCCION: } & - & - \\
\hline \multicolumn{4}{|c|}{ SUMAN COSTOS DE PRODUCCION: } & & $4.294,40$ \\
\hline & & ESUMEN: & & & \\
\hline LIQUIDACION DE LA: & ORDEN DE PRODUCCIOI & & & SALCHIPAPA & \\
\hline Nro. Unidades Producidas: & & 1 & & & \\
\hline V/MATERIALES DIRECTOS: & & & $2.046,50$ & V/Unitario Costo: & \\
\hline V/MANO DE OBRA DIRECTA: & & & $2.247,90$ & & $4.294,40$ \\
\hline V/ COSTOS GENERALES DE FABRIC : & & & - & & \\
\hline TOTAL COSTO DE PRODUCCION : & & & $4.294,40$ & V/Unitario Venta.: & \\
\hline UTILIDAD : & $61 \%$ & & $2.619,59$ & & 7.500 \\
\hline OBSERVACIONES: & & & SUBTOTAL & IMPO CONSUMO & VALOR TOTAL \\
\hline & & & $6.913,99$ & 553,12 & $7.467,11$ \\
\hline ELABORADO POR : & RE & ADO POR: & & APROBA & DO POR : \\
\hline
\end{tabular}




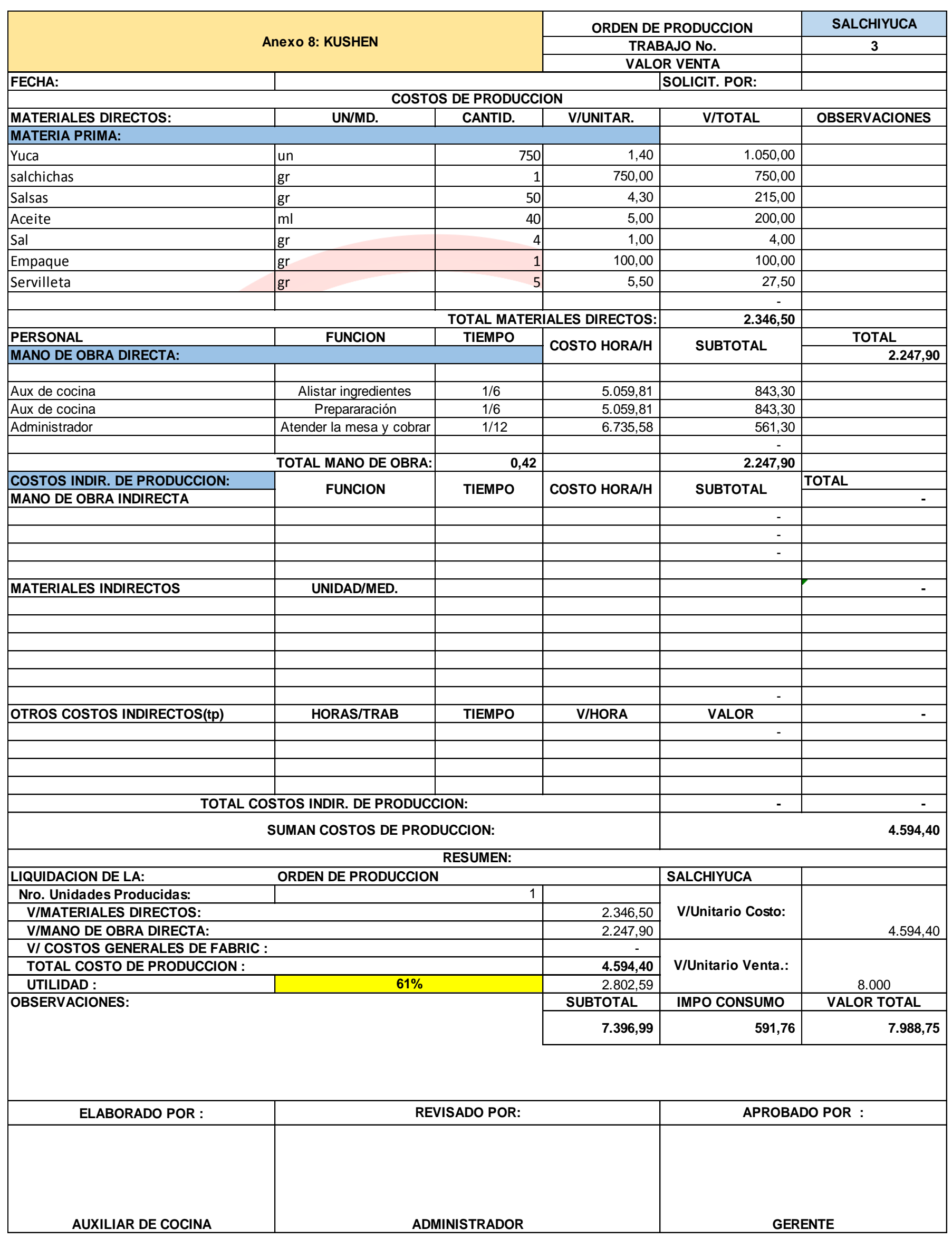




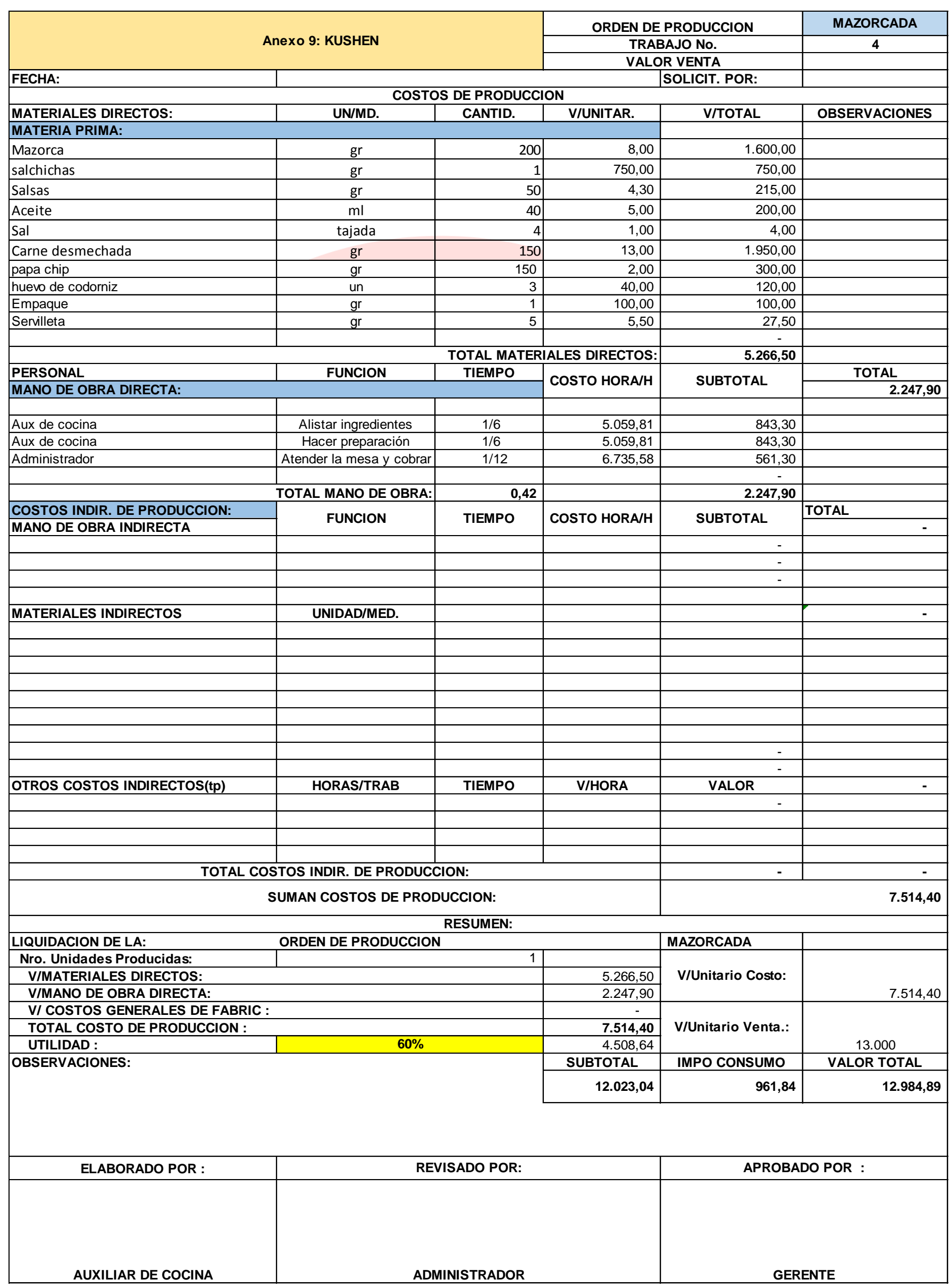




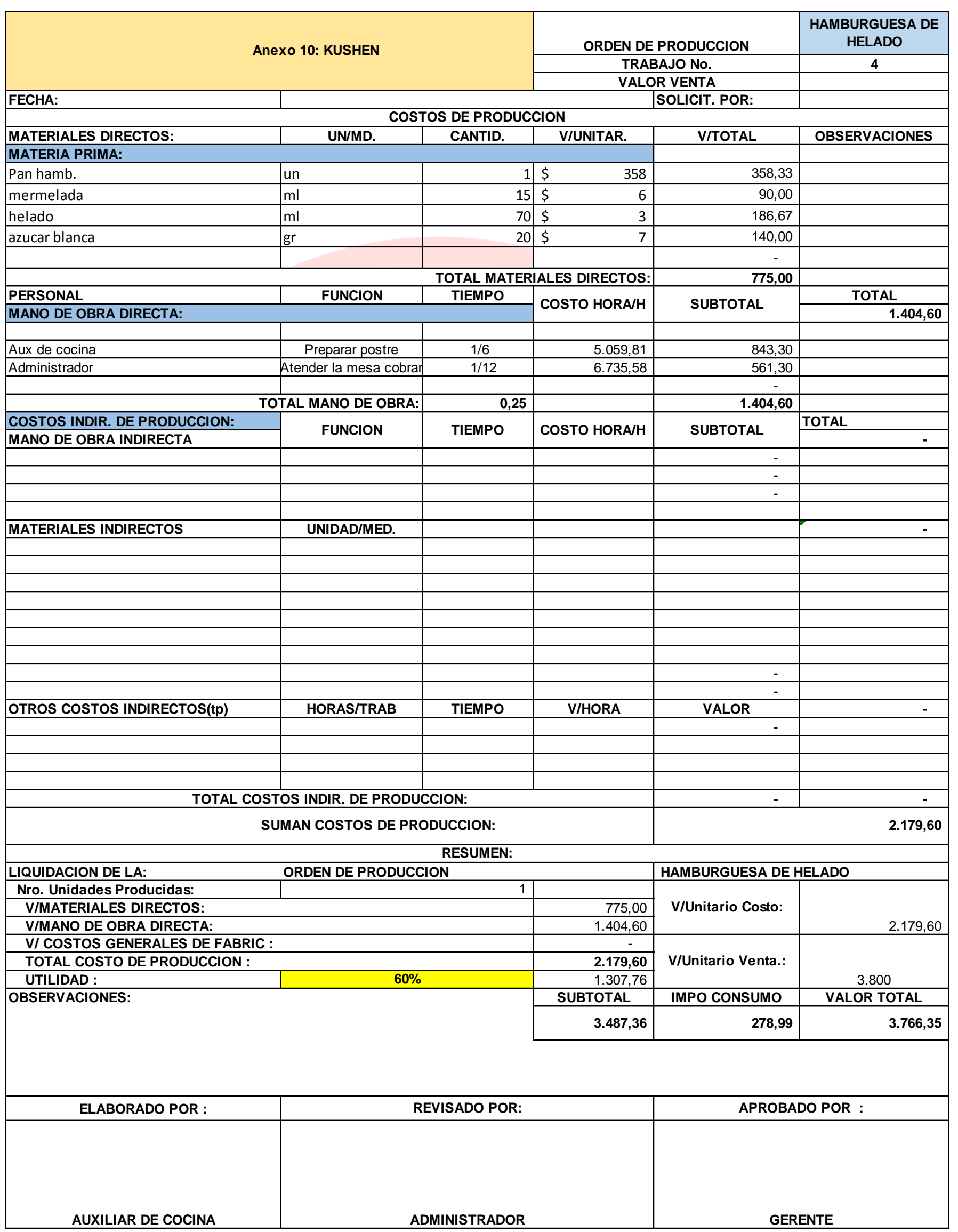




\section{Anexo 11: LISTA DE PRECIOS}

\begin{tabular}{|l|r|r|r|}
\hline \multicolumn{2}{|c|}{ PRECIO } & $\begin{array}{c}\text { Impuesto al } \\
\text { consumo }\end{array}$ & Precio total \\
\hline Hamburguesa & 7.248 & 580 & 7.800 \\
\hline Salchipapa & 6.914 & 553 & 7.500 \\
\hline Salchiyuca & 7.397 & 592 & 8.000 \\
\hline Mazorcada & 12.023 & 962 & 13.000 \\
\hline Hamburguesa de helado & 3.487 & 279 & 3.800 \\
\hline
\end{tabular}

\section{Anexo 12: INVERSIÓN INICIAL}

\section{ACTIVOS FIJOS}

Maquina Registradora

$300.000,00$

Nevera

$900.000,00$

Estufa con plancha

$1.200 .000,00$

Fregadero

$200.000,00$

$600.000,00$

Freidora

$800.000,00$

Campana extractora de olor

$500.000,00$

Horno microondas

$500.000,00$

Implementos de cocina (cuchillos, otros)

$2.000 .000,00$

Carrito rompetrafico

$300.000,00$

Mesas y sillas

$1.000 .000,00$

TOTAL INVERSION EN ACTIVOS FIJOS

$8.300 .000,00$

\section{CAPITAL DE TRABAJO}

Ingredientes (materias primas)

$500.000,00$

Empaques (bolsas)

$100.000,00$

Elementos (servilletas, palillos)

$150.000,00$

Elementos de aseo

$50.000,00$

Sueldos

$2.830 .895,00$

Servicios públicos

$300.000,00$

Uniformes

$150.000,00$

Arriendo

$800.000,00$

TOTAL CAPITAL DE TRABAJO

4.880.895,00 


\author{
PUESTA EN MARCHA \\ Adecuaciones local \\ Permisos (legales) \\ Canecas basura \\ Menús \\ Letreros \\ Decoración \\ TOTAL PUESTA EN MARCHA
}

INVERSION TOTAL INICIAL

RECURSOS PROPIOS

FINANCIACION
$900.000,00$

$500.000,00$

$70.000,00$

$120.000,00$

$300.000,00$

$200.000,00$

2.090.000,00

$15.270 .895,00$

$5.270 .895,00$

$10.000 .000,00$

(El capital de trabajo es lo necesario para iniciar la operación, para periodos posteriores este estará inmerso dentro los costos y gastos de cada periodo)

\section{Anexo 13: INVERSIÓN INICIAL DE SUCURSAL}

\section{ACTIVOS FIJOS}

Maquina Registradora

$321.300,00$

Nevera

$963.900,00$

Estufa con plancha

$1.285 .200,00$

Fregadero

$214.200,00$

Freidora

$642.600,00$

Campana extractora de olor

$856.800,00$

Horno microondas

$535.500,00$

Implementos de cocina (cuchillos, otros)

$535.500,00$

Carrito rompetrafico

Loza

$321.300,00$

Mesas y sillas

$1.071 .000,00$

TOTAL INVERSION EN ACTIVOS FIJOS

$6.747 .300,00$

CAPITAL DE TRABAJO

TOTAL CAPITAL DE TRABAJO 
PUESTA EN MARCHA

Adecuaciones local

$963.900,00$

Permisos (legales)

$535.500,00$

Canecas basura

$74.970,00$

Menús

$128.520,00$

Letreros

$321.300,00$

Decoración

$214.200,00$

TOTAL PUESTA EN MARCHA

2.238.390,00

INVERSION TOTAL SUCURSAL

$8.985 .690,00$ 


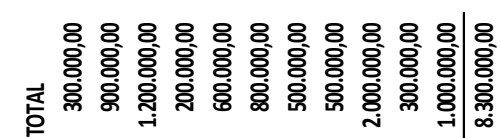

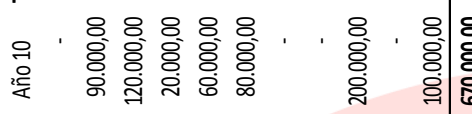

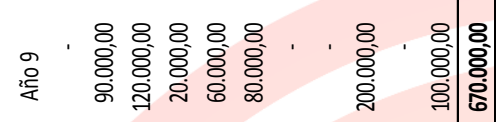

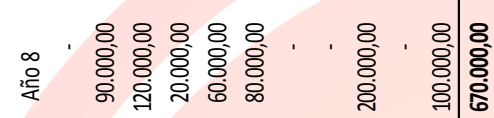

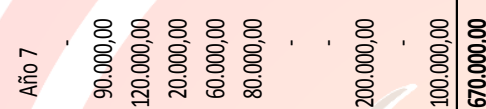

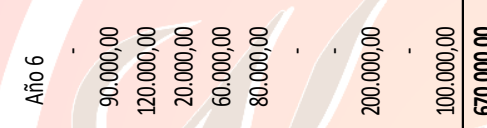

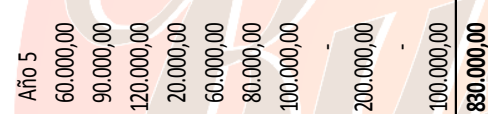

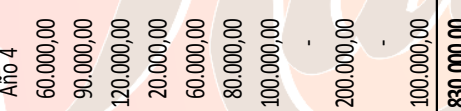

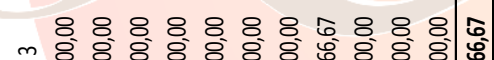

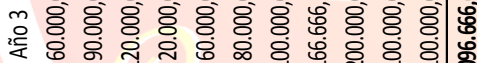
8888888688 20 80.000 < o व

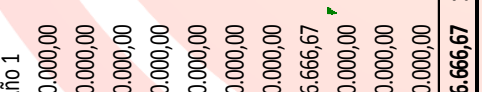

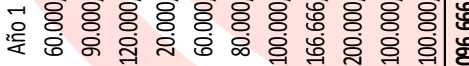

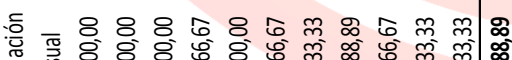
旁密

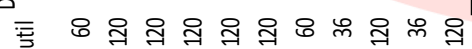
票

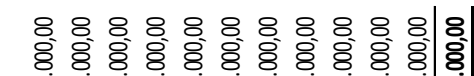

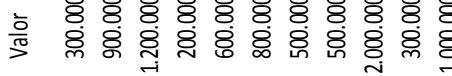

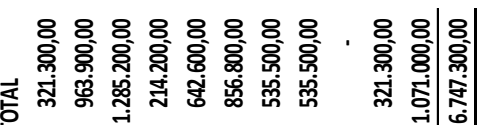
$7.88888,1,8$

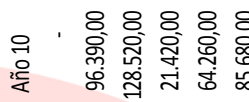

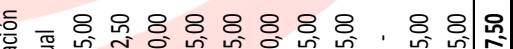

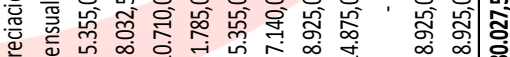

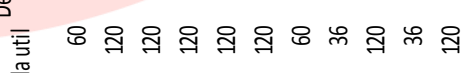

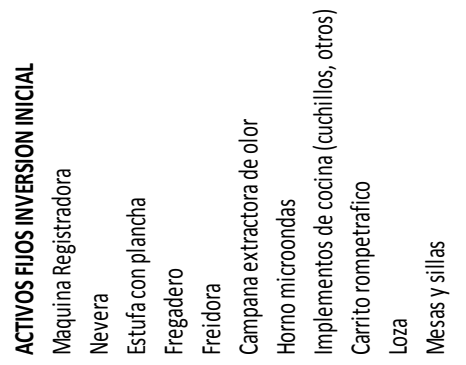

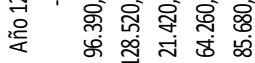

$88888+88$

ㄱ.

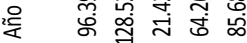

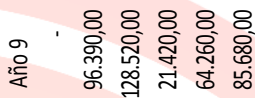

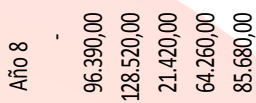

8.888 .8

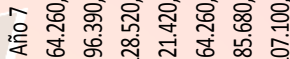

这 की

8888888

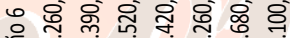

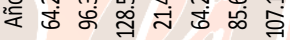

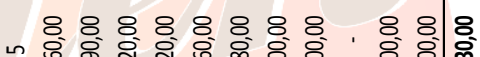

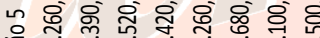

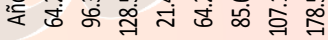

$88888888 \quad 888$ +

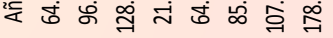

$88.8888,88$

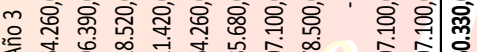

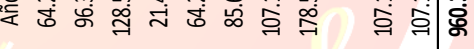

운

尊 票

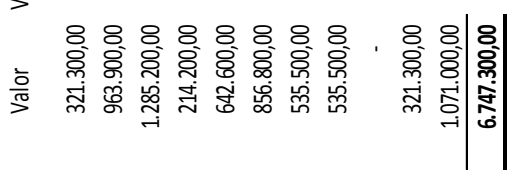

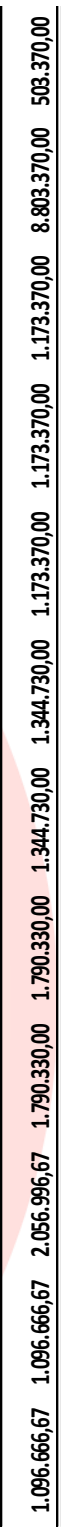

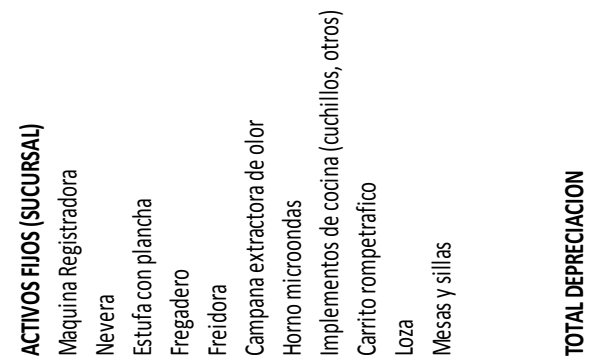




\section{Anexo 15: CALCULO FINANCIACION DE LA INVERSION}

$\begin{array}{lr}\text { Valor préstamo } & \$ 10.000 .000 \\ \text { Tiempo } & 36 \\ \text { Tasa EA } & 22,33 \% \\ \text { Tasa nominal } & 20 \% \\ \text { Tasa Nom mensı } & 2 \% \\ \text { Cuota } & \$ 373.296\end{array}$

\begin{tabular}{|c|c|c|c|c|}
\hline Periodo & Cuota & Capital & Intereses & $\begin{array}{c}\text { Saldo } \\
\text { Préstamo }\end{array}$ \\
\hline 0 & & & & 10.000 .000 \\
\hline 1 & 373.296 & 203.917 & 169.379 & 9.796 .083 \\
\hline 2 & 373.296 & 207.371 & 165.925 & 9.588.711 \\
\hline 3 & 373.296 & 210.884 & 162.412 & 9.377 .827 \\
\hline 4 & 373.296 & 214.456 & 158.840 & 9.163 .372 \\
\hline 5 & 373.296 & 218.088 & 155.208 & 8.945 .283 \\
\hline 6 & 373.296 & 221.782 & 151.514 & 8.723 .501 \\
\hline 7 & 373.296 & 225.539 & 147.757 & 8.497 .963 \\
\hline 8 & 373.296 & 229.359 & 143.937 & 8.268 .604 \\
\hline 9 & 373.296 & 233.244 & 140.052 & 8.035 .360 \\
\hline 10 & 373.296 & 237.194 & 136.102 & 7.798.166 \\
\hline 11 & 373.296 & 241.212 & 132.084 & 7.556 .954 \\
\hline 12 & 373.296 & 245.297 & 127.999 & 7.311 .657 \\
\hline 13 & 373.296 & 249.452 & 123.844 & 7.062.204 \\
\hline 14 & 373.296 & 253.677 & 119.619 & 6.808 .527 \\
\hline 15 & 373.296 & 257.974 & 115.322 & 6.550 .553 \\
\hline 16 & 373.296 & 262.344 & 110.952 & 6.288 .209 \\
\hline 17 & 373.296 & 266.787 & 106.509 & 6.021 .422 \\
\hline 18 & 373.296 & 271.306 & 101.990 & 5.750 .116 \\
\hline 19 & 373.296 & 275.901 & 97.395 & 5.474 .214 \\
\hline 20 & 373.296 & 280.575 & 92.721 & 5.193 .640 \\
\hline 21 & 373.296 & 285.327 & 87.969 & 4.908.313 \\
\hline 22 & 373.296 & 290.160 & 83.136 & 4.618 .153 \\
\hline 23 & 373.296 & 295.074 & 78.222 & 4.323.078 \\
\hline 24 & 373.296 & 300.072 & 73.224 & 4.023 .006 \\
\hline 25 & 373.296 & 305.155 & 68.141 & 3.717.851 \\
\hline 26 & 373.296 & 310.324 & 62.972 & 3.407 .528 \\
\hline 27 & 373.296 & 315.580 & 57.716 & 3.091 .948 \\
\hline 28 & 373.296 & 320.925 & 52.371 & 2.771 .023 \\
\hline 29 & 373.296 & 326.361 & 46.935 & 2.444 .662 \\
\hline 30 & 373.296 & 331.889 & 41.407 & 2.112.773 \\
\hline 31 & 373.296 & 337.510 & 35.786 & 1.775 .263 \\
\hline 32 & 373.296 & 343.227 & 30.069 & 1.432 .036 \\
\hline 33 & 373.296 & 349.040 & 24.256 & 1.082 .996 \\
\hline 34 & 373.296 & 354.952 & 18.344 & 728.043 \\
\hline 35 & 373.296 & 360.965 & 12.331 & 367.079 \\
\hline \multirow[t]{2}{*}{36} & 373.296 & 367.079 & 6.218 & 0 \\
\hline & 13.438 .658 & 10.000 .000 & 3.438 .658 & \\
\hline
\end{tabular}

\begin{tabular}{|r|r|r|r|r|}
\hline \multicolumn{2}{|l|}{ RESUMEN POR AÑO } & \multicolumn{1}{l|}{ Capital } & \multicolumn{1}{l|}{ Interés } & \multicolumn{1}{l|}{ Saldo } \\
\hline 2017 & 4.479 .553 & 2.688 .343 & 1.791 .209 & 7.311 .657 \\
\hline 2018 & 4.479 .553 & 3.288 .650 & 1.190 .902 & 4.023 .006 \\
\hline 2019 & 4.479 .553 & 4.023 .006 & 456.546 & 0 \\
\hline 2020 & - & - & - & - \\
\hline 2021 & - & - & - & - \\
\hline & $\mathbf{1 3 . 4 3 8 . 6 5 8}$ & $\mathbf{1 0 . 0 0 0 . 0 0 0}$ & $\mathbf{3 . 4 3 8 . 6 5 8}$ & \\
\hline
\end{tabular}


Anexo 16: PUNTO DE EQUILIBRIO

\begin{tabular}{lc} 
Costos Fijos & $\$ 4.072 .283,89$ \\
Deuda & $\$ 373.296$ \\
\cline { 2 - 2 } TOTAL & $\$ 4.445 .579,94$
\end{tabular}

$$
\begin{aligned}
& \mathrm{PE}=\quad \text { Costos fijos } \\
& \text { Margen de contribución total ponderado }
\end{aligned}
$$

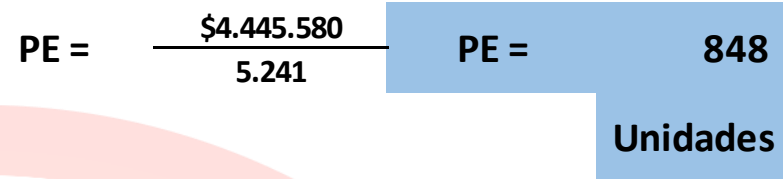

\begin{tabular}{|l|r|r|r|r|r|r|}
\hline \multicolumn{7}{|c|}{ CALCULO DEL PUNTO DE EQUILIBRIO POR PRODUCTO } \\
\hline & Hamburguesa & \multicolumn{1}{|c|}{ Salchipapa } & Salchiyuca & Mazorcada & $\begin{array}{l}\text { Hamburguesa } \\
\text { helado }\end{array}$ & TOTAL \\
\hline Participación & $50 \%$ & $15 \%$ & $15 \%$ & $18 \%$ & $2 \%$ & $100 \%$ \\
\hline Precio unitario & 7.248 & 6.914 & 7.397 & 12.023 & 3.487 & \\
\hline Costo variable & 2.282 & 2.047 & 2.347 & 5.267 & 775 & \\
\hline $\begin{array}{l}\text { Margén de } \\
\text { Contribución }\end{array}$ & 4.966 & 4.867 & $\mathbf{5 . 0 5 0}$ & $\mathbf{6 . 7 5 7}$ & $\mathbf{2 . 7 1 2}$ & \\
\hline $\begin{array}{l}\text { Margén Contrib. } \\
\text { ponderado }\end{array}$ & 2.483 & 730 & 758 & 1.216 & 54 & $\mathbf{5 . 2 4 1}$ \\
\hline PE por producto & 424 & 127 & 127 & 153 & 17 & $\mathbf{8 4 8}$ \\
\hline
\end{tabular}

\begin{tabular}{|l|r|r|r|r|r|r|}
\hline & Hamburguesa & \multicolumn{1}{|c|}{ Salchipapa } & \multicolumn{1}{c|}{ Salchiyuca } & \multicolumn{1}{c|}{ Mazorcada } & \multicolumn{1}{c|}{$\begin{array}{c}\text { Hamburguesa } \\
\text { helado }\end{array}$} & \multicolumn{1}{c|}{ TOTAL } \\
\hline Ventas & 3.073 .814 & 879.700 & 941.155 & 1.835 .700 & 59.162 & $\mathbf{6 . 7 8 9 . 5 3 1}$ \\
\hline (-) Costo variable & 967.762 & 260.386 & 298.557 & 804.099 & 13.148 & $\mathbf{2 . 3 4 3 . 9 5 1}$ \\
\hline (=) Utilidad marginal & $\mathbf{2 . 1 0 6 . 0 5 2}$ & $\mathbf{6 1 9 . 3 1 4}$ & $\mathbf{6 4 2 . 5 9 8}$ & $\mathbf{1 . 0 3 1 . 6 0 1}$ & $\mathbf{4 6 . 0 1 4}$ & $\mathbf{4 . 4 4 5 . 5 8 0}$ \\
\hline (-) Costos Fijos & 2.222 .790 & 666.837 & 666.837 & 800.204 & 88.912 & $\mathbf{4 . 4 4 5 . 5 8 0}$ \\
\hline (=) Utilidad neta & -116.738 & -47.523 & -24.239 & $\mathbf{2 3 1 . 3 9 7}$ & -42.897 & $\mathbf{0}$ \\
\hline
\end{tabular}




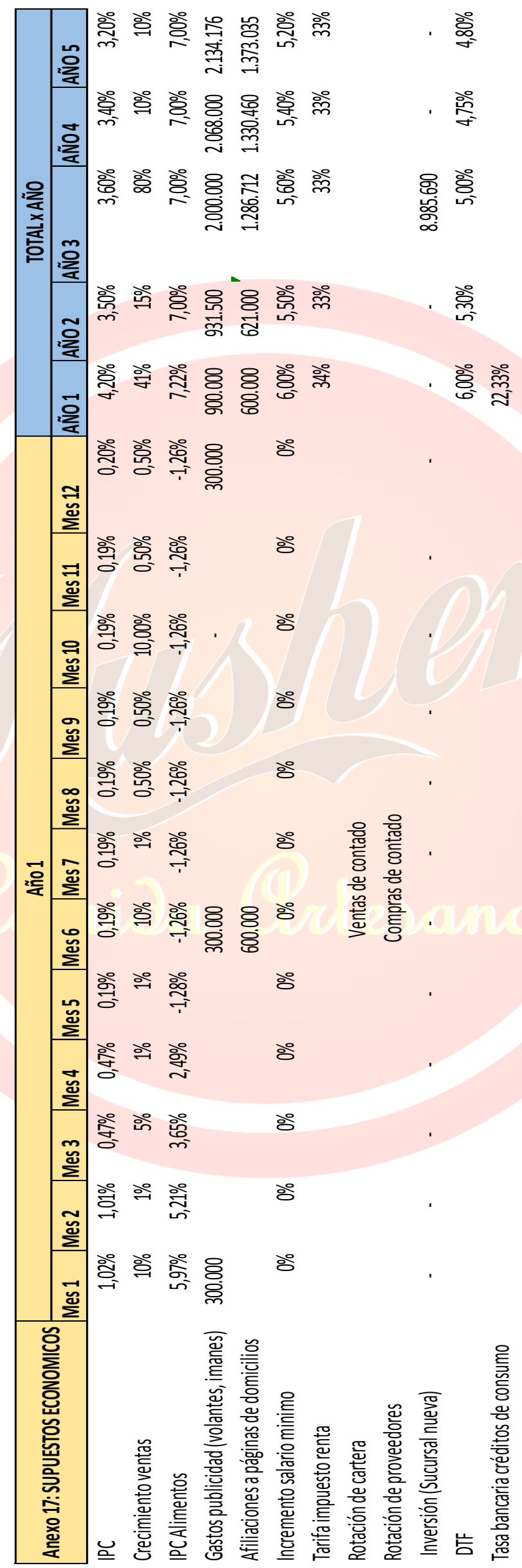




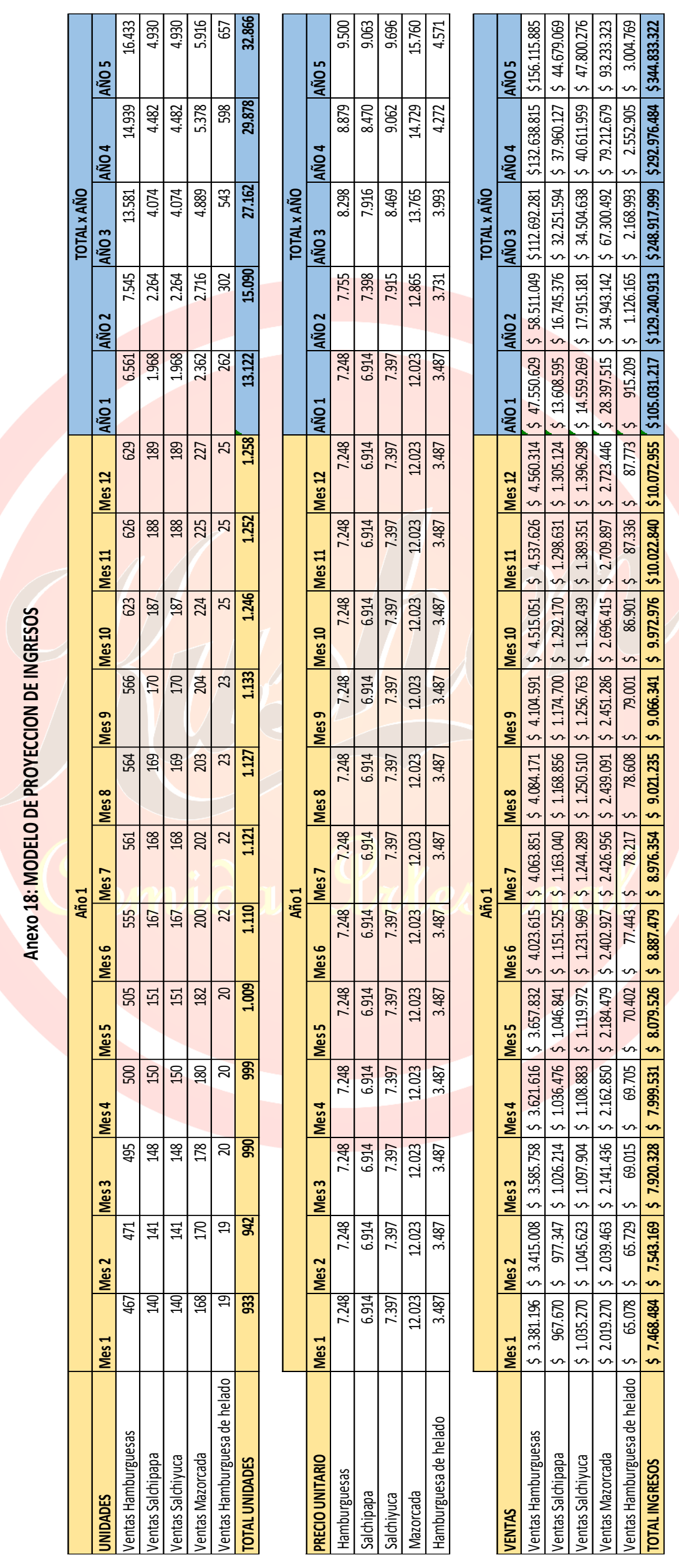




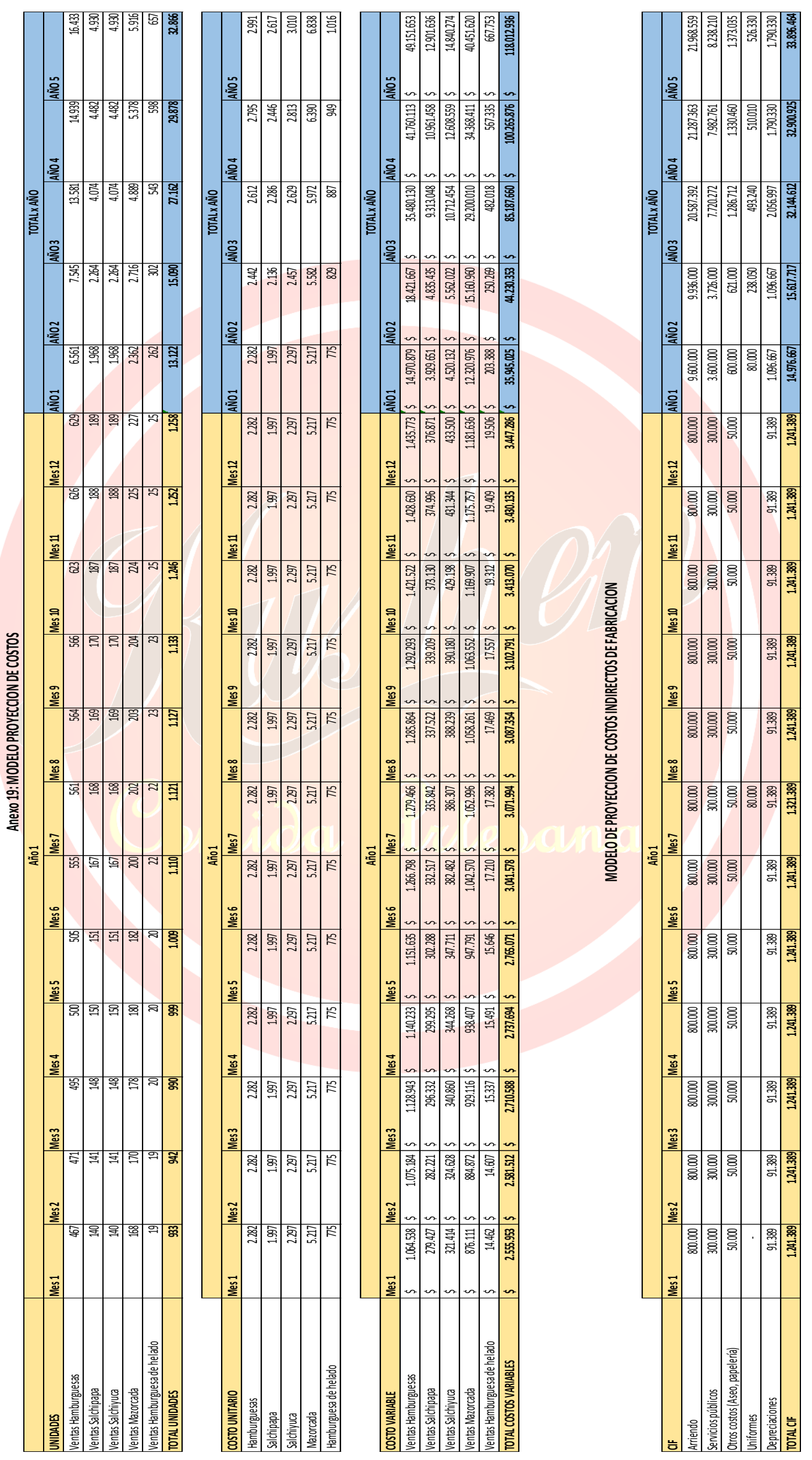




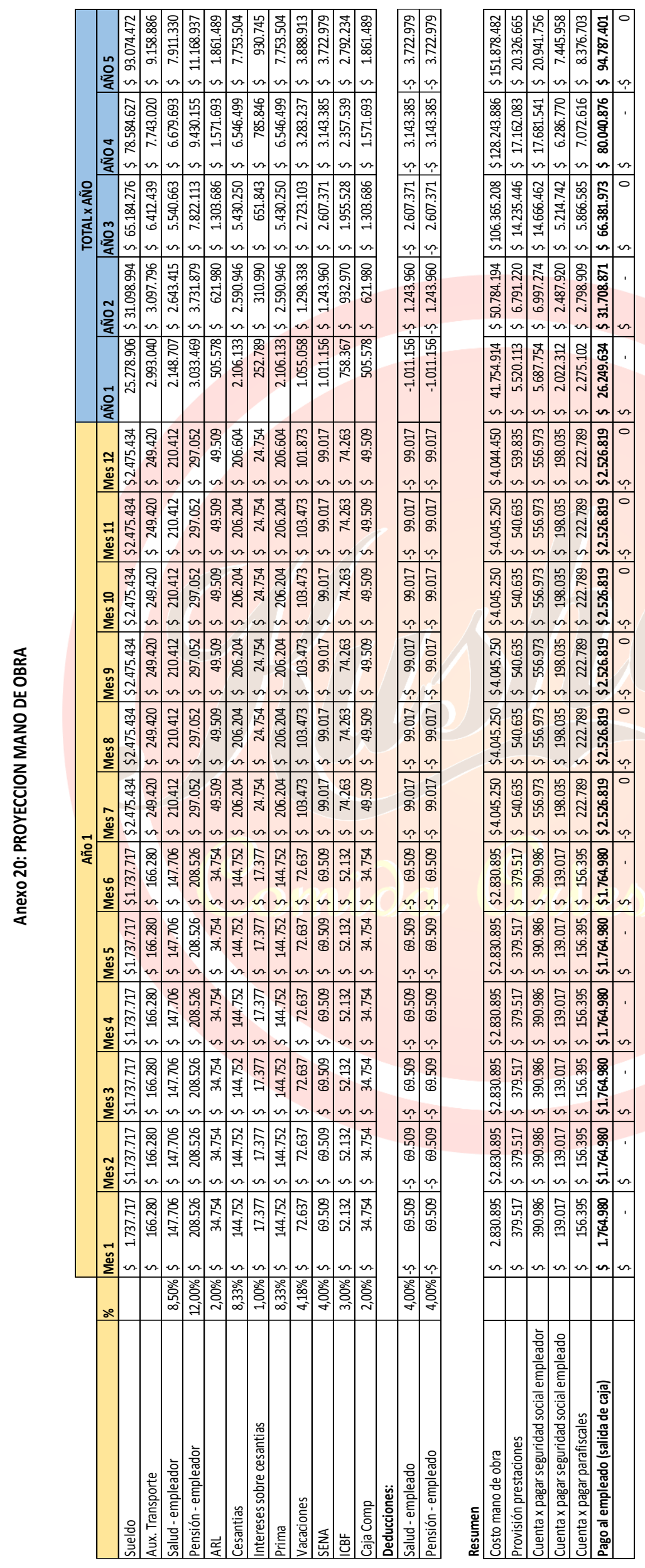

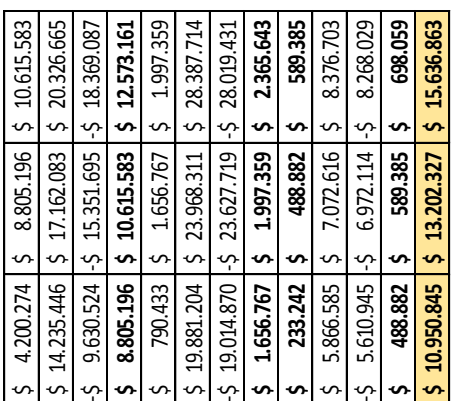

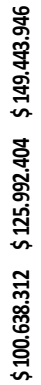

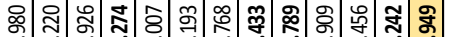

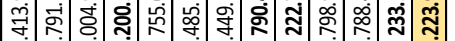

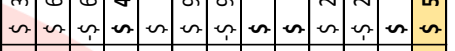

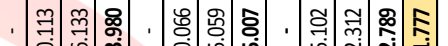

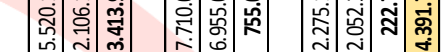

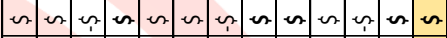

ઈ.

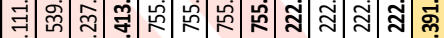

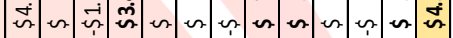

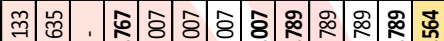

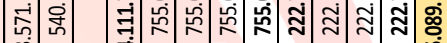

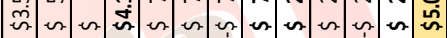

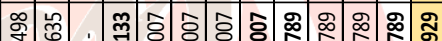

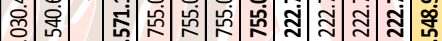

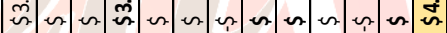

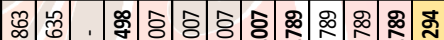

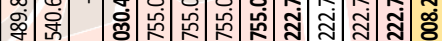

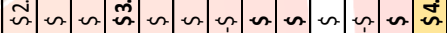

సే 亗 .

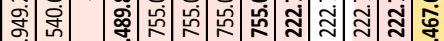

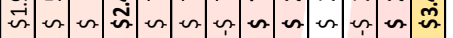

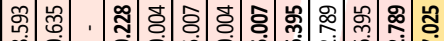

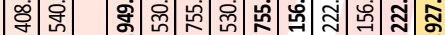

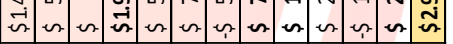

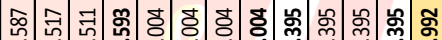

ه

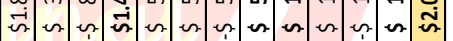

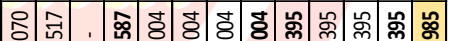

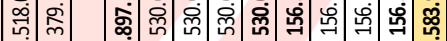

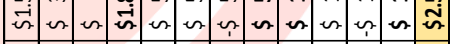

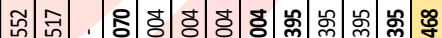

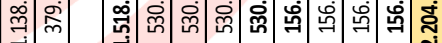

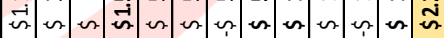

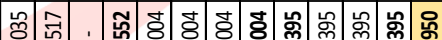

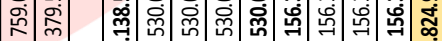

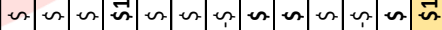

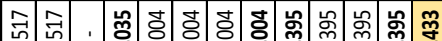

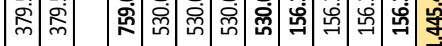

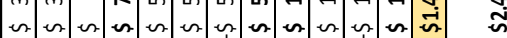

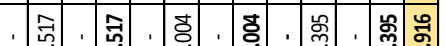

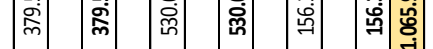
年)

is

过

趈

$\infty$

웅

.

A

ڤึ.

ळ

该

丳

证

$\infty$

密

$\infty$

胥

$\stackrel{\circ}{m}$

疍 


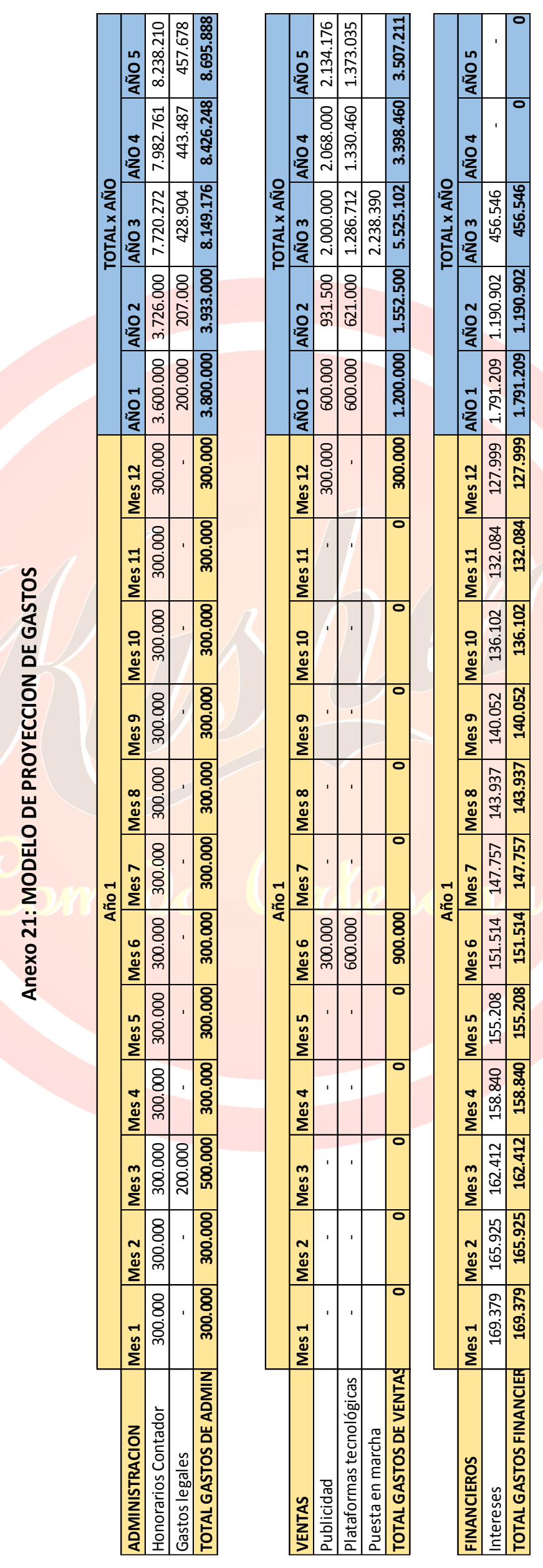




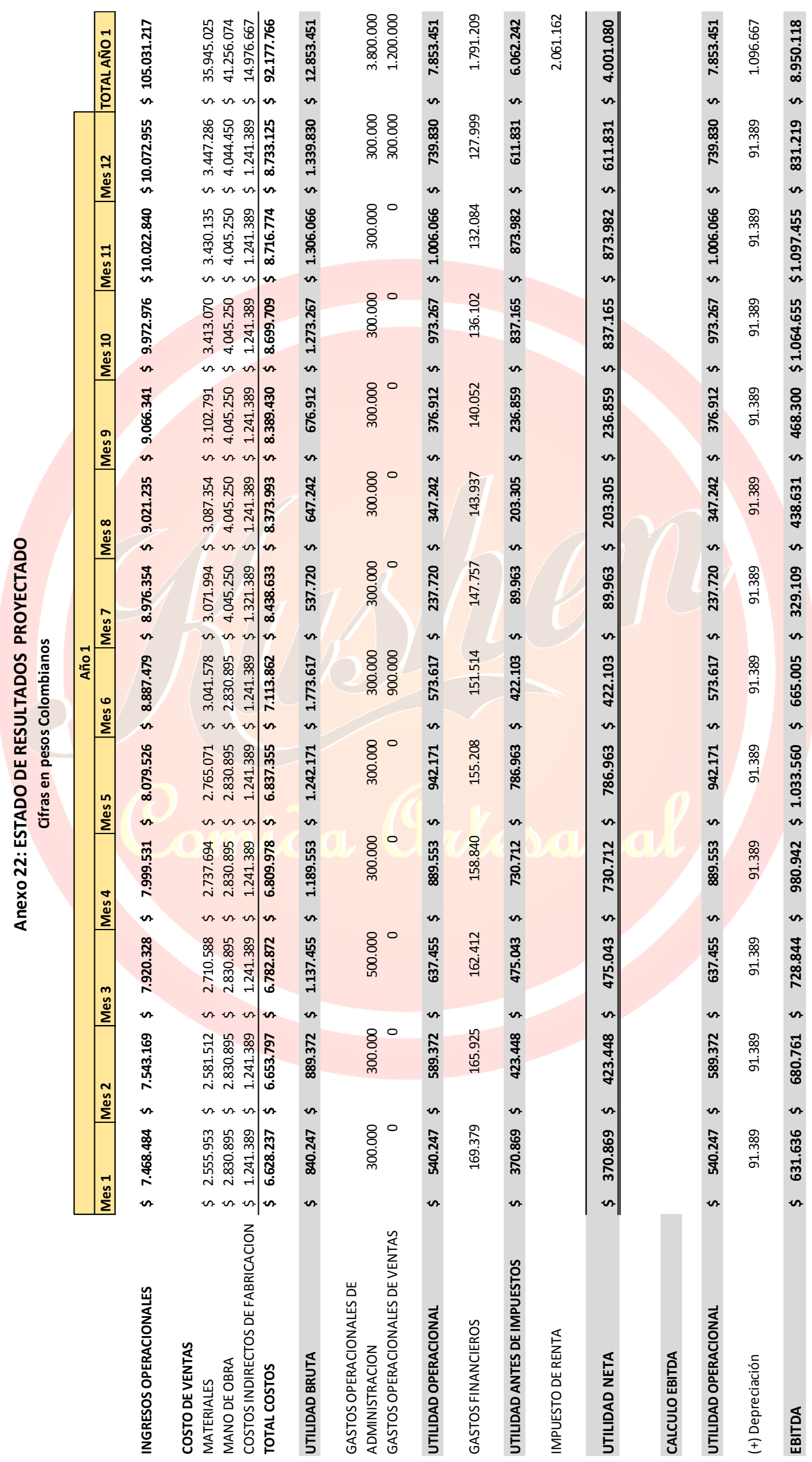




\section{Anexo 23: ESTADO DE RESULTADOS PROYECTADO ANUAL \\ Cifras en pesos Colombianos}

\begin{tabular}{|c|c|c|c|c|c|c|c|c|c|c|}
\hline & & & & & & TOTAL $x$ & X AÑO & & & \\
\hline & AÑO 0 & & AÑ & 01 & & ÑO 2 & AÑO 3 & & 104 & AÑO 5 \\
\hline INGRESOS OPERACIONALES & $\$$ & - & & 05.031 .217 & & 129.240 .913 & \$248.917.999 & & 292.976.484 & $\$ 344.833 .322$ \\
\hline OSTO DE VENTAS & & & & & & & & & & \\
\hline MATERIALES & & & & 35.945 .025 & $\$$ & 44.230 .353 & $\$ 85.187 .660$ & & 100.265 .876 & $\$ 118.012 .936$ \\
\hline MANO DE OBRA & & & & 41.754 .914 & & 50.784 .194 & $\$ 106.365 .208$ & & 128.243 .886 & $\$ 151.878 .482$ \\
\hline COSTOS INDIRECTOS DE FABRICACION & & & & 14.976 .667 & $\$$ & 15.617 .717 & $\$ 32.144 .612$ & & 32.900 .925 & $\$ 33.896 .464$ \\
\hline TOTAL COSTOS & $\$$ & - & & 92.676 .606 & & 110.632 .264 & $\$ 223.697 .480$ & & 261.410.687 & $\$ 303.787 .882$ \\
\hline UTILIDAD BRUTA & $\$$ & - & & 12.354.611 & $\$$ & 18.608 .649 & $\$ 25.220 .518$ & $\$$ & 31.565 .797 & $\$ 41.045 .440$ \\
\hline GASTOS OPERACIONALES DE & & & & & & & & & & \\
\hline ADMINISTRACION & & 3.040 .000 & & 3.800 .000 & & 3.933 .000 & 8.149 .176 & & 8.426 .248 & 8.695 .888 \\
\hline GASTOS OPERACIONALES DE VENTAS & & & & 1.200 .000 & & 1.552 .500 & 5.525 .102 & & 3.398 .460 & 3.507 .211 \\
\hline UTILIDAD OPERACIONAL & $-\$$ & 3.040 .000 & $\$$ & 7.354.611 & $\$$ & 13.123.149 & $\$ 11.546 .240$ & $\$$ & 19.741 .089 & $\$ 28.842 .342$ \\
\hline GASTOS FINANCIEROS & & & & 1.791 .209 & & 1.190 .902 & 456.546 & & 0 & b \\
\hline UTILIDAD ANTES DE IMPUESTOS & $-\$$ & 3.040 .000 & $\$$ & 5.563 .402 & $\$$ & 11.932.247 & \$ 11.089 .694 & $\$$ & 19.741.089 & $\$ 28.842 .342$ \\
\hline IMPUESTO DE RENTA & & & & 1.891 .557 & & 3.937 .641 & 3.659 .599 & & 6.514 .559 & 9.517 .973 \\
\hline UTILIDAD NETA & $-\$$ & 3.040 .000 & $\$$ & 3.671 .845 & $\$$ & 7.994 .605 & $\$ 7.430 .095$ & & 13.226 .530 & $\$ 19.324 .369$ \\
\hline
\end{tabular}

\section{CALCULO EBITDA}

UTILIDAD OPERACIONAL

(+) Depreciación
$\$$

$1.096 .667 \quad 1.096 .667$

2.056 .997

1.790 .330

1.790 .330 


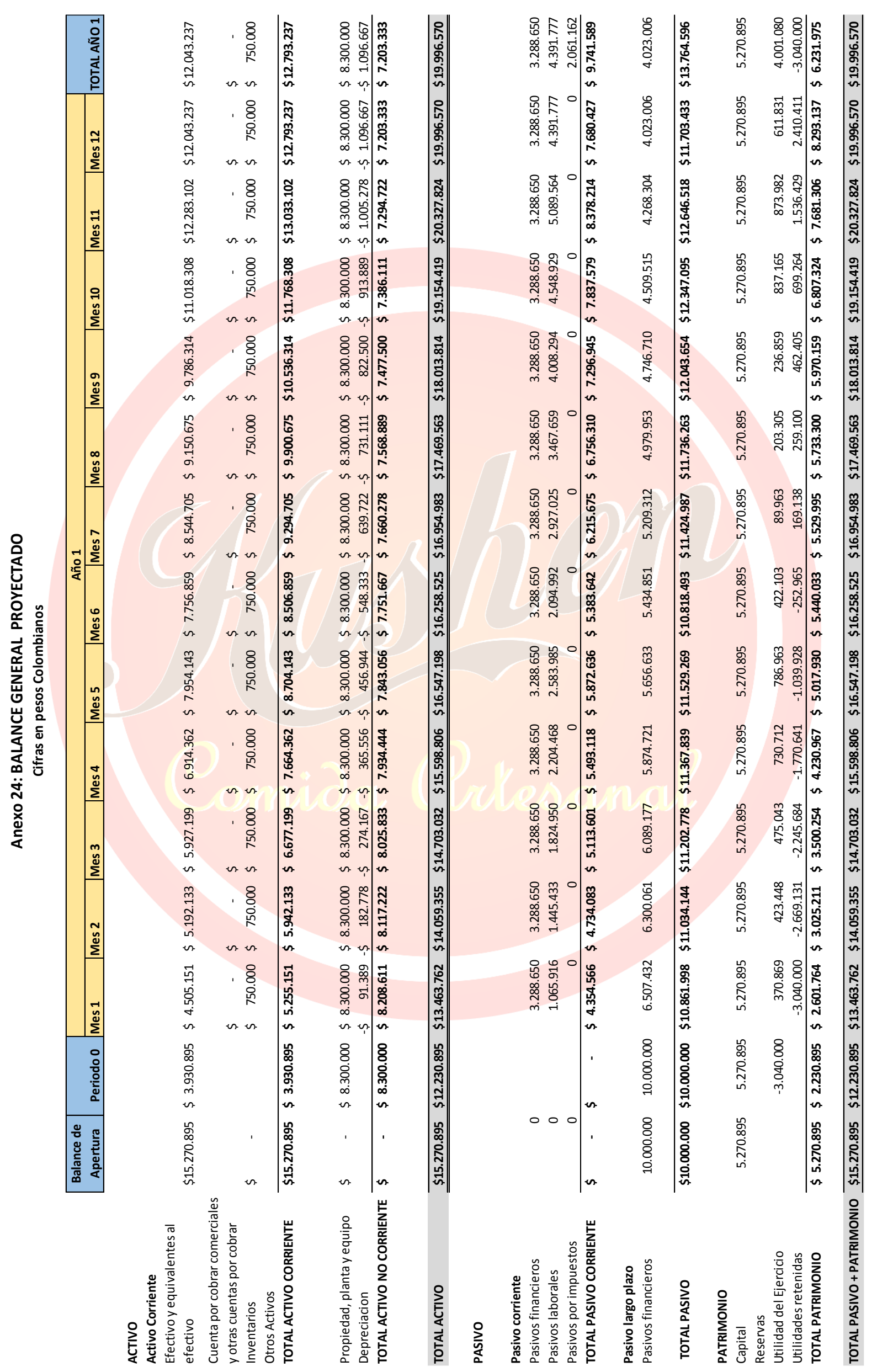


Anexo 25: BALANCE GENERAL PROYECTADO ANUAL

Cifras en pesos Colombianos

\begin{tabular}{|c|c|c|c|c|c|c|}
\hline \multirow[b]{2}{*}{ Balance de Apertura } & \multicolumn{6}{|c|}{ TOTAL x AÑO } \\
\hline & AÑO 0 & AÑO 1 & AÑO 2 & AÑO 3 & AÑO 4 & AÑO 5 \\
\hline
\end{tabular}

\section{ACTIVO}

Activo Corriente

Efectivo y equivalentes al

efectivo

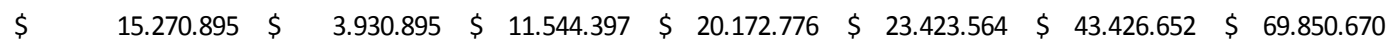

Cuenta por cobrar comerciales y otras cuentas por cobrar Inventarios

Otros Activos

TOTAL ACTIVO CORRIENTE

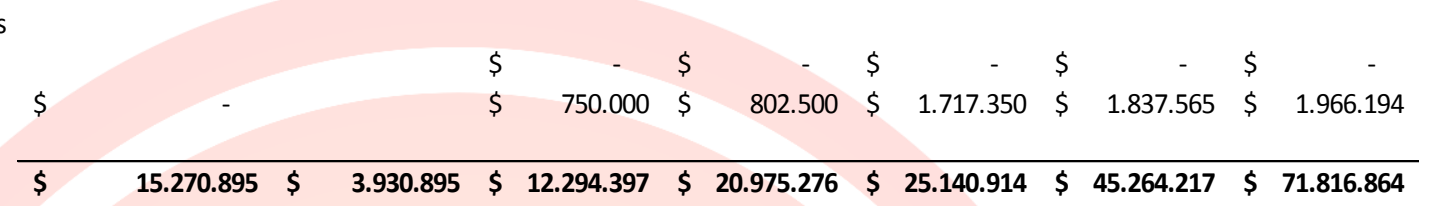

Activo Largo Plazo

Propiedad, planta y equipo

Depreciacion

$\begin{array}{lllllllllllllll}\$ & - & \$ & 8.300 .000 & \$ & 8.300 .000 & \$ & 8.300 .000 & \$ & 15.047 .300 & \$ & 15.047 .300 & \$ & 15.047 .300\end{array}$

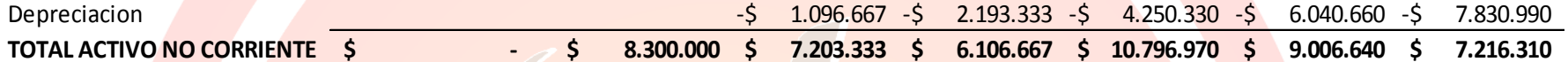

TOTAL ACTIVO

\begin{tabular}{llllllllllllll}
\hline$\$$ & 15.270 .895 & $\$$ & 12.230 .895 & $\$$ & 19.497 .730 & $\$$ & 27.081 .943 & $\$$ & 35.937 .884 & $\$$ & 54.270 .857 & $\$ 79.033 .174$ \\
\hline \hline
\end{tabular}

PASIVO

Pasivo corriente

Pasivos financieros

Pasivos Laborales

Pasivos por impuestos

TOTAL PASIVO CORRIENTE

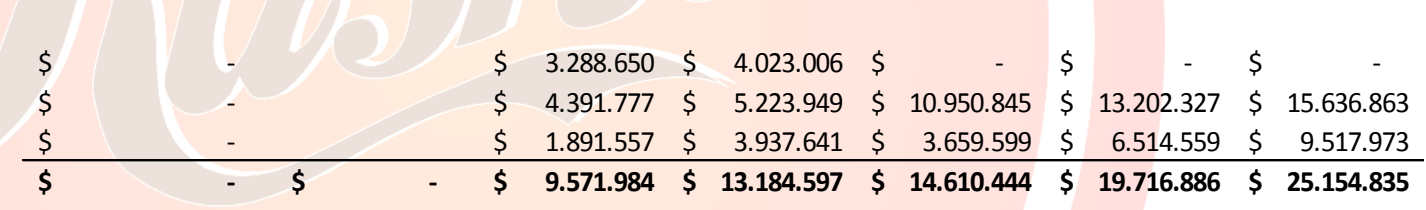

Pasivo largo plazo

Pasivos financieros

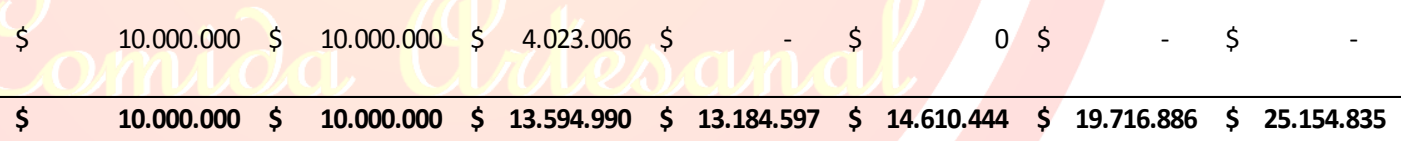

TOTAL PASIVO

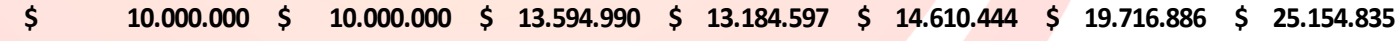

PATRIMONIO

Capital

Reservas

Utilidad del Ejercicio

Utilidades retenidas

TOTAL PATRIMONIO

$\begin{array}{llllllllllllll}\$ & 5.270 .895 & \$ & 5.270 .895 & \$ & 5.270 .895 & \$ & 5.270 .895 & \$ & 5.270 .895 & \$ & 5.270 .895 & \$ & 5.270 .895\end{array}$

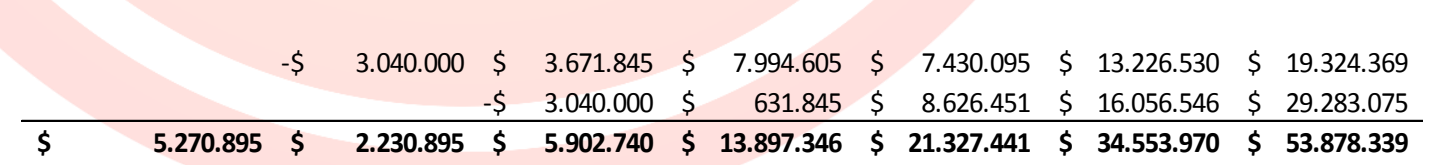

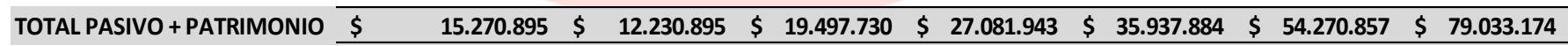




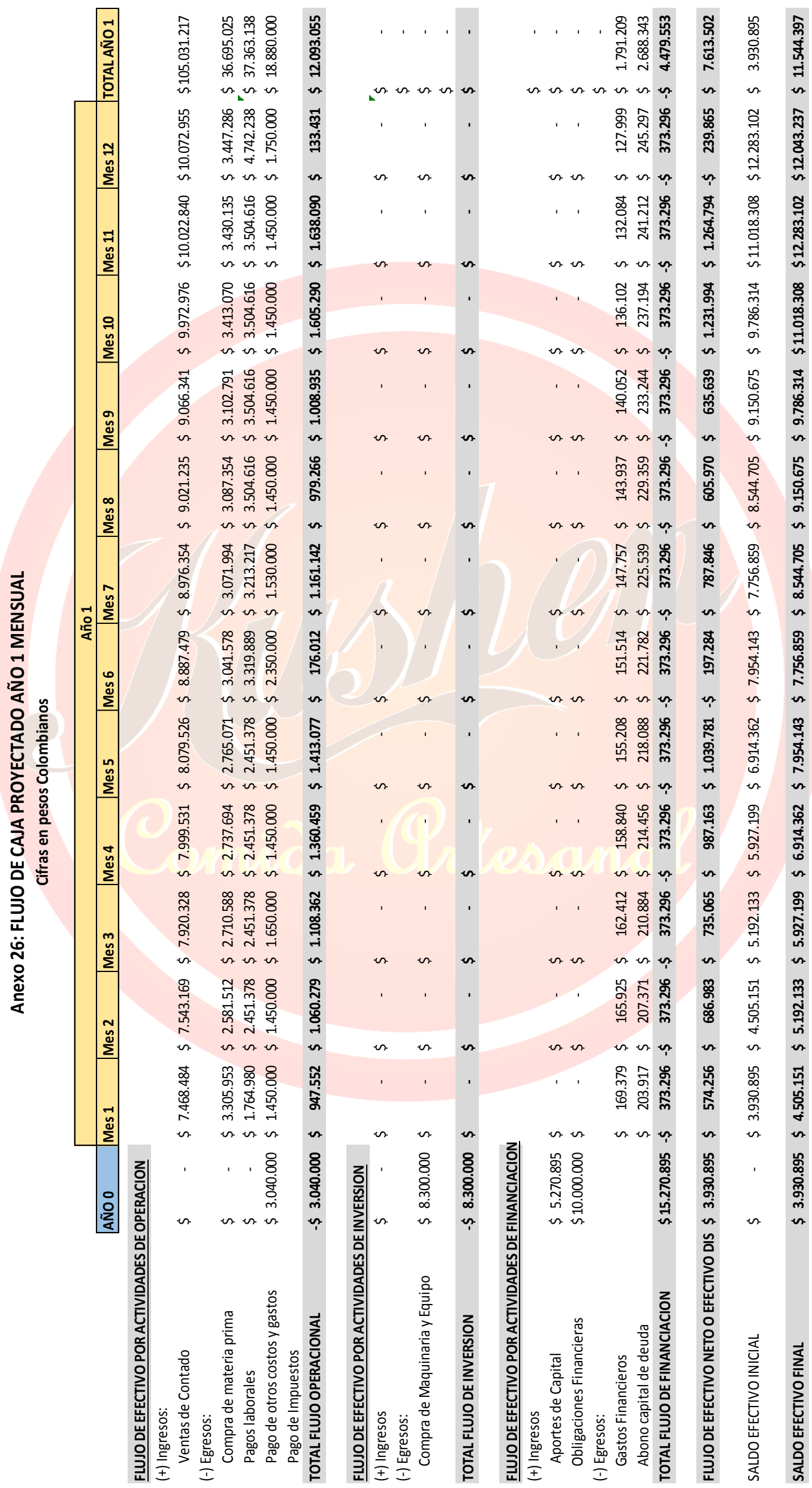




\section{Anexo 27: FLUJO DE CAJA PROYECTADO ANUAL Cifras en pesos Colombianos}

\begin{tabular}{|c|c|c|c|c|c|c|c|}
\hline \multirow[b]{2}{*}{ FLUJO DE EFECTIVO POR ACTIVIDADES DE OPERACIO } & AÑO 0 & \multicolumn{2}{|c|}{ AÑO 1} & AÑO 2 & AÑO 3 & AÑO 4 & AÑO 5 \\
\hline & & & & & & & \\
\hline \multicolumn{8}{|l|}{$(+)$ Ingresos: } \\
\hline Ventas de Contado & $\$$ & \multicolumn{2}{|c|}{$\$ 105.031 .217$} & $\$ 129.240 .913$ & \multirow[t]{2}{*}{$\$ 248.917 .999$} & $\$ 292.976 .484$ & $\$ 344.833 .322$ \\
\hline \multicolumn{7}{|c|}{ 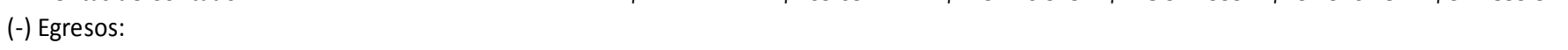 } & \\
\hline Compra de materia prima & $\$$ & \multicolumn{2}{|c|}{$\$ 36.695 .025$} & $\$ 44.282 .853$ & $\$ 86.102 .510$ & $\$ 100.386 .091$ & $\$ 118.141 .566$ \\
\hline Pagos laborales & $\$$ & \multicolumn{2}{|c|}{$\$ 37.363 .138$} & $\$ 49.952 .022$ & $\$ 100.638 .312$ & $\$ 125.992 .404$ & $\$ 149.443 .946$ \\
\hline Pago de otros costos y gastos & $\$ 3.040 .000$ & \multicolumn{2}{|c|}{$\$ 18.880 .000$} & $\$ 20.006 .550$ & $\$ 43.761 .894$ & $\$ 42.935 .303$ & $\$ 44.309 .232$ \\
\hline Pago de Impuestos & & \multicolumn{2}{|c|}{$\$$} & $\$ 1.891 .557$ & $\$ 3.937 .641$ & $\$ \quad 3.659 .599$ & $\$ 6.514 .559$ \\
\hline TOTAL FLUJO OPERACIONAL & $-\$ 3.040 .000$ & \multicolumn{2}{|c|}{ \$ 12.093 .055} & $\$ 13.107 .931$ & $\$ 14.477 .641$ & $\$ 20.003 .088$ & $\$ 26.424 .018$ \\
\hline FLUJO DE EFECTIVO POR ACTIVIDADES DE INVERSIC & & & & & & & \\
\hline (+) Ingresos & $\$$ & $\$$ & - & $\$$ & $\$$ & $\$$ & $\$$ \\
\hline (-) Egresos: & & & & & & & \\
\hline Compra de Maquinaria y Equipo & $\$ 8.300 .000$ & $\$$ & - & $\$$ & $\$ 6.747 .300$ & $\$$ & $\$$ \\
\hline TOTAL FLUJO DE INVERSION & $-\$ 8.300 .000$ & $\$$ & - & $\$$ & $-\$ 6.747 .300$ & $\$$ & $\$$ \\
\hline & & & & & & & \\
\hline FLUJO DE EFECTIVO POR ACTIVIDADES DE FINANCI & & & & & & & \\
\hline$(+)$ Ingresos & & & & & & & \\
\hline Aportes de Capital & $\$ 5.270 .895$ & $\$$ & - & $\$$ & $\$$ & $\$$ & $\$$ \\
\hline Obligaciones Financieras & $\$ 10.000 .000$ & $\$$ & - & $\$$ & $\$$ & $\$$ & $\$$ \\
\hline (-) Egresos: & & & & & & & \\
\hline Gastos Financieros & ) & $\$$ & 1.791 .209 & $\$ 1.190 .902$ & 456.546 & $\$$ & $\$$ \\
\hline Abono capital de deuda & & $\$$ & 2.688 .343 & $\$ 3.288 .650$ & $\$ 4.023 .006$ & $\$$ & - \\
\hline TOTAL FLUJO DE FINANCIACION & $\$ 15.270 .895$ & $-\$$ & 4.479.553 & $-\$ \quad 4.479 .553$ & $-\$ \quad 4.479 .553$ & $\$$ & $\$$ \\
\hline FLUJO DE EFECTIVO NETO O EFECTIVO DISPONIBLE & $\$ 3.930 .895$ & $\$$ & 7.613.502 & $\$ 8.628 .379$ & $\$ \quad 3.250 .788$ & $\$ 20.003 .088$ & $\$ 26.424 .018$ \\
\hline SALDO EFECTIVO INICIAL & $\$$ & $\$$ & 3.930 .895 & $\$ 11.544 .397$ & $\$ 20.172 .776$ & $\$ 23.423 .564$ & $\$ 43.426 .652$ \\
\hline SALDO EFECTIVO FINAL & $\$ 3.930 .895$ & & 11.544.397 & $\$ 20.172 .776$ & $\$ 23.423 .564$ & $\$ 43.426 .652$ & $\$ 69.850 .670$ \\
\hline
\end{tabular}

